Portland State University

PDXScholar

\title{
Literaturproduktion in der DDR : "Vom Entstehen und Sterben" Erich Loests Es geht seinen Gang und vom Entstehen und Gedeihen Christa Wolfs Nachdenken über Christa T.
}

Gudrun Hommel-Ingram

Portland State University

Follow this and additional works at: https://pdxscholar.library.pdx.edu/open_access_etds

Part of the German Literature Commons

Let us know how access to this document benefits you.

\section{Recommended Citation}

Hommel-Ingram, Gudrun, "Literaturproduktion in der DDR : "Vom Entstehen und Sterben" Erich Loests Es geht seinen Gang und vom Entstehen und Gedeihen Christa Wolfs Nachdenken über Christa T." (1989). Dissertations and Theses. Paper 3994.

https://doi.org/10.15760/etd.5878

This Thesis is brought to you for free and open access. It has been accepted for inclusion in Dissertations and Theses by an authorized administrator of PDXScholar. Please contact us if we can make this document more accessible: pdxscholar@pdx.edu. 
AN ABSTRACT OF THE THESIS OF Gudrun Hommel-Ingram for the Master of Arts in German presented May 9, 1989.

Title: Literaturproduktion in der DDR: "Vom Entstehen und Sterben Erich Loests

Es geht seinen Gang und vom Entstehen und Gedeihen Christa Wolfs

Nachdenken über Christa T.

APPROVED BY MEMBERS OF THE THESIS COMMITTEE:

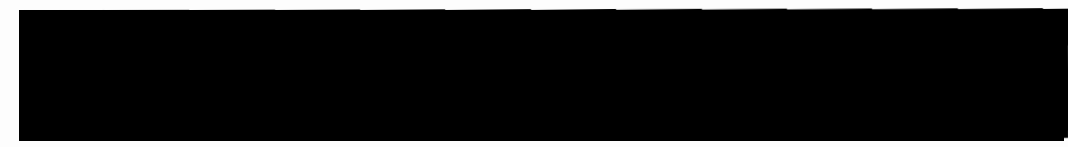

William B. Fischer, Chairman

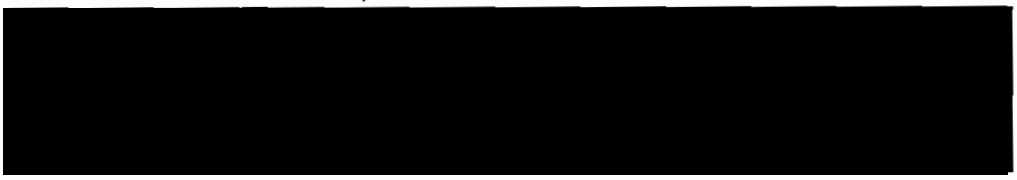

Linda B. Parshall
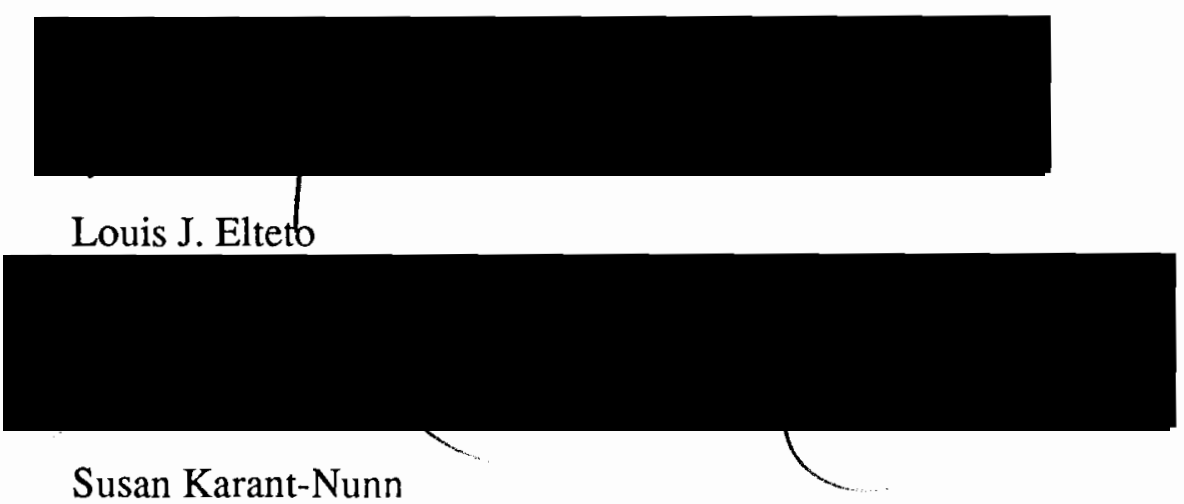

Christa Wolf is perhaps the best known East German author outside the German Democratic Republic. Her works have been translated into many languages, and on her recent sixtieth birthday she was able to look back on an illustrious literary career. Erich Loest's life as an East German writer has been more troublesome, from his years as a 
young adult on the eastern side of the wall to his life in the Federal Republic since 1981. Both writers have worked under a political system which imposes strict guidelines on its artists, as regards conception and production of their works. Both authors have adhered to, yet also sometimes attempted to stray from these guidelines in the name of artistic freedom, especially during periods of political change, toward more openness. Wolf and Loest both remained true to the political system with and for which they have lived since the conception of the East German state, yet their attempts to participate in the political dialogue have frequently been thwarted. The writers' role in a socialist country can be powerful, for it is their responsibility to translate political ideologies and goals into heroes and plots in their work. Their own political ideas and philosophical backgrounds inevitably come into play in their work, but more prominent are the realities of Kulturpolitik.

In this thesis, I have attempted to illustrate the relationship between the creation of a novel and the plethora of often unpredictable methods of censorship. The authors' own interpretation of their role affects their work, but in East Germany various institutions and organizations try to assure the proper reflection of the party's political and philosophical goals. Censorship begins with the Selbstzensur within the author, and often does not cease even after publication. Along the way, after conception of an idea and the first words on paper, the system tries to impose its agenda on the work, which the author can permit or can try to avoid through various means, which are discussed in this paper.

Political and ideological theses, proclaimed at regular intervals at party and writer's congresses, have developed and changed over the years. Consequently, state control over writers has fluctuated, resulting in ideological unevenness in Wolf's and Loest's published works. Having traced the path of Christa Wolf's Nachdenken über Christa T. and Erich Loest's Es geht seinen Gang from conception to completion and beyond, and having analyzed the authors' adherence to or deviation from the ideas of socialist realism in their works, I have found inconsistencies in many Zensurmaßnahmen. 
LITERATURPRODUKTION IN DER DDR:

"VOM ENTSTEHEN UND STERBEN" ERICH LOESTS

ES GEHT SEINEN GANG

UND VOM ENTSTEHEN UND GEDEIHEN CHRISTA WOLFS

NACHDENKEN ÜBER CHRISTA T.

von
GUDRUN HOMMEL-INGRAM

A thesis submitted in partial fulfillment of the requirements for the degree of

MASTER OF ARTS

in

GERMAN

Portland State University

1989 
TO THE OFFICE OF GRADUATE STUDIES:

The members of the Committee approve the thesis of Gudrun Hommel-Ingram presented May 9, 1989.

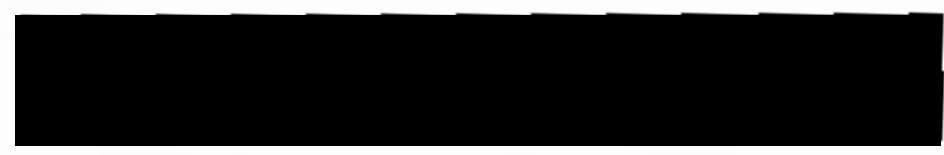

William B. Fischer, Chairman

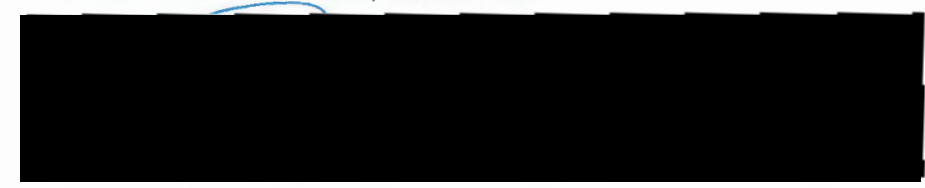

Linda B.Parshall
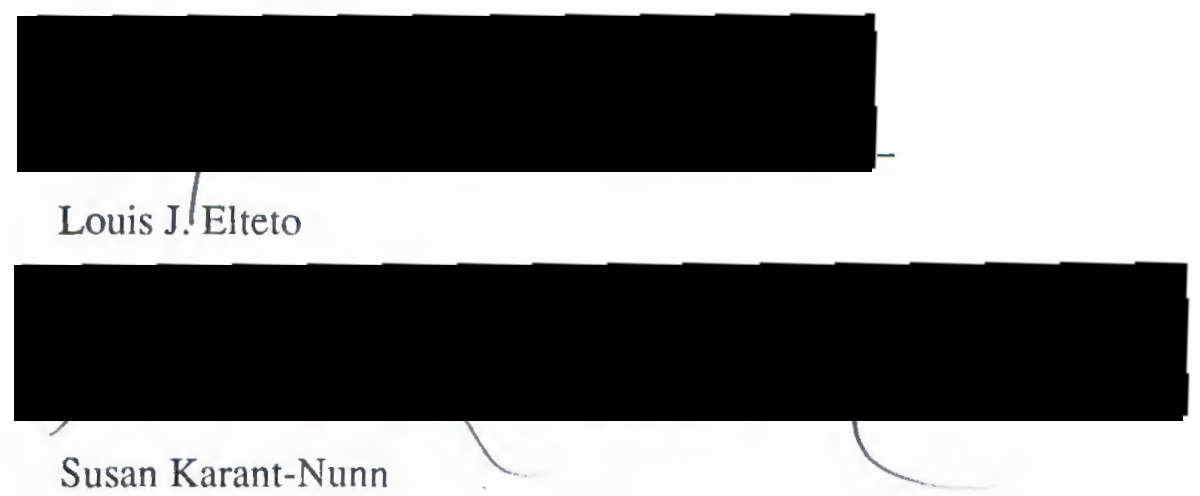

APPROVED:

Linda B. Parshall, Chair, Department of Foreign Languages and Literatures

Bernard Ross, Vice Provost for Graduate Studies 


\section{ACKNOWLEDGMENTS}

Meinem Ehemann Jon möchte ich von ganzem Herzen für seine Fürsorge, Unterstützung, sein Verständnis und seine hausmännlichen Fähigkeiten danken. Er ist ein wahrer Freund. Professor William Fischer verdient meinen herzlichen Dank, denn er hat mich nicht nur mit professionellem Rat unterstützt, sondern mich auch ermahnt oder mir Mut zugesprochen, wenn es notwenig war. Elke Stenzel ist mir eine unersătzliche Freundin geworden, die ich für ihre unermütliche Unterstützung, sei es durch Büchersendungen, konstruktive Kritik oder großes Einfühlungsvermögen, nie mehr missen möchte. Auch im Namen der deutschen Bundespost und der Buchhandlung Schöhning in Mainz bedanke ich mich von ganzem Herzen bei meinem Vater Ortwin, sowie meiner Mutter Inge, denn ohne ihre ständige Aufmerksamkeit und ihre regelmäßigen Büchersendungen hätten mir viele aufschlussreiche Materialien nicht zur Verfügung gestanden. Weiterhin danke ich Peter Fischer und Frau Professor Nussbaum für viele hilfreiche Materialien, Vorschläge und gute Zusprüche. Bei meiner Arbeit an diesem Projekt bin ich auch auf Vertreter des Menschenschlages gestoßen, der sich unprofessionell und unmenschlich verhält. Ihnen gebührt kein Respekt. Als Retter in der Not hat sich David Fogg verdient gemacht. Ohne seine Geduld und sein Fachwissen läge die These nebst Computer auf dem Meeresgrund. ¡Muchas Gracias! 
SEITE

ACKNOWLEDGMENTS. iii

KAPITEL

I EINLEITUNG

II IDEOLOGISCHE UND POLITISCHE VORAUSSETZUNGEN 5

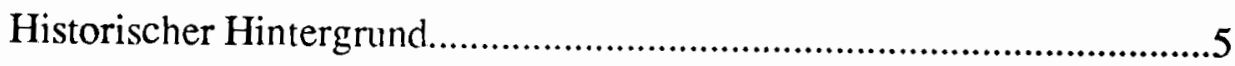

Der sozialistische Realismus........................................................ 7

Kulturpolitische Etappen.............................................................12

Biermann: Ausbürgerung und Folgen .............................................. 20

Institute und Organisationen ......................................................... 37

III "NACHDENKEN" ÜBER DIE MÖGLICHEN ANGRIFFSPUNKTE IM WERK WOLFS UND LOESTS: EINE GEZIELTE NACHERZÄHLUNG.....48

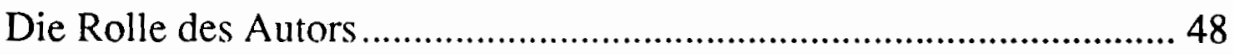

Nachdenken über Nachdenken üiber Christa T..................................... 52

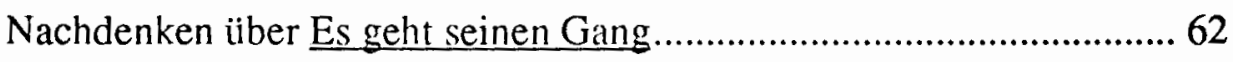

IV "DER VIERTE ZENSOR": DARSTELLUNG DER REZEPTION ...................72

Auch ein Linientreuer Autor braucht Geld .........................................72

Der wievielte Zensor? Die Rolle des Verlags.......................................76

Einfluß der Bundesrepublik ..........................................................83

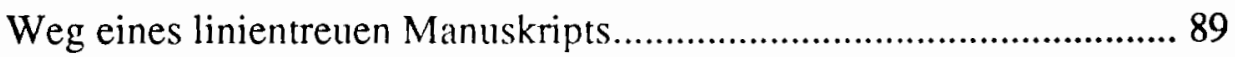

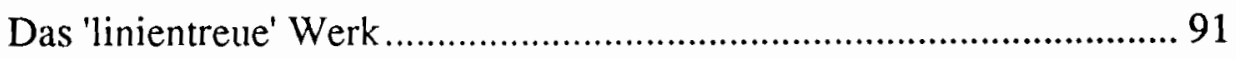

Wer setzt die Richtlinien? Die Schriftsteller selbst?.............................92

"Sie ist ihrer Zeit.voraus". Christa Wolf und Christa T..........................98 
Rezeption: Sind sie ihrer Zeit hinterher?

Loests und Wülffs 'Rebellion' ........................................................ 117

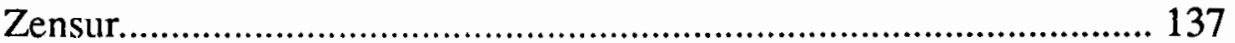

V "WARUM SCHREIBEN SIE?" UND WIE? ...............................................151

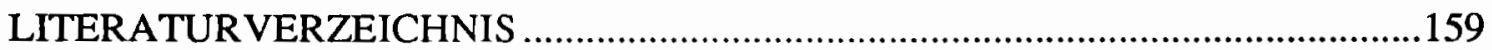


"Warum schreiben Sie?" Darauf hat unsereiner hundert und mehr Antworten parat, von denen jede im besten Fall eine Teilwahrheit und damit auch eine Teilluige darstellt. Es ist eine Frage, die auch Erstaunen zeigt, als wäre Schreiben etwas ganz Besonderes. Als schrieben nur wenige, und die meisten schrieben eben nicht. Mag sein, daß dem so ist. Dennoch erstaunt diese Frage nicht minder. Angesichts der Unfertigkeit dieser Welt müßte die Frage ganz anders lauten. Angesichts von so viel Leid und Irrsinn, die beschrieben werden muissen, müßte die Frage eigentlich lauten: "Warum schreiben sie nicht?"

- Joachim Seyppel

in seinem Buch Ich bin ein kaputter Typ. 


\section{KAPITEL I}

\section{EINLEITUNG}

Der Literatur in einem sozialistischen Land, hier der Deutschen Demokratischen Republik, wird durch den Staat eine wichtige politische Rolle zugeteilt. Sie soll zur ideologischen Erziehung der Staatsbürger beisteuern, was während bestimmter Phasen der Kulturpolitik unterschiedlich ausgeführt wird. DDR-Autoren sollen jedoch immer, egal zu welchem Zeitpunkt in der politischen Entwicklung des Staates, die gesellschaftliche, ideologische und moralische Überlegenheit des sozialistischen Systems darstellen.

Diese These befaßt sich nicht allgemein mit den politischen und ideologischen Zielen und deren Ausführung durch die Literatur in der DDR, sondern analysiert die eigentlichen Produktionsschritte und die Rezeptionsgeschichte einzelner veröffentlichter Werke und zieht Schlüsse über den Literaturproduktionsprozeß in der Deutschen Demokratischen Republik.

Bei einer Behandlung des Themas DDR-Literatur kann der Aspekt der Selbstzensur nicht unbeachtet bleiben. Selbstverständlich haben sich die beiden hier behandelten DDR-Autoren Christa Wolf und Erich Loest dieser unterzogen, doch hat sie ihr innerer Zensor nicht davon abgehalten, ihr persönliches literarisches Konzept zu realisieren und ihre Werke zu veröffentlichen. Da ihre Bücher auf den Markt kamen, im Osten und im Westen Deutschlands, kann neben ihrer Entstehungsgeschichte auch die Folgen ihres Erscheinens verfolgt werden. In beiden Fällen ist eine Analyse ihrer Rezeptionsgeschichte möglich, welche dieser These zugrunde liegt.

Aufgrund der politischen und ideologischen Gegebenheiten in der DDR und aufgrund der Rolle, die einem Autor zugeteilt wird, muß ein literarisches Werk in seinem 
Entstehen beeinflußt werden, und dessen ist sich ein Autor in der DDR bewußt. Das Werk und der Autor selbst sind nicht nur von Bedeutung, sondern auch der Einfluß, der von Vertretern der Kultur- und Literaturpolitik genommen wurde. Ich glaube, daß man zwar ohne einen genauen Einblick in die Entstehungsgeschichte eines DDR-Romans, ohne Einblick in die Motivation des Autors und ohne Kenntnis der Rezeption auf das Werk seinen literarischen Werk erkennen und es darum genießen kann. Ich bin jedoch, besonders nach Vollendung dieser Arbeit, von dem Wert einer Analyse der werkspezifischen Bedingungen und Voraussetzungen zum Schreiben in einem sozialistischen Land, sowie einem Verständnis der Produktionsschritte und deren Beschränkungen überzeugt. Erstaunlich war für mich sogar, daß beide Werke überhaupt erscheinen durften, denn ihre scharfe Kritik an der DDR-Gesellschaft und ihrer Menschen ist unverkennbar.

Gewisse literarische Ausführungen in dem Werk selbst helfen weiterhin dem Leser, einen Einblick in gesellschaftliche Gegebenheiten zu gewinnen und illustrieren, was seitens des Autors kritisiert wird. Die Darstellung der Protagonisten, besonders der sozialistischen Helden, ist von Bedeutung, denn dem Autor obliegt die Aufgabe, deren Gedanken und Verhalten positiv, und darum beispielhaft, darzustellen. Anhand der Reaktion seitens der Zensoren auf die spezifischen Ausführungen im literarischen Werk können Schlüsse über die Arbeitsbedingungen der DDR-Autoren bezogen werden. Aus diesem Grund wird in Kapitel drei, der Behandlung spezifischer Produktionsschritte in Kapitel vier vorausgesetzt, eine gezielte Interpretation der beiden Werke gegeben, mit denen sich diese These besonders befaßt. Christa Wolfs Nachdenken über Christa T und Erich Loests Es geht seinen Gang oder Mühen in unserer Ebene sind etwa von Lektoren, Verlegern und Rezensenten hauptsächlich aufgrund ihrer Protagonisten angegriffen und zensiert worden. Der Inhalt der beiden Werke wird den meisten Lesern bekannt sein. Die ausführliche Darstellung Christa T.s und Wolfgang Wülffs, besonders deren Handeln und 
deren Gedanken, wurde wiederholt angegriffen und ist darum nicht nur aufschlussreich, sondern in dieser Arbeit unerläßlich.

Die Interaktion zwischen Literatur und den kulturpolitischen Voraussetzungen ist komplex, dadurch schwer durchschaulich. Kapitel zwei erläutert die ideologischen und politischen Hintergründe und Voraussetzungen, unter denen Schriftsteller in der DDR arbeiten müssen. Wie bei der Besprechung der Rolle des Autors, sowie in den Schlußgedanken darauf hingewiesen wird, haben viele Autoren mehr kreative Freiheit, als mancher westliche Leser einzusehen vermag. Nicht alle Kunstschaffenden lehnen die Rolle des Staates in ihrer Arbeit ab. Doch scheint sich in den vierzig Jahren seit Bestehen der DDR eine Mehrheit der Schriftsteller fortlaufend kritisch mit ihrem Staat und seiner Kulturpolitik auseinandergesetzt zu haben. Anhand der beiden Werke Wolfs und Loests, die in den sechziger und siebziger Jahren entstanden, wird dargestellt, durch welche zensierenden Maßnahmen das Konzept eines literarischen Werkes und dessen Ausführung beeinflußt werden, und wie diese beiden Betroffenen darauf reagiert haben. Kapitel vier liefert die Verbindung zwischen den Textanalysen und ihrer Rezeptionsgeschichte. Oft sind Vermutungen über das Thema der Zensur in der DDR geäußert worden, doch haben sich bis jetzt sehr wenige aus westlicher Sicht damit befaßt. In meinen Nachforschungen bin ich als einzige auf Köhler-Hausmann gestoßen, die sich in Literaturbetrieb in der DDR: Schriftsteller und Literaturinstanzen speziell mit dem Literaturbetrieb in der DDR beschäftigt. Sie beschränkt sich nicht auf Verfasser von Romanen, Erzählungen oder Kurzgeschichten, sondern weitet ihre Arbeit auf Film und Bühne aus. Die akkuratesten Quellen liefern jedoch entweder die Autoren selbst, oder die bei Forschungen auf dem Gebiet DDR-Literatur unersetzlichen Dokumentensammlungen von Schubbe, Lübbe und Rüß. Anhand der Stellungnahme direkt betroffener Autoren zu ihrem Staat und dessen Zensurmaßnahmen, war es mir nicht nur möglich, zensurartige Methoden der Kultur- und Literaturpolitik in der DDR zu erläutern, sondern auch spezi- 
fische Produktionsschritte darzustellen. In welchem Maße und zu welchem Zeitpunkt während des Schaffungsprozesses 'der vierte Zensor' eingreifft, dies ist von Bedeutung.

Die Aktualität dieses Themas könnte schnell überholt sein, oder so könnte man meinen, denn die politischen und gesellschaftlichen Veränderungen, die sich in der DDR vollziehen, weisen auf eine Lockerung der straffen parteilichen Zügel hin. Beeinflußt durch die Reformbewegung in der Sowjetunion könnte sich das Leben der DDR-Bürger, und somit das ihrer Schriftsteller, drastisch verändern. Ich zweifele jedoch an einer baldigen Änderung der Lage. Anhand meiner Forschung auf dem Gebiet der DDRAutoren und ihrer Leser stieß ich, zu meinem Erstaunen, wiederholt auf gesetzliche und kulturpolitische Maßnahmen, die früheren Reformversuchen schnell Einhalt geboten hatten. Zu beobachten wäre, ob sich die, bis zu diesem Zeitpunkt verhältnismäßig chaotisch durchgeführte, Zensur in der DDR konsequenter durchsetzen wird, oder ob sie sich dem sowjetischen Beispiel anschließen und sich lockern kann. 
KAPITEL II

\section{IDEOLOGISCHE UND POLITISCHE VORAUSSETZUNGEN HISTORISCHER HINTERGRUND}

Am 7./8.5.1945 endete der Zweite Weltkrieg, die Deutsche Wehrmacht kapitulierte. Was blieb war ein weitgehend zerstörtes Land und seine entmutigte Bevölkerung. Die Verwaltung des ehemals faschistischen Staates wurde von den Alliierten übernommen, die das Land in vier Zonen aufteilten, drei westliche und eine sowjetische Besatzungszone (SBZ). Die Katastrophe hatte einen tiefen Eindruck in der Bevölkerung hinterlassen.

Zwölf Jahre Faschismus und Krieg waren nicht in eine innerdeutsche Befreiungsbewegung eingemündet, sondern hatten zu einer allgemeinen Verrohung, Demoralisierung und Preisgabe humaner Normen geführt, die einen Neuanfang in jeder Hinsicht notwendig - und doch gleichzeitig fast unmöglich machten. 1

Von Anfang an wurden sowohl in den Westzonen als auch in der Ostzone unterschiedliche Wege zur Reform eingeschlagen. Eine geringe gemeinsame politische und ökonomische Basis bestand, sodaß die Entwicklung auseinander statt miteinander schon damals deutlich zu erkennen war. Zu den Veränderungen im wirtschaftlichen, sozialen und gesellschaftlichen Leben in der SBZ gehörten unter anderem die Verstaatlichung großer Wirtschaftsunternehmen, die Bodenreform, und die Durchführung einer Bildungs- und Justizreform. Veränderungen in den verschiedenen Besatzungszonen sollten das alte Deutschland äußerlich und politisch verändern, den Verlierern des Krieges wurden von westlichen und östlichen Siegermächten ein Weg zum Aufbau, zur 
Emeuerung ihrer gescheiterten Politik angeboten. Dadurch wurde "das als politische Subjekt handlungsunfähige deutsche Volk...zum Objekt einer anhaltenden Kontroverse zwischen dem kapitalistisch-westlichen und dem sozialistisch-östlichen Lager."2 Der 'kalte Krieg' hielt die Spannungen aufrecht.

Diese Zeit der Veränderungen bedeutete auch eine Zeit der Hoffnung vieler Intellektueller. Ehemalige Mitglieder des Bundes proletarisch-revolutionärer Schriftsteller Deutschlands, der 1928 gegründet worden war, fanden sich nun wieder in der Ostzone zusammen. Sie hatten ihre Hoffnungen auf eine bessere Zukunft in einem ihnen sympathischen Staat nicht aufgegeben, hatten weiterhin an den Sozialistischen Realismus geglaubt, und waren nun wieder zum Teil vereint. In der SBZ gründeten sie am 3. Juli 1945 den "Kulturbund zur demokratischen Erneuerung Deutschlands", zeigten sich begeistert darüber, endlich wieder aktiv an der Besserung des Menschen und seines Lebens, sowie an der Bewältigung der Vergangenheit mitwirken zu können.

Während viele der Intellektuellen, im Osten und Westen des geteilten Landes, zuversichtlich in die Zukunft schauten, wurde auf politischer Ebene der Ost-West Gegensatz immer deutlicher und gipfelte 1949 in der Gründung zweier deutscher Staaten. Deutschland wurde gespalten. Das Ziel der Westmächte war, die "...Wiederherstellung des europäischen Gleichgewichts mit der Erneuerung der politischen, wirtschaftlichen, sozialen und gesellschaftlichen Verhältnisse..."nach ihrer Vorstellung. ${ }^{3}$ Die Sowjetunion behielt ihre Ziele, die denen der Westmächte sehr entgegengesetzt waren, fest im Auge. Die Westmächte waren an der Wiederherstellung des Gleichgewichts in Europa interessiert, die Sowjetunion wollte ihren politischen Einflußbereich gen Westen ausbreiten. Der Zerfall der ehemaligen Koalition, die scheinbar im Interesse aller

2 ebda 9.

${ }^{3}$ Heiner Timmermann, Bundesrepublik - DDR, Grundzüge im Vergleich (Opladen: Leske + Budrich, 1984) 30. 
gegründet worden war, wurde endgültig, denn sie basierte auf politischen und gesellschaftlichen Vorstellungen, die sich zu stark voneinander unterschieden. Im Mai 1949 trat das Grundgesetz für die Bundesrepublik Deutschland in Kraft. Am 7.10.1949 beschloß der Volksrat der Ostzone die Gründung der Deutschen Demokratischen Republik. ${ }^{4}$

\section{DER SOZIALISTISCHE REALISMUS}

Eine Behandlung des Themas Kulturpolitik der DDR setzt gewisse Erläuterungen des marxistisch-leninistischen Kulturbegriffs, sowie des 'sozialistischen Realismus' voraus. Es ist nicht Sinn dieser Arbeit, eine detaillierte Analyse der ideologischen und politischen Voraussetzungen der Kulturpolitik der DDR durchzuführen. ${ }^{5}$ Ohne ein gewisses Verständnis dieser Begriffe ist jedoch eine Diskussion der DDR-Literatur nicht möglich, da sie einen integralen Teil des literarischen und kulturellen Selbstverständnisses dieses Landes darstellen.

"Unter sozialistischer Kultur wird die in der sozialistischen Gesellschaft entstehende 'qualitativ höhere' Kultur verstanden, die das 'gesamte progressive Kulturerbe der Menschheit' in sich aufnimmt. ${ }^{6}$ Kultur wird sich 'angeeignet', ist ein "Bildungsgut."7 Mit Hilfe der Kulturpolitik soll in einem sozialistischen Staat, in diesem Falle die DDR, die sozialistische Kulturrevolution durchgeführt werden. Die vorliegende Arbeit wird

${ }^{4}$ Für eine ausführliche Besprechung der politischen Entwicklung der DDR siehe Hermann Weber, DDR. Grundriß der Geschichte: 1945 - 1981 (Hannover: Fackeltrăger, 1982) und/oder Hans Georg Lehmann, Chronik der DDR: 1045/46 bis heute (München: Beck, 1987).

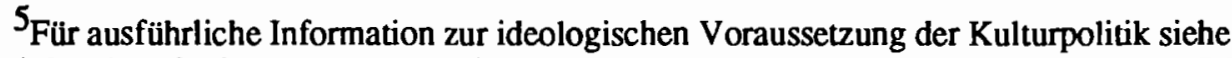
Bundesministerium für innerdeutsche Beziehungen, DDR-Handbuch Band l A - L (Frankfurt/Main: 1985), 767-775 und Wolfgang R. Langengruber, Rolf Rytlewski und Bernd Weyergraf, Hrsg., Kulturpolitisches Wörterbuch Bundesrepublik Deutschland/Deutsche Demokratische Republik (Stuttgart: Metzler, 1983) 390-396.

${ }^{6}$ Martin Ahrends, Trabbi. Telespargel und Trănenpavillon. Das Wörterbuch der DDR-Sprache (München: Heyne, 1986) 114. 
noch genauer auf die Etappen der Kulturpolitik der DDR eingehen. Allgemeines Ziel dieser Kulturpolitik ist jedoch, laut "Erklärung der Kommunistischen und Arbeiterparteien" im Jahre 1957:

Die Verwirklichung der sozialistischen Revolution auf dem Gebiet der Ideologie und Kultur und die Herausbildung einer der Arbeiterklasse, dem schaffenden Volk und der Sache des Sozialismus ergebenen zahlreichen Intelligenz. 8

Diese Ziele sind noch nicht erreicht worden, teilweise, weil dieser Prozeß Teil der Umgestaltung der gesamten Gesellschaft ist und diese Gesellschaft im real existierenden Sozialismus noch nicht vollendet ist.

Gesellschaftspolitische Veränderungen wurden während der Russischen Revolution, unter anderem auch durch kulturpolitische Mittel erzielt, sodaß sie sich dort als ein wichtiges Instrument politischer Umwälzung bewiesen hatten. Verständlich ist darum, daß die Entwicklung einer sozialistischen Gesellschaft auf dem Gebiet der SBZ unter sowjetischer Führung eine aktive Kulturpolitik beinhalten mußte. Laut Marx und Engels waren folgende theoretischen Gesichtspunkte wichtig zur "Bestimmung von Kultur im Marxismus:

die Entfaltung des Menschen als produzierendes, sich in der Gesellschaft verwirklichendes Wesen im Zentrum, das heißt der Prozeß, in welchem 'die Umstände ebensosehr die Menschen wie die Menschen die Umstände machen' ".9

Kultur, zumindest nach marxistisch-leninistischer Ideologie, braucht neben der den Sozialismus unterstützenden Intelligenz Menschen, die entweder als Sozialisten noch nicht voll entwickelt sind und sich als Teil eines Entwicklungsprozesses sehen und aktiv an ihm teilnehmen, oder voll entwickelte Sozialisten, wie das in der DDR-Gesellschaft aber noch nicht der Fall ist. Besonders wichtig dabei ist, daß diese Menschen nicht das

8 Langengruber, 488.

9 ebda 391. 
Bildungsprivileg besitzen, demnach nicht der herrschenden Klasse entstammen, wie etwa in der bürgerlichen Klassengesellschaft, sondern der Gruppe der Werktätigen angehören.

Die Debatte um die Literaturtheorie des 'sozialistischen Realismus' läuft, laut Jäger, schon seit der Formulierung des Begriffs in den dreißiger Jahren. Jäger zieht folgenden Schluß: "Hinter den ausgeleierten Formeln steckt die sogenannte Machtfrage, der Anspruch auf ein 'Bekenntnis' zu einer letztlich undefinierbaren Methode."10 Trotzdem läßt sich der Versuch einer Definition nicht umgehen, besonders da er oft und ausführlich in Sachwörterbüchern, auf Schriftstellerkongressen, in Streitgesprächen etwa in den sozialistischen Ländern formuliert wurde.

Unter sozialistischem Realismus versteht man heutzutage eine künstlerische Richtung. Der Begriff ist jedoch administrativen Ursprungs und war schon immer ein "kulturpolitisches Losungswort"11. Stalin wird meist als Vater dieses Begriffes angegeben, dem Chefredakteur der "Iswestija" wird von anderen die Urheberschaft zugesprochen. Anhand der Zustimmung unter Stalin und dem darauffolgenden Verwurf der Interpretation dieses Begriffes, sowohl in der Sowjetunion als auch in der DDR, ließe sich darstellen, in welchem Ausmaß Schwankungen in den Führungsrollen und ideologischen Interpretationen nicht nur die Terminologie, sondern auch die davon betroffenen Dogmen beeinflussen. Dies soll nicht Aufgabe dieser Arbeit sein. ${ }^{12}$ Angeführt werden hier jedoch die ursprünglichen fünf Punkte, formuliert von dem Leningrader Parteisekretär J. Shdanow im Jahre 1934, da sie veranschaulichen, wie eindeutig Maßstäbe zur Literaturproduktion dargelegt wurden, und welche Rolle hier die

10Manfred Jäger, Kuluur und Politik in der DDR (Köln: Verlag Wissenschaft und Politik,1982) 48. 11 ebda 33.

12 Siehe DDR-Handbuch, Stichwort Kulturpolitik (S.767) für ausführlichere Analyse der politischen Ramifikationen. 
Partei schon einnehmen darf und soll, da ihre Vorstellung von Fortschritt in der Literatur realisiert werden soll.

Der sozialistische Realismus:

1. trennt die Wahrheit von der objektiven Wirklichkeit und bindet sie zwecks politisch-pädagogischer Einwirkung an deren - jeweils von der Partei bestimmte - revolutionäre Veränderung;

2. reduziert die Sujetbreite vorwiegend auf die Arbeitswelt, um soziale, psychologische erotische und mythologische Beziehungselemente auszuschalten, die das gewünschte Bild von der Wirklichkeit abweichend einfärben könnten;

3. verfügt über eine revolutionäre Romantik mit einem positiven Helden, um das kalkulierte Werk zu emotionalisieren;

4. separiert die sozialistische L. von der bürgerlichen "Verfallsliteratur";

5. läßt durch kritische Aneignung des klassischen Erbes von der Welt-L. nur ein Kompendium des Realismus gelten, in dem nur Werke zugelassen werden, die zugleich auch im Sinne der Partei als fortschrittlich gelten. ${ }^{13}$

Richtlinien wurden gegeben, Maßstäbe gesetzt, einer bestimmten literarischen Methode sollten sich die Schriftsteller verpflichtet fühlen. Daß ihnen dadurch ein großes $\mathrm{Maß}$ an künstlerischer Freiheit entzogen wurde, oder sie sich selbst entziehen sollten, hinterließ bei vielen Skepsis.

Die DDR, gegründet mit Hilfe der Sowjetunion und deutschen Kommunisten, mußte sich dementsprechend auch kritisch mit der Unbestimmtheit des sozialistischen Realismus auseinandersetzen. Die Intellektuellen, die aktiv an dem Aufbau eines neuen, sozialistischen Landes mitwirkten und zu Beginn viel Redefreiheit genossen, hatten zum Teil die Lange Debatte in der Sowjetunion um diesen Begriff mit verfolgt. Anna Seghers sprach gewiß für viele, als sie "die Skepsis gegenüber den politischen und pseudoästhetischen Vorgaben und Vorhalten, die wenig geeignet waren, dichterische Produktivität zu befördern" 14 aussprach. "Der sozialistische Realismus wird bejahend oder polemisch von

$13_{\text {ebda }} 526$.

14 Jăger, 37. 
Menschen erwähnt, die in Verlegenheit kommen, wenn man sie genau fragt, was das ist." 15 Und doch wurde der Begriff und die damit verbundenen Ideen und Ziele nicht geändert. Kritikern wurde wiederholt "vorgehalten, der sozialistische Realismus sei kein Stil, sondern eine Methode. Das sollte heißen, er lasse mehrere unterschiedliche realistische Stilarten $\mathrm{zu} . " 16$

Im Kulturpolitschen Wörterbuch Bundesrepublik Deutschland/ Deutsche

Demokratische Republik wird er beschrieben als eine

"...künstlerische Methode; sich dynamisch entwickelndes System von Prinzipien und Zielsetzungen der künstlerischen Aneignung der Wirklichkeit vom Standpunkt der revolutionären Arbeiterklasse und der sozialistischen Gesellschaft."17

Das Kleine Politische Wörterbuch der DDR beschreibt 1978 den sozialistischen

Realismus als eine

"künstlerische Richtung und Schaffensmethode, die die Wirklichkeit in ihrer revolutionären Entwicklung, in ihrer Bewegung zur sozialistischen und kommunistischen Gesellschaft hin künstlerisch gestaltet.... die Grundsätze sozialistischer Parteilichkeit und Volksverbundenheit sind unabdingbare Grundprinzipien des sozialistischen Realismus.... Die Methode...befähigt die Schriftsteller und Künstler zu einer wahrheitsgetreuen Darstellung der Wirklichkeit durch tiefes Eindringen in die sozialen Zusammenhänge und Gesetzmäßigkeiten."18

Im Jahre 1968 sah sich die DDR bereits als eine fortgeschrittene sozialistische Gesellschaft an. Die Funktion der Kunst im sozialistischen Realismus hatte sich gewandelt. Nicht mehr sollte sie nur als "Waffe im Klassenkampf" eingesetzt werden, sondern eine "...den Sozialismus stabilisierende Wirkung" haben.19 "Die drei

\section{0}

15 ebda 37. (Jager selbst zitiert aus" Über Kunstwerk und Wirklichkeit, I, Berlin, DDR 1970, S.

16 ebda 39.

${ }^{17}$ Langenbucher, 598.

18Dietrich Steinbach, Hrsg., Literarisches Leben in der DDR (Stuttgart: Klett, 1984) 113.

${ }^{19}$ Christel Blumensath und Heinz Blumensath, Einführung in die DDR-Literatur (Stuttgart: Metzler, 1983) 113. 
Grundmerkmale sozialistisch-realistischer Kunst...waren Realismus, Parteilichkeit, Volksverbundenheit."20

\section{KULTURPOLITISCHE ETAPPEN}

Die kulturpolitische Entwicklung in der DDR läßt sich anhand von Etappen darstellen. Der Nachkriegsperiode, die sich durch ihre antifaschistische Literatur auszeichnete und etwa bis 1949 dauerte, folgte eine Etappe, die Jäger mit "Ideologisierung nach Plan" betitelt. ${ }^{21}$ Während dieser Phase, die von 1949 bis 1953 dauerte, wurde die Intelligenz der DDR sehr gefördert. Ihre Rolle war von großer Bedeutung für den Aufbau einer sozialistischen Gesellschaft. Die Lage der Intelligenz sollte verbessert werden, zum Teil, indem im Krieg zerstörte Universitäten und Hochschulen bald wieder aufgebaut und die Arbeiter- und Bauernfakultät eingerichtet wurden. 1949 wurde die Akademie der Künste gegründet, 1945 war der Kulturbund entstanden, 1952 sonderte sich daraus der Schriftstellerverband ab und nahm Stellung zum 'sozialistischen Realismus'. Der Sozialistische Realismus, wie erläutert, wurde in offiziellen Interpretationen fundiert.

Das sowjetische Modell war Vorbild nicht nur für politische und ökonomische Aspekte des jungen Landes, sondern auch seine kulturellen Institutionen und Einstellungen wurden nachgeahmt. Auf Schriftstellerkongressen und Parteitagen formulierten sowohl die Intelligenz als auch die Funktionäre ihre Thesen zur Verwirklichung ihrer kulturellen und politischen Ziele. Besonders auf die Schriftstellerkongresse soll in der Rezeptionsanalyse der Werke Wolfs und Loests genauer eingegangen werden,

\section{$20_{\text {ebda }} 114$.}

${ }^{21}$ Manfred Jăger, Kultur und Politik in der DDR (Koln: Verlag Wissenschaft und Politik, 1982) letzte Umschlagseite 
da während dieser Kongresse bedeutende literarische und kulturpolitische Richtungen angewiesen werden.

Im Jahre 1951 wurde die Staatliche Kommission für Kunstangelegenheiten in der DDR gegründet. Obwohl den Künstlern und Schriftstellern bis zu diesem Zeitpunkt ein recht großes Maß an Freiheit zugestanden worden war, ließ Ministerpräsident Otto Grotewohl keinen Zweifel an der, nun in zunehmenden Maße der Politik untergeordneten Rolle der Kunst. Als Maxime gab er aus:

Was sich in der Politik als richtig erweist, ist es auch unbedingt in der Kunst. Es ist doch klar daß ein Werk, selbst wenn es gewisse künstlerische Qualitäten in sich trägt vom Volk abgelehnt werden muß, wenn seine Grundrichtung reaktionär ist. Ich will damit sagen, daß die politische Kritik bei der Beurteilung unserer Kunst primär ist und daß die künstlerische Kritik sekundär ist. 22

Neben der Staatlichen Kommission für Kunstangelegenheiten wurden in diesem Jahr auch das "Amt für Literatur und Verlagswesen", im darauffolgenden Jahr das Staatliche Komitee für Filmwesen" und das "Staatliche Rundfunkkomitee" eingerichtet. Die staatliche Lenkung der Kultur war offensichtlich geworden.

"'Der Kampf gegen den Formalismus in Kunst und Literatur, für eine fortschrittliche deutsche Kultur' und die Orientierung auf den 'Sozialistischen Realismus'" wurde auf der 5. Tagung des Zentralkomitees der SED 1951 beschlossen. ${ }^{23}$ Mit diesem Begriff wird seit den dreißiger Jahren in der Sowjetunion, daraus folgend auch in anderen sozialistischen Ländern

"...eine kulturpolitische Zentralkategorie zur Kennzeichnung alles Reaktionären, Nichtsozialistischen, Bürgerlich-Dekadenten in der Kunst. F[ormalismus] bezeichnet also nicht eine bestimmte Strömung der Kunst,

${ }^{22}$ Wolfgang R. Langengruber, Rolf Rytlewski und Bernd Weyergraf, Hrsg., Kulturpolitisches Wörterbuch Bundesrepublik Deutschland/Deutsche Demokratische Republik (Stuttgart: Metzler, 1983) 393 ff. (darin: Neues Deutschland v.2.9.52)

23 Bundesministerium für innerdeutsche Beziehungen, DDR-Handbuch Band $1 \mathrm{~A}-\mathrm{L}$ (Frankfurt/Main: 1985) 769. 
Sondern eine zu verdammende weltanschauliche Haltung, die sich im Kunstwerk ausdrückt." 24

Verdammt wurden tatsächlich eine Anzahl Kunstschaffender und deren Werke im Laufe der Debatte um die Auslegung der beiden Begriffe, darunter etwa Werke von Bertolt Brecht, Musik von Hanns Eisler, eine Ernst-Barlach-Ausstellung und die Verfilmung eines Arnold Zweig Romans. Auch hier beeinflußte die Sowjetunion wieder die kulturpolitischen Richtlinien, die jedoch durch teils heftige Kritik der Künstler zurückgewiesen wurden. Die deutschen Künstler hatten begonnen ihre eigenen Wege einzuschlagen, nicht unbedingt getrennt von der sowjetischen Führung, aber unabhängiger. Ihnen wurde vorgeworfen, ihre Kunst bliebe "hinter den Forderungen der Epoche" zurück. ${ }^{25}$ "Schuld daran seien der Formalismus und 'Unklarheiten über Weg und Methoden' der Kunstschaffenden."26 Das ZK der SED gründete die "Staatliche Kommission für Kunstschaffende", um den Künstlern zu helfen, für die Gesellschaft 'angebrachtere' Werke zu schaffen. Einige der etablierten Institutionen wurden jedoch bald darauf wieder abgeschafft und stattdessen durch das am 7.1.1954 gegründete Ministerium für Kultur ersetzt.

Die Schwankungen in den Beziehungen von Staat und Künstlern setzten sich auch in den folgenden Jahren fort, die Aufbauphase der DDR war von innerer Unsicherheit und außenpolitischen Ereignissen durchsetzt. Laut Zipser und Schoeps hatte die bisherige Kulturpolitik der SED vor allem Stagnation erzeugt. Innenpolitische Probleme bereitete der 17. Juni 1953. Er brachte einen Aufstand der Arbeiter, die mit einem Streik gegen eine "Erhöhung der technischen Arbeitsnormen (TAN) um mindestens 10\%"

${ }^{24}$ Martin Ahrends, Trabbi, Telespargel und Tränenpavillon. Das Wörterbuch der DDR-Sprache (München: Heyne, 1986) 63.

25 Richard A.Zipser und Karl-Heinz Schoeps, DDR-Literatur im Tauwetter Band 1-3 (Bern: Peter Lang, 1985) 21. Die Autoren Zitieren aus: Elimar Schubbe, Dokumente zur Kunst- Literatur- und Kulturpolitik der SED 1949-1970 (Stuttgart: Seewald, 1972) 178-186.

$26_{\text {ebda }} 21$. 
protestieren. ${ }^{27}$ Für außenpolitische Unruhe sorgte nicht nur die weiterhin schwierige Beziehung zur Bundesrepublik, sondern auch Stalins Tod im Jahre 1953, und dessen unerwartete Verurteilung auf dem XX. Parteitag der KPdSU im Jahre $1956 .{ }^{28}$ Jäger weist auf die zu befürchtenden Folgen für Ulbricht hin. "Der XX. Parteitag...stimulierte mit seinen Entstalinisierungstendenzen die Kritik an der bisherigen SED-Politik. Die Führung um Ulbricht hatte Mühe, die von Moskau ausgehende Gefährdung ihrer Macht abzufangen." 29 Heftig reagierte die DDR auf die als Revisionisten abgestempelten Künstler und Literaturwissenschaftler der inneren Opposition. Anhand des Schriftstellers Hans Mayer verdeutlicht Jäger die Kritik der Oppositionellen. In einem Artikel, der in der Wochenzeitung des Kulturbundes, "Sonntag" abgedruckt wurde, zog der Verfasser " ...eine Bilanz des mageren literarischen Lebens in der DDR, sprach von Stagnation und Sterilität, polemisierte gegen die rotangestrichenen Gartenlauben vor allem der Lyrik. Er verlangte, endlich die kenntnisreiche Auseinandersetzung mit der Moderne zu beginnen, also nicht mehr so zu tun als habe Joyce den Ulysses nie geschrieben." 30

Daraufhin verloren die zuständigen Redakteure ihre Stellen und landeten im Zuchthaus.

Die Intelligenz ordnete sich zum Teil nicht der Parteidisziplin unter und mußte im Endeffekt dafür büßen. Besondere Repressalien erfuhr eine Gruppe um den Ost-Berliner Philosophie-Dozenten W. Harich. Der Leiter des Aufbau-Verlages Janka, deren Anhänger zum Teil verurteilt und inhaftierte wurden, mußte auch büßen. Harich und Janka hatten sich für den Marxismus-Leninismus, aber gegen Stalinismus ausgesprochen. Harich hatte auch "die undialektische Schönfärberei, den kunsttheoretischen Dilettantismus und die

${ }^{27}$ Hans Georg Lehmann, Chronik der DDR $1945 / 49$ bis heute (München: Beck, 1987) 38.

${ }^{28}$ Im April 1989, 33 Jahre nach dem XX. Parteitag, auf dem Nikita S. Chruschtschow in einer geheimgehaltenen Rede Stalin verurteilte, wurde diese Rede zum erstenmal in der Sowjetunion veröffentlicht. (The Oregonian, Thursday, April 6, 1989)

29 Jăger, 76.

30 Jäger, 78. 
Schikanierung einiger Künstler" angeprangert."31 Ähnlich erging es Anhängern des Philosophen Ernst Bloch, die sich für die "geistige Freiheit der Kunst" einsetzten. ${ }^{32}$ Der Schriftsteller Erich Loest unterstütze Bloch auch in seiner Verteidigung freiheitlicher Ideale. Sieben Jahre Zuchthaus brachte ihm diese Gleichgesinnung ein. "Ulbrichts Säuberungen der aufbegehrenden Intelligenz hatte deren endgültige Entmachtung zur Folge." ${ }^{33}$ Einige, wie Loest, wurden zu Zuchthausstrafen verurteilt, andere, wie Loests Freund Zwerenz, entzogen sich der Verhaftung, indem sie in den Westen gingen.

Die neue "Tauwetterphase", die nach dem XX. Parteitag der KPdSU im Frühjahr 1956 eingetreten war, hatte demnach nicht lange angehalten. Stalins Verurteilung, der Einsatz einer Anzahl junger Künstler für größere künstlerische Freiheit trug nur kurze Zeit Früchte. Alexander Abusch, der stellvertretende Kulturminister der DDR, hatte zwar 1956 zugestanden, daß es "neben der Methode des sozialistischen Realismus auch andere Schaffensmethoden gäbe", 34 zur Zeit der Kulturkonferenz der SED im Oktober 1957 hatte sich der Wind jedoch schon wieder gedreht.

Der V. Parteitag der SED im Juli 1958 markierte eine neue Etappe der Kulturpolitik der DDR. Walter Ulbricht hielt eine Rede, in der er von der Kluft zwischen Künstlern und Werktätigen sprach, diese Kluft bedauerte und nun die Arbeiter aufforderte, sich an der Schaffung der sozialistischen Kultur zu beteiligen. Er ließ sich aus über die "Entwicklung des 'schreibenden' Arbeiters, der jetzt die Höhen der Kultur erklimmen sollte." Die in dieser sich entwickelnden sozialistischen Gesellschaft noch bestehende Trennung von 'Kunst und Leben', Künstler und Volk', 'Geist und Macht' sollte

31Zipser, 21.

32 Bloch (1885-1977) entwickelte auf der Grundlage des Marxismus 'Das Prinzip Hoffnung', ein theologisches Weltprinzip. (Vgl. Duden Lexikon, 7. Auflage, 1983)

33Langengruber, 393.

${ }^{34}$ Zipser, 22. 
endgültig aufgehoben werden. ${ }^{35}$ Kennzeichnend für diese neue Phase der Kulturpolitik ist die Autorenkonferenz im Kulturpalast des elektrochemischen Kombinats Bitterfeld. Unter der Losung "Greif zur Feder, Kumpel, die sozialistische Nationalliteratur braucht dich!" wurden auf dieser I. Bitterfelder Konferenz im April 1959 Arbeiter aufgerufen, sich aktiv am Schreiben zu beteiligen. Künstlern und Schriftstellern wurde nahegelegt "in die Betriebe zu kommen, auf die Bauplätze des Sozialismus zu gehen und in Romanen, Erzählungen, Bühnenwerken und Gedichten das Heldentum der Arbeiter zu feiern". 36 Zur Folge hatte diese neue Phase unter anderem die Entstehung von 'Betriebsromanen', 'Traktorenlyrik' und 'Brigadetagebüchern'. In der Geschichte der Literatur der Deutschen Demokratischen Republik die unter der Leitung Horst Haases entstand, befindet sich eine Erläuterung des Bitterfelder Weges aus DDR-Sicht. Ausführlich wird darin auf die 'Zirkel schreibender Arbeiter' und deren Geschichte eingegangen.

Literarische Talente unter den Werktätigen sollten in einer Bewegung schreibender Arbeiter bewußt gefördert, die Bedürfnisse der Werktätigen nach einer niveauvollen unterhaltenden Literatur stärker berücksichtigt werden. Im Zusammenhang mit den neuen Zügen im Leben der Arbeiterklasse trug diese kulturpolitische Orientierung dazu bei, daß sich die meisten Schriftsteller rege am politischen und gesellschaftlichen Leben beteiligten und manche für längere Zeit in Betriebe und landwirtschaftliche Produktionsgenossenschaften gingen, um Leben und Arbeit der Werktätigen besser kennenzulernen. ${ }^{37}$

Ein besseres Verständnis der Schriftsteller für den sozialistischen Helden, den Arbeiter, war demnach eines der Ziele dieser Strategie.

35 Dieter Steinbach, Hrsg., Wolf Biermann und die Tradition: Von der Bibel bis Ernst Bloch (Stuttgart: Klett, 1980) 6.

36Jager, 83. Seine Fußnote liest sich wie folgt: "Ein großer Schritt wird vorbereitet", in: Helmut Hauptmann, Hsg. DDR-Reportagen. Leipzig, 1969, S.237 ff. In der 1974 erschienenen 2. Aufl. ist dieser Beitrag nicht mehr erhalten.

${ }^{37}$ Horst Haase, Hsg., Geschichte der Literatur der Deutschen Demokratischen Republik Band 11 (Berlin: Volk und Wissen, 1976) 228. 
Ein weiteres Ziel war eine "kulturpolitische Massenbewegung der Arbeiterklasse und des ganzen Volkes". ${ }^{38}$ Der zur Feder greifende Kumpel war größtenteils jedoch nicht geeignet, Literatur von hoher Qualität zu schaffen, sodaß in vielen Fällen seine Werke nur geringen Zuspruch fanden. Von offizieller Seite wurde später in Haases Literaturgeschichte darauf hingewiesen, daß es "zeitweilig...eine Fehlorientierung in dem Sinne..."gab, " daß die schreibenden Arbeiter eine Hauptquelle der sozialistischen Nationalliteratur seien". 39 Es sei nicht die Hauptaufgabe der Arbeiter gewesen "den schriftstellerischen Nachwuchs zu bilden" 40

Jäger unterstellt der DDR, sie habe den Bitterfelder Weg nicht eingeleitet, um die Literatur der Arbeiterwelt von unten freizusetzten, sondern es handele sich...in Wahrheit...um eine von oben initiierte Kampagne zur ideologisch-politischen Abstützung eines Wirtschaftsprogramms und zur Mobilisierung der Bereitschaft der Arbeiter, im sozialistischen Wettbewerb Höchstleistungen zu erstreben." ${ }^{41}$ In der offiziellen Literaturgeschichte der DDR von Haase wird auch im direkten Zusammenhang mit der Behandlung des Bitterfelder Weges die Entstehung der Landwirtschaftlichen Produktionsgenossenschaften (LPG) besprochen. Dort heißt es:

Die Überwindung der einzelbäuerlichen Lebensweise, der Übergang der Bauern zu gemeinschaftlicher Arbeit sowie die Hilfe der Arbeiterklasse in diesem Prozeß war eines der ergiebigsten Sujets der DDR-Literatur. Der 'sozialistische Frühling' auf dem Lande 1960 brachte eine Fülle von operativen literarischen Kleinformen hervor. ${ }^{42}$

Die Behandlung von Konflikten wurde in diesen Werken des Bitterfelder Weges nicht ausgeschlossen, solange sie zu einem guten Ende führten. Der Held durfte nicht aufgeben,

38 Jăger, 83.

${ }^{39}$ Haase, 230.

40 ebda, 230.

$41_{\text {Jăger, } 83 .}$

${ }^{42}$ Haase, 230. 
sondern zeigte oft den anderen einen neuen Weg, der nicht selten ursprünglich auf Widerstand der Mitarbeiter gestoßen war. Natürlich war er der Partei verbunden, hatte als Ziel die neue sozialistische Gesellschaft ins Auge gefaßt und glich einem 'Übermenschen'.

Die II. Bitterfelder Konferenz fand 1964 statt. In den vorangegangenen fünf Jahren hatte sich in politischer Hinsicht viel ereignet, kulturpolitisch mußte später jedoch der Schluß gezogen werden, daß der Bitterfelder Weg nicht den erwarteten Erfolg gebracht hatte. Immer seltener waren die schreibenden Arbeiter von der Partei, den Verbänden und besonders dem Publikum unterstützt worden, da ihre Werke nicht den Erwartungen entsprachen. Nur einige Arbeiterschriftsteller hatten sich zu Berufsschriftstellern entwickelt und entfernten sich oft mit der Zeit von der Arbeiterwelt, ihrem Themenkreis. In seiner Rede auf der II. Bitterfelder Konferenz faßte jedoch Walter Ulbricht noch die von ihm beobachteten Resultate zusammen. Er lobte die Zusammenarbeit der Arbeiter und Kunstschaffenden, sprach von der Überwindung der Kluft zwischen Kunst und Volk und von einem neuen "...Verhältnis der Freundschaft und Zusammenarbeit zwischen der Macht der Arbeiter und Bauern und dem sozialistischen Künstler... Die Arbeiterklasse ist zur bestimmenden Kraft auch im kulturellen Bereich geworden. "43 Daß dies nicht der Fall war, sollte sich später in der DDR-internen Beurteilung dieser fünf Jahre zeigen. Ulbricht verdeutlichte in seiner Rede, daß der Bitterfelder Weg "die Entwicklung der deutschen sozialistischen Nationalkultur über einen längeren Zeitraum" sei. Auf diese Weise wollte er Kritikern zuvorkommen, die den "tiefen Wandlungsprozeß", den er darstellte, nicht als solchen einschätzten. 


\section{BIERMANN: AUSBÜRGERUNG UND FOLGEN}

Die ökonomische Entwicklung in der DDR hatte schon seit ihrer Gründung im Jahre 1949 unter starkem Druck gestanden. Der ostdeutsche Sektor hatte sich nicht an dem Marschall-Plan beteiligt und hatte Reparationskosten an die Sowjetunion zahlen müssen. Seit dem Arbeiteraufstand am 17. Juni 1953 konnte die Partei nicht umhin, sich im eigenen Lande verstärkt mit den ökonomischen Schwierigkeiten und dem Leistungsdruck auf die Arbeiter auseinanderzusetzen. Außerhalb ihrer Grenze machte die Technik schnelle Fortschritte, sodaß mit dem internationalen technischen Wettbewerb Schritt gehalten werden mußte. Während sich kulturpolitisch der Bitterfelder Weg als eine Lösung anzubieten schien, wurden der Flucht DDR-Deutscher qualifizierter Arbeitskräfte auf eine andere Art Einhalt geboten. Am 13. August 1961 errichtete die DDR die Berliner Mauer, die dort damals als 'antiimperialistischer Schutzwall" bezeichnet wurde. Die offizielle DDR Literaturgeschichte Haases beschreibt diese Maßnahme charakteristisch für ostdeutsche Darstellungen der Ereignisse:
Als sich im Frühjahr 1961 die imperialistische Politik der Provokationen verstärkte und zur unmittelbaren Vorbereitung militärischer Aktionen gegen den Arbeiter-und-Bauern-Staat führte, wurde...die Staatsgrenze der DDR gegenüber Westberlin geschlossen. Diese Maßnahme war von großer nationaler und internationaler Bedeutung, weil sie den Frieden in Mitteleuropa sicherte und die Politik des westdeutschen Imperialismus, den Sozialismus von deutschem Boden zurückzudrängen, zum Scheitern brachte. 44

Wie sich der Mauerbau auf die Intellektuellen und die Kulturpolitik auswirkte, wird heute noch unterschiedlich beurteilt. Zipser und Schoeps berichten, der Mauerbau habe dazu beigetragen, zuerst eine relativ liberale Kulturpolitik zuzulassen, was einigen Künstlem und Schriftstellern das Gefühl vermittelte, ihr Staat wäre nun, nach der Abgrenzung zum Westen bereit, sich mit internen Problemen zu beschäftigen. Jäger 
hingegen weist darauf hin, daß die SED-Führung "...nach dem Mauerbau das Interesse an einem attraktiven Schaufenster dem Westen gegenüber verloren" habe. ${ }^{45}$ Noch kurz vor dem 13. August hatten sich einige westdeutsche Schriftsteller, darunter Günter Grass und Martin Walser, zum V. Schriftstellerkongreß in der DDR eingefunden. Nach dem weltweit protestierten Bau der Mauer bestand keine enge direkte Verbindung zwischen west- und ostdeutschen Schriftstellern mehr, und man konzentrierte sich in der DDR auf interne Unruhestifter. Peter Huchel, der Chefredakteur der Zeitschrift der Akademie der Künste, "Sinn und Form" wurde Ende 1962 entlassen, Peter Hacks wurde wegen seines Stückes "Die Sorgen und die Macht" stark kritisiert, da es angeblich keinen Beitrag zum sozialistischen Realismus leistete. Scharfe Kritik wurde auch an Günter Kunert, Stefan Heym und Stephan Hermlin geübt. Christa Wolf sprach in diesem Zusammenhang von

"Gängeleien, Banausentum, falschen Forderungen an die Literatur, mangelnder Weltoffenheit, restriktiver Verlagspolitik, Apologie des Bestehens, provinzieller Selbstzufriedenheit und Enge usw. Ihre [Wolfs] Nebenbemerkung, es gebe keine wirkliche Literaturkritik in der DDR, und die Literaturwissenschaft sei noch weitgehend dogmatisch...."46

bedeuteten den Anfang einer Karriere, während der sie sich wiederholt für ihre fortschrittliche Literatur und Denkweise sollte rechtfertigen müssen.

Ein Hauptproblem der DDR-Politik war schon immer und ist auch weiterhin die unterschiedliche Auffassungen von der Funktion ihrer Literatur. Die sich darum entfachenden Meinungsverschiedenheiten zwischen Literaturkritikern, Autoren, Funktionären, und zum Teil auch Lesern, werden auch heute noch in verschiedenen Arenen ausgetragen, auf Parteitagen etwa, bei Schriftstellerkongressen und in Literaturzeitschriften. Beispiele dafür gibt es darum genügend, wie sich Künstler öffentlich mit den Mängeln ihrer Gesellschaft auseinandersetzten, und welche Konsequenzen sie zum Teil daraus ziehen mußten. Man denke nur an die schon erwähnten Brecht, Kunert, Loest und 
Wolf und verfolge den aktuellen Streit um das Buch Der Vormundliche Staat des DDRRechtsanwalts und Autors Rolf Henrich. Henrich ließ sein Buch im April 1989 in der Bundesrepublik veröffentlichen, ohne sich die Genehmigung seiner Regierung einzuholen. Ihm wurde daraufhin seine Anwaltslizenz entzogen.

Der Unberechenbarkeit der Kulturfunktionäre waren und sind sich die meisten Intellektuellen gewiß bewußt, denn schon seit 1949 konnten sie die kulturpolitischen Schwankungen verfolgen. Laut Zipser und Schopes nahmen die Spannungen im Jahre 1965 wieder ab, der Liedermacher Wolf Biermann machte eine DDR-Tournee, DDRAutoren bereisten die BRD und stellten bei der Frankfurter Buchmesse aus." 47

Der Liedermacher und Autor Wolf Biermann war 1962 ins künstlerische und politische Rampenlicht gerückt. ${ }^{48}$ Sein Schicksal symbolisiert für viele Bundesbürger und andere an der deutsch-deutschen Beziehung Interessierte, welchem Druck politisch aktive Intellektuelle in der DDR ausgesetzt sind. Der überzeugte Kommunist Biermann war als Sechzehnjähriger 1953 aus der Bundesrepublik in die DDR gezogen und war dort schriftstellerisch und politisch aktiv tätig gewesen. Im Dezember 1965 ließ sich Erich Honecker, der spätere Parteisekretär der DDR, in einer Rede an das 11. ZK-Plenum der SED über Leute wie Biermann aus, die er als äußerst staatsfeindlich und -gefährlich ansah. Dieses

11. Plenum wurde nun wieder von der Partei als Plattform für härtere kulturpolitische Maßnahmen benutzt.

Das Charakteristische all dieser Erscheinungen [Biermann etwa] besteht darin, daß sie objektiv mit der Linie des Gegners übereinstimmen, durch die Verbreitung von Unmoral und Skeptizismus besonders die Intelligenz und die Jugend zu erreichen und im Zuge einer sogenannten

Liberalisierung die DDR von innen aufzuweichen. ${ }^{49}$

${ }^{47}$ Zipser, 24.

${ }^{48} \mathrm{Vgl}$. Thomas Rothschild, Hrsg., Wolf Biermann. Liedermacher und Sozialist (Reinbek bei Hamburg: Rohwolt, 1976) für eine ausführliche Auseinandersetzung mit dem 'Fall Biermann' und dessen prekärer Lage in der DDR vor seiner Ausbürgerung.

${ }^{49}$ Blumensath, 180. 
Sie spielten demnach, laut Honecker, wieder einmal dem imperialistischen Westen in die Hand.

Biermann war 1963 aus der SED ausgeschlossen worden und erhielt 1965 Auftrittsverbot. Seit diesem Zeitpunkt wurden auch seine Texte nicht mehr in der DDR verlegt. ${ }^{50}$ Er lebte zum Teil von Auftritten in Kirchen, die ihm nicht untersagt werden konnten, und dem Honorar seiner in der Bundesrepublik veröffentlichten Gedichtbände wie etwa Drahtharfe und Liebesgedichte. Die Literatur hatte sich zu emanzipieren versucht. ${ }^{51}$ Mit dieser Emanzipationphase, einem kurzen kulturpolitischen Frühling, setzte sich das 11. ZK-Plenum im Dezember 1965 auseinander. Honecker befaßte sich in seinem Bericht an das 11. Plenum mit der künstlerischen "Darstellung von angeblichen Mängeln und Fehlern in der Deutschen Demokratischen Republik." 52 Er unterstellte in seinem Bericht den Künstlern, sie wären für eine Rückwärtsentwicklung, oder zumindest eine Hemmung der Entwicklung des sozialistischen Bewußtseins verantwortlich. Als "spießbürgerlich", "halbanarchistisch", "lebensverneinend", bezeichnet er die Künstler. "Nihilistische, ausweglose und moralzersetzende Philosophien" unterstellte er, unter anderem, der Literatur. ${ }^{53}$ Die Intellektuellen forderte er auf nicht gegen, sondern für die Erhöhung der Arbeitsproduktivität und somit des Lebensstandards zu arbeiten, und diese nicht zu unterminieren.

Die Partei sei "...selbstverständlich nicht gegen die Darstellung von Konflikten und Widersprüchen, wie sie beim Aufbau des Sozialismus auftreten. Wir sind nicht für eine oberflächliche Widerspiegelung der Wirklichkeit. Uns geht es um den parteilichen Standpunkt des Künstlers

50 In Elimar Schubbes Sammlung lassen sich die Entwicklungen und die Kontroverse um Biermann anhand der Dokumente nachvollziehen. Eine kurze Zusammenfassung der Ereignisse befindet sich auch in: Gisela Helwig, Hrsg., Die DDR-Gesellschaft im Spiegel ihrer Literatur, (Köln: Verlag Wissenschaft und Politik, 1986) Einleitung 11-13.

$51_{\text {Jăger, } 115 .}$

${ }^{52}$ Steinbach, Literarisches Leben in der DDR, 39.

53 ebda $39-40$. 
bei der politischen und ästhetischen Bewertung unserer Wirklichkeit und damit auch um sein aktives Mitwirken bei der Darstellung der Konflikte und ihrer Lösung und im Sozialismus." 54

Besonders angesprochen wurden damit Wolf Biermann und diejenigen, die sich für ihn einsetzten. Offen griff Honecker Biermann wegen seines Gedichtbandes Die Drahtharfe an, den er im Westberliner Wagenbach-Verlag hatte veröffentlichen lassen. Vorgeworfen wurden ihm unter anderem "im Namen eines schlecht getarnten spießbürgerlichanarchistischen Sozialismus...scharfe Angriffe gegen...Gesellschaft und Partei".55 Keinen Zweifel ließ Honecker an den Konsequenzen, die sich für die Intellektuellen der DDR daraus ergäben. Die Warnung an sie war deutlich, ihrer Emanzipation mußte ein Ende gesetzt werden.

"Es ist an der Zeit, der Verbreitung fremder und schädlicher Thesen und unkünstlerischer Machwerke, ...entgegenzutreten. Es stärkt nicht die Autorität des Deutschen Schriftstellerverbandes und anderer Organisationen, wie zum Beispiel des Deutschen Kulturbundes, wenn sie sich nicht mit diesen Machwerken auseinandersetzen".56

Biermann erhielt, wie schon erwähnt, ein Aufführungs-, Veröffentlichungs- und Ausreiseverbot. Anfang 1966 trat das Verbot in Kraft, Manuskripte außerhalb der DDR ohne die Genehmigung des Büros für Urheberrechte anzubieten. Veröffentlichungen im Ausland waren demnach ohne Erlaubnis nicht mehr gestattet.

Die Abrechnung mit Biermann auf dem Il. Plenum ist nur das im Westen bekannteste Beispiel derer, die dort öffentlich angeprangert wurden. Heiner Müller, Peter Hacks und Stefan Heym zählten dazu. Neben einzelnen Schriftstellern verurteilten die Plenumsteilnehmer auch Beatmusik und Filme der DEFA, Bühnenbildner und Schauspieler, Komponisten und Intendanten. Die Warnungen an die Künstler waren deutlich. In den folgenden Jahren entwickelte sich eine Lyrikdebatte, von der viele junge Lyriker

54 ebda 40.

$55_{\text {ebda }} 40$.

$56_{\text {ebda }} 41$. 
wie etwa Sarah Kirsch, Volker Braun und Rainer Kirsch betroffen waren. Walter Ulbrichts Kulturpolitik war in diesen Jahren von heftigen Auseinandersetzungen gekennzeichnet, die nicht zu einer Verständigung zwischen Partei und Intellektuellen führte. Die Auffassungen dessen, was und wie geschrieben werden sollte, und welche Rolle der Autor in dem sich noch entwickelnden sozialistischen Staat einzunehmen hatte, waren zu verschieden, um eine reibungslose Zusammenarbeit zu garantieren. Laut Schoeps ließen sich jedoch immerhin "gewisse Lockerungen gegenüber der Position der frühen fünfziger Jahre...verzeichnen... Die scharfe Partei-Kritik an einigen literarischen Werken bezog sich vor allem auf ihren Inhalt, nicht mehr auf die Form". 57

Ein Führungswechsel an oberster politischer Stelle sollte eine neue Epoche einleiten, die selbstverständlich große Auswirkungen auf die Kulturpolitik der DDR hatte. Der 1. Sekretär der SED Walter Ulbricht war auf der 16. Tagung des ZK der SED am 3. Mai 1971 von Erich Honecker abgelöst worden. Offiziell trat Ulbricht aus "Altersgründen" zurück, inoffiziell wurde er entfernt, da eine neue politische Richtung für die DDR gesetzt werden sollte. Ulbricht hatte bisher die These vertreten, "der Sozialismus entspräche einer relativ selbständigen Gesellschaftsformation mit einer 'Menschengemeinschaft' ".58 Nun hieß es jedoch, die "entwickelte sozialistische Gesellschaft" der DDR auszubauen, wozu die Kulturpolitik einen wichtigen Beitrag beisteuem sollte. Die Kulturschaffenden, die unter Ulbricht seiner Interpretation vom sozialistischen Intellektuellen nicht entsprachen, wurden demnach nicht mehr so sehr als Sand im Getriebe betrachtet, sondern erhielten mehr Freiheit in ihrem Schaffen.

Der VIII. Parteitag der SED vom 15. bis zum 19. Juni 1971 in Ost-Berlin läutete eine literaturpolitische Phase der DDR ein, die als eine neue Tauwetterperiode bekannt

57 Zipser und Schoeps, 25.

58 Lehmann, 95. 
wurde. Die zum Teil engstirnige und starrsinnige Kulturpolitik der Ulbricht Ära lockerte sich unter Honecker. Erläutert Jäger:

"Die Veränderungen [wurden jedoch wieder]...'von oben' verfügt und blieben eingebettet in das Dogma von der prinzipiell richtigen Politik, die konsequent weiterbetrieben werde und sich nur nach den Notwendigkeiten der jeweils neuen Entwicklungsetappe zu modifizieren habe." 59

Honeckers bekannte Sätze aus seinem Schlußwort auf dem VIII. Parteitag der

SED leiteten diese 'neue Entwicklungsetappe' der Kulturpolitik ein, die als der Beginn einer fünfjährigen liberalen kulturpolitischen Phase gesehen werden kann.

Wenn man von der festen Position des Sozialismus ausgeht, kann es meines Erachtens auf dem Gebiet von Kunst und Literatur keine Tabus geben. Das betrifft sowohl die Fragen der inhaltlichen Gestaltung als auch des Stils - kurz gesagt: die Fragen dessen, was man künstlerische Meisterschaft nennt.... Unsere Partei und unser Staat sind daran interessiert, die Lösung unserer großen gesellschaftlichen Aufgaben in unmittelbarer Tuchfühlung mit unseren Künstlern zu bewältigen. ${ }^{60}$

In dieser Schlußrede betonte Honecker weiterhin das Interesse des Staates, mit der unmittelbaren Hilfe der Künstler die "...großen gesellschaftlichen Aufgaben...zu bewältigen", was unter anderem durch "offenherzigen, sachlichen und schöpferischen Meinungsstreit" geschehen sollte. 61 Er wünschte sich sogar, daß sich ein noch lebhafterer Meinungsstreit entfalten solle, denn das könne nur der Qualität und Wirksamkeit der sozialistischen Kultur zugute kommen. Er forderte die Künstler auf, nicht nur die Arbeiterklasse als Thema ihrer Werke zu wählen, sondern auch andere Themen zu behandeln, die den Lesern helfen würden, die Probleme ihrer Zeit zu meistern. Daß die Vorschriften, die die Partei den Schriftsteller bis zu diesem Zeitpunkt gemacht hatte, trotz der neuen Freiheiten auch weiterhin bestehen blieben, wurde von Honecker folgendermaßen ausgedrückt:

59 Jăger, 133.

60 Steinbach, Literarisches Leben in der DDR, 56.

$61_{\text {ebda }} 56$. 
Dabei übersehen wir nicht, daß es in gleichem Maße erforderlich ist, unseren Künstlern durch die dazu berufenen Organe besser mit Rat und Tat zur Seite zu stehen. In unserer Gesellschaft ist - wie wir wissen - kein Boden für eine die schöpferische Tätigkeit unserer Künstler beeinträchtigende Praxis. ${ }^{62}$

Den Schriftstellern wurde nun die Möglichkeit eingeräumt, entweder das, was sie zum Teil bisher für die Schublade geschrieben hatten, ans Tageslicht zu bringen, oder sich offen mit Themen zu befassen und literarische Stile zu entwickeln, die bisher als kontrovers galten. Ulrich Plenzdorfs Buch und Stück Die neuen Leiden des jungen W. ist als ein Beispiel für die damalige neue kulturpolitische Phase zu nennen. Die Debatte um dieses 1972 veröffentlichte Werk vollzog sich öffentlich unter anderem in den Literaturzeitschriften "Neue Deutsche Literatur" und "Sinn und Form" und auf dem 9. Plenum des ZK der SED im Mai 1973. Sowohl Plenzdorfs Prosafassung, 1972 veröffentlicht, als auch sein 1973 erschienenes Schauspiel mit dem selben Titel hatten unter den Jugendlichen der DDR großen Anklang gefunden, waren zum Teil aber von offizieller Seite wegen ihrer Sprache und ihres Inhalts stark kritisiert worden. In einem Gespräch vom Dezember 1972 mit vier Berliner Jugendlichen, die auf Einladung der NDL über Plenzdorfs Bühnenfassung sprachen, kamen positive Reaktionen zur Sprache. ${ }^{63}$ Die Befragten waren der Meinung, Plenzdorf habe die Gedanken und Gefühle der Jugendlichen aus Arbeiterkreisen authentisch dargestellt. "Er will eben nicht immer alles nach Plan machen. Bei uns ist alles zu sehr im voraus organisiert, die Ausbildung, der ganze Lebensweg." 64 Daß diese Debatte überhaupt stattfand, ist ein Beweis für die größere Toleranz, die die politische Führung der Literatur tatsächlich zugestand. Dank des neuen Ersten Sekretärs

62 ebda 57.

${ }^{63} \mathrm{Vgl}$. Helmut Fischbeck, Hrsg., Literaturpolitik und Literaturkritik in der DDR (Frankfurt/Berlin/München: Diesterweg, 1976) 105 - 127. Dort befindet sich eine Analyse der Ereignisse um Plenzdorfs Werk, dargestellt Anhand offizieller Reaktionen. Auf S. 106 auch der Abdruck des Gesprächs aus NDL 3/1973.

64 ebda 108. 
des ZK der SED Erich Honecker durften Konflikte in der DDR-Gesellschaft literarisch aufgegriffen und behandelt werden.

Die Lockerung der politischen Spannungen zwischen der Bundesrepublik und der DDR trugen weiterhin dazu bei, der DDR ein größeres Selbstbewußtsein zu geben. Die Regierung der Bundesrepublik unter Willy Brandt hatte den Alleinvertretungsanspruch für ganz Deutschland aufgegeben, der im Dezember 1955 unter der Bezeichnung Hallstein-Doktrin erklärt worden war. 1955 war auf einer Botschafterkonferenz auf die Auswirkungen hingewiesen worden, die sich für dritte Staaten ergeben würden, falls diese diplomatische Beziehungen zur DDR aufnehmen würden. Die Sowjetunion war davon ausgeschlossen. Am 3.Juni 1971 traten auch das Vier-Mächte-Abkommen über Berlin und die Ostverträge der Bundesrepublik in Kraft, welche "wesentliche Voraussetzungen für die Entkräftung des deutsch-deutschen Konfliktes seit dem Ende der Ära Ulbricht" bilden. ${ }^{65}$ Brandt hatte seit seinem Regierungsantritt die bis zu diesem Zeitpunkt vertretene Ein-Staaten Theorie revidiert und sprach nun von zwei deutschen Staaten, aber einer Nation. ${ }^{66}$ Am 21.6.1973 trat weiterhin der "Vertrag über die Grundlagen der Beziehungen zwischen der Bundesrepublik Deutschland und der Deutschen Demokratischen Republik" in Kraft, der die "Normalisierung der Beziehungen zwischen beiden Staaten..." einleitete und "...ihren gemeinsamen Beitritt zu den Vereinten Nationen am 18.9.1973" ermöglichte. ${ }^{67}$ Der Führungswechsel in der DDR und die Regierung Brandt in der Bundesrepublik, die damit verbundene politische Entspannung, sowie die internationale Anerkennung der DDR brachten demnach ein gestiegenes Selbstbewußtsein mit sich, einen "Prestige- und Machtzuwachs"68, der sich auf allen

$65_{\text {Lehmann, } 74 .}$

66 Timmermann, 144.

67 ebda 145.

68Wolfgang Emmerich, Kleine Literaturgeschichte der DDR (Darmstadt: Luchterhand, 1985$) 177$. 
Ebenen der Gesellschaft auswirkte. Die DDR "konnte sich demzufolge politisch und ideologisch selbstbewußter - oder mit einer westlichen Vokabel: liberaler - geben". 69

Der oft im Nachhinein als Liberalisierungsperiode bezeichneten Phase zwischen 1971 und 1976 fehlte aber die Unabhängigkeit von der Partei, von der Ideologie des Sozialismus. Für parteitreue, und somit ideologietreue Künstler sollte es keine Tabus mehr geben, so hatte es Honecker in seiner Rede ausgedrückt. Die Rolle der Künstler blieb bestehen, sie waren ihrer Aufgabe im sozialistischen Staat nicht entledigt worden, obwohl sich nicht alle in dieser Rolle sahen.

Man verstand sich nicht mehr als Sprachrohr der Partei (das galt aber längst nicht für alle Schreibenden). Jetzt mußten sich viele Schriftsteller erst einsam in einem mühevollen Prozeß der Selbstfindung Klarheit über ihren ästhetischen und gesellschaftlichen Standort verschaffen. Diese neue Haltung hatte man von Seiten der Kulturbehörde nicht vorausgesehen, sie war vielmehr das unerwünschte Resultat eines langandauernden Erziehungsprozesses. Der Autor sollte sich ja als gesellschaftliches Wesen verstehen und angesichts der bevorstehenden kollektiven Lösung, die die neue Wirklichkeit einzuklagen schien, sein unbedeutendes Ich, sein künstlerisches Subjekt, ohne Weheklage kleinhalten. ${ }^{70}$

Es ist eine Tatsache, daß Bücher wie Stefan Heyms Der König David Bericht und Hermann Kants Das Impressum jetzt gedruckt wurden, die bis zu diesem Zeitpunkt entweder nur im Westen erschienen waren oder, wie in Kants Fall, keine Druckgenehmigung erhalten hatten. Viele nun veröffentlichten Werke wurden jedoch heftig umstritten. Für Rainer Kirsch z.B. bedeutete die Liberalisierung seinen Ausschluß aus der SED aufgrund seiner 1973 veröffentlichten Komödie Heinrich Schlaghands Höllenfahrt. Während viele sozialistische Künstler die Entspannung in der Kulturpolitik begrüßten, gab es auch solche, die damit unzufrieden waren. Erik Neutsch, Helmut Sakowski und Harry Thürk drückten ihre Gefühle und Befürchtungen auf dem VII. Schriftstellerkongreß

69 ebda 177.

70Hans-Jürgen Schmith, Hrsg., Die Literatur der DDR Band 11 (= Hansers Sozialgeschichte der deutschen Literatur vom 16. Jahrhundert bis zur Gegenwart Band 11, Rolf Grimminger, Hrsg.) (München: dtv, 1983) 21. 
im November 1973 aus. Sie waren "dem Parteiapparat eng verbunden"71 und sahen die offenen Debatten, die vorwiegend in den Literaturzeitschriften ausgetragen wurden, als Gefahr für die Stärke der Parteiführung an. Als ein "...mühsam austariertes Gleichgewicht zwischen Tabulockerung und Aufrechterhaltung der staatlichen Ordnung auf literarischem Gebiet"72 bezeichnet Emmerich die Probleme dieser Jahre. Zu viele Künstler hatten von Honeckers Versprechen Gebrauch gemacht, ihre Auffassung von einem sozialistischen Staat ausgedrückt, hatten über Nöte ihrer Mitmenschen in diesem Staat gesprochen, hatten zu viele unliebsame Themen aufgegriffen. Wie Schmidt erläutert, änderten sich die Ziele der Schreibenden.

Das Schreiben für einen offiziellen Leser, für ein Publikum, das sich an den vorausgreifenden großen Taten aufbauen sollte, verlagerte sich mehr und mehr auf ein engagiertes Schreiben für Leser, die sich in der sozialistischen Gesellschaft persönlich angesprochen sehen wollten. ${ }^{73}$

Dazu kam noch, daß DDR-Schriftsteller in der Bundesrepublik publizieren ließen, wie es zum Beispiel Reiner Kunze tat. Er hatte im September 1976 seinen kurzen Prosaband Die wunderbaren Jahre im S. Fischer Verlag in Frankfurt am Main verlegen lassen, jedoch nicht, ohne sich vorher den Verlagsvertrag vom zuständigen Amt, dem Büro für Urheberrechte in Ost-Berlin, genehmigen zu lassen. Da aber das Manuskript nie einem DDR-Verlag vorgelegt worden war, verstimmte das Erscheinen in der Bundesrepublik die DDR-Behörden. Infolgedessen wurde Reiner Kunze am 29. Oktober 1976 aus dem Schriftstellerverband der DDR ausgeschlossen und verließ im April 1977 die DDR. Diese behördlichen Maßnahmen gegen einen DDR-Schriftsteller schienen laut

$71_{\text {Jăger, } 154 .}$

72Emmerich, 184.

${ }^{73}$ Schmith, 21. 
Jäger als "Hauptziel...ohnehin die Einschüchterung von Kunzes Berufskollegen"74 zu haben. Eine kulturpolitische Phase schien zu enden, eine Neue begann.

Der sogenannten Liberalisierungsperiode wurde im November 1976 durch die Ausbürgerung Wolf Biermanns endgültig ein Ende gesetzt. Biermann hatte, nach Jahren des Verbots, die Genehmigung für eine Konzerttournee durch die Bundesrepublik erhalten. Das erste Konzert, das am 13. November in Köln stattfand, wurde vom bundesdeutschen Fernsehen übertragen und in vielen DDR-Haushalten gesehen. Am 16.11.1976 entzog die DDR-Regierung Biermanns Staatsbürgerschaft und verweigerte ihm die Rückreise in die DDR. In der Meldung des Allgemeinen Deutschen Nachrichtendienstes der DDR (ADN) vom 16.11. heißt es:

Diese Entscheidung [den Entzug des Rechtes auf weiteren Aufenthalt in der DDR] wurde auf Grund des 'Gesetzes über die Staatsbürgerschaft der Deutschen Demokratischen Republik - Staatsbürgergesetz - vom 20. Februar 1967, Paragraph 13', nach dem Bürgern wegen grober Verletzung der staatsbürgerlichen Pflichten die Staatsbürgerschaft der DDR aberkannt werden kann, gefaßt.... Mit seinem feindseligen Auftreten gegenüber der Deutschen Demokratischen Republik hat er sich selbst den Boden für die weitere Gewährung der Staatsbürgerschaft der DDR entzogen. ${ }^{75}$

Am 17.11.1976, also einen Tag nach Biermanns Ausbürgerung, zeigte sich, daß viele seiner Kollegen nicht gewillt waren, die staatlichen Maßnahmen gegen ihn zu akzeptieren. Derart drastische Schritte, die Aberkennung der Staatsbürgerschaft, waren bisher nicht vorgekommen und konnten auf Seite der Künstler weder unbemerkt noch unbeantwortet bleiben. Zwölf bekannte DDR-Autoren solidarisierten sich spontan und verfaßten einen offenen Protestbrief, den sie der westlichen Nachrichtenagentur übergaben. Die Verfasser hatten sich darauf geeinigt, den Brief zuerst der Nachrichtenagentur im eigenen Land zukommen zu lassen, die jedoch nicht darauf reagierte. Ein derartiges Nicht-Reagieren der Presse scheint nicht ungewöhnlich zu sein. Aus Erfahrung

74Jăger, 160.

75 Dietrich Steinbach, Hrsg., Wolf Biermann und die Tradition: Von der Bibel bis Ernst Bloch (Stuttgart: Klett, 1981) 127. 
müssen die Unterzeichner gewußt haben, daß zum Beispiel kritische Leserbriefe an Zeitungen und Zeitschriften oft entweder nicht gedruckt wurden und unbeantwortet blieben, oder darauf in Form eines persönlichen Besuches oder einer Einladung, bzw. Vorladung mit der Aufforderung zu einem persönlichen Gespräch reagiert wurde. Den Verfassern des Protestbriefes wurde, so scheint es, anstatt des Inhalts eher die Tatsache verübelt, daß der Brief in den Westen gelangte. Die DDR-Regierung sah sich wieder einmal in eine Lage versetzt, bei der sie ihr Gesicht verlieren konnte.

Obwohl sich die Unterzeichner des Proștestschreibens nicht unbedingt mit Biermann identifizierten, stellten sie jedoch klar da, daß die Maßnahmen gegen ihn nicht angebracht waren für einen sozialistischen Staat.

Unser sozialistischer Staat, eingedenk des Wortes aus Marxens '18. Brumaire', dem zufolge die proletarische Revolution sich unablässig selber kritisiert, müßte im Gegensatz zu anachronistischen Gesellschaftsformen eine solche Unbequemlichkeit gelassen nachdenkend ertragen können. ${ }^{76}$

Nachdem sie betont hatten, daß sie ihren Staat in seiner Ideologie unterstützten, forderten sie, Biermanns Ausbürgerung rückgängig zu machen. Diese Forderung wurde jedoch zur Bitte, als der von allen Anwesenden unterzeichnete Protestbrief noch dem Bildhauer Fritz Cremer in seiner Wohnung vorgelegt wurde. Er schlug vor, "fordern" durch "bitten" zu ersetzen. Gerhard Wolf und Stephan Hermlin, die Überbringer des Schreibens, stimmten zu, der Protestbrief wurde zu einem Bittbrief. ${ }^{77}$ Die Erstunterzeichner waren, in der hier aufgeführten Reihenfolge, Sarah Kirsch, Christa Wolf, Volker Braun, Franz Fühmann, Stephan Hermlin, Stefan Heym, Günter Kunert, Heiner Müller, Rolf Schneider, Gerhard Wolf, Jurek Becker und Erich Arendt und Fritz Cremer. Tags darauf behauptete Cremer jedoch, "Gerhard Wolf und Hermlin hätten seinen Namen mißbraucht". ${ }^{78}$ Er zog seine

${ }^{76}$ Steinbach, Wolf Biermann und die Tradition 85.

${ }^{77}$ Eine genauere Erlăuterung in "Der Spiegel", Nr.48 vom 23. Nov. $81: 85$ ff., Bericht von KarlHeinz Jakobs 
Unterschrift zurück. In den darauffolgenden Tagen schlossen sich noch andere Schriftsteller an, darunter Ulrich Plenzdorf und Karl-Heinz Jakobs, oder sie verfaßten ihre eigenen Schreiben. Letztlich waren es 150 Künstler, die sich gegen die staatlichen Maßnahmen aussprachen.

Für die Ausbürgerung stimmten jedoch andere renommierte DDR-Künstler, darunter Hermann Kant, Peter Hacks, Anna Seghers und Erik Neutsch. In der Zeitschrift "Die Weltbühne" drückte Peter Hacks sein Misfallen in Worten aus, die nicht nur für seine Einstellung zu Biermann und Böll bedeutend sind, sondern mit denen er auch den Sowjetischen Schriftsteller Alexander Solschenizyn beleidigt.

Er [Biermann] hat die Zustimmung von Heinrich Böll. Böll, man kennt ihn, ist drüben der Herbergsvater für dissidierende Wandergesellen. Biermann hat in seinem Bett übernachtet, und ich hoffe, er hat nicht noch Solschenizyns Läuse darin gefunden. ${ }^{79}$

Publikationsverbot, Parteistrafen, Parteiausschlüsse, Verhaftungen, Auftrittsverbote, Ausreisen in den Westen, das waren die sichtbaren Folgen der Protestwelle. Laut Jakobs gingen in den folgenden fünf Jahren über einhundert Kulturschaffende aus der DDR ins Ausland. Entweder wurden sie ausgebürgert oder reisten mit einem langfristigen Visum in den Westen. Darunter befanden sich Sarah Kirsch, Rudolf Bahro, Reiner Kunze, Jurek Becker, Günter Kunert, Joachim Seyppel, Kurt Bartsch, Erich Loest und Jakobs selbst. Bernd Jentsch, der sich zur Zeit der Biermann Ausbürgerung in der Schweiz befand, kehrte nicht mehr in die DDR zurück. ${ }^{80}$ Bedeutend ist auch, daß sich die Unzufriedenheit nicht nur in den Reihen der älteren Kulturschaffenden bemerkbar

${ }^{79}$ Steinbach, Wolf Biermann und die Tradition, 136.

80Jakobs sprach 1987 wăhrend eines Aufenthaltes in Portland, Oregon über das Thema der Zensur in der DDR. Ich lernte inn dort kurz kennen und übersandte ihm durch Frau Prof. Nussbaum Fragen, die sich auf den Protestbrief selbst und die Folgen darauf beziehen. Von besonderem Interesse schienen mir Andeutungen auf 'foul play' zu sein, die in seinem Spiegel Artikel "Wir werden ihre Schnauzen nicht vergessen" zu finden sind sowie seine jetzige Einstellung und Beziehung zu Christa Wolf. Ein Jahr nach Erhalten meiner Fragen erwiderte er, er könne keine Antwort geben, da die Fragen so detailliert seien, daß er ein ganzes Buch schreiben müsse um Rede und Antwort zu stehen. 
machte. Auch die jüngere, in der DDR aufgewachsene Künstlergeneration, bekam die

Repressalien zu spüren, denn auch sie äußerte sich zum Teil kritisch. Schmitt stellt fest:

Gerade Kunert machte im Jahr nach Biermanns Ausbürgerung auf die heillose Situation aufmerksam, die die Verlagerung der DDR-Literatur von Ost nach West beschleunigte: Die Verdrängung der Realität aus dem allgemeinen Bewußtsein stieß immer mehr auf ein progressiv literarisches Bewußtsein, das die Wirklichkeit, so wie sie erfahren wurde, nicht tabuisiert sehen wollte. Kunert nennt das Parteibewußtsein »affirmativ" und »funktional«, das Bewußtsein der Schriftsteller »existentiell und kritisch $\ll .81$

Zur Folge der Proteste und darauffolgenden Strafen hatte auch, daß sich die DDRLiteratur nun in einem noch größeren $\mathrm{Ma} B$ als während der Liberalisierungsperiode in die Bundesrepublik verlegte. Zum einen liegt das daran, daß die in den Westen verzogenen Schriftsteller ihre Literatur nun auch dort veröffentlichen. In der DDR verbliebenen Künstlern wurde jedoch auch nun von westlicher Seite mehr Aufmerksamkeit geschenkt, denn die westdeutschen Medien waren, besonders aufmerksam geworden durch den Fall Biermann, stark auf den Literaturbetrieb in der DDR fixiert. "Briefwechsel und Diskussionen in westdeutschen Zeitungen, Vorabdrucke, Anthologien und mehr und mehr einzelne Werke rücken oft in den Mittelpunkt des Literaturbetriebs.... Auch Verfilmungen wichtiger literarischer Werke finden nur im Westfernsehen statt". 82

Neue strafliche Sanktionen erhöhten in der DDR die Einflußnahme des Staates auf den Literaturbetrieb. Am 28. Juni 1979 wurde das Dritte Stafrechtsänderung-Gesetz erlassen, das die Übergabe von schriftlichen Materialien an dritte untersagt, wenn dies der DDR schaden könnte. Jurek Becker hatte 1978 in bezug auf Schriftsteller wie Heym noch gebeten, "nur an die nackte Existenz sollte es den Dichtern nicht gehen"83. Stefan Heym mußte jedoch 9000,- Mark wegen Verstoßes gegen Devisenbestimmungen zahlen und

${ }^{81}$ Schmitt, 16. Darin wird zitiert: Kunert, Günter: Offener Brief aus Ost-Berlin: Ein Schriftsteller ohne Inspiration erzeugt Flugsand. In: "Die Zeit", Nr. 33 vom 5.8.77, 37.

82Schmith, 17.

${ }^{83}$ Emmerich, 31. 
eine Gruppe seiner Schriftstellerfreunde, die sich brieflich für ihn einsetzten, wurde aus dem Schriftstellerverband ausgeschlossen. Becker gehörte auch dazu. Erläutert Jäger:

Wann die Paragraphen gegen wen angewandt werden, liegt im Ermessen der politischen Instanzen; am liebsten sähe man es, wenn der Einschüchterungseffekt allein Prozesse, die immer lästige Unruhe erregen, erübrigt. So bereitet sich auf vielen Ebenen, auch in den Künstlerverbänden, ein Klima des Mißtrauens und der Niedergeschlagenheit aus. ${ }^{84}$

Derartig dramatische Veränderungen in der Beziehung zwischen Kunstschaffenden und Staat mußten sich in dem Verhalten oder zumindest der Psyche der Kunstschaffenden niederschlagen. Emmerich spricht von einem Exodus, der in Gang gekommen sei, wobei er sich auf die Auswanderungen und Reisen in den Westen bezieht ${ }^{85}$. Jäger sieht den "Einschüchterungseffekt" wirken. "Schon bereitet sich auf vielen Ebenen, auch in den Künstlerverbänden, ein Klima des Mißtrauens und der Niedergeschlagenheit aus".86 Dennis Tate, ein bekannter DDR-Literaturexperte aus Schottland, beurteilt die Situation jedoch optimistischer:

This does not mean, however, that in the aftermath of the 'Biermann' crisis' there was another attempt to suppress dissent as extensively as in the period following the Eleventh Plenum in 65. On the contrary, these authors - now internationally respected - have been treated with what appears to have been considerable tolerance since 1976. Apart from minor (if significant) exceptions such as Braun's essay "Büchners Briefe", their recent creative writings and essays have all been published in the GDR. ${ }^{87}$

Tate führt Christa Wolf, Franz Fühmann, Günter de Bruyn, Stefan Hermlin und Volker Braun an, die in der DDR blieben und dort literarisch Wertvolles veröffentlichen wollen und dürfen. Bedauerlicherweise, so Tate, ist die Liste der 'Dissidenten' lang, aber

84 Jăger, 165.

${ }^{85}$ Emmerich, 187.

86Jăger, 165.

${ }^{87}$ Dennis Tate. The East German Novel, Identity, Community, Continuity, (Bath: University Press, 1984) 228. 
diese seien nicht "...the sole keepers of the...socialist conscience" ${ }^{88}$ Trotz der räumlichen Distanz verbindet die in und außerhalb der DDR lebenden Schriftsteller eine ihnen gemeinsame Aufgabe und ein Ziel, den Kampf um das Recht auf schöpferische Freiheit in ihren Werken. Diese zurückgebliebenen, kritisch denkenden Autoren haben, sich, laut Tate, keinesfalls den SED Parolen angepaßt, was anscheinend zur Folge hat, daß sie nur noch selten offiziell gelobt und mit Preisen geehrt werden, wie das in den sechziger Jahren der Fall war. Trotzdem sind sie dem Staat nicht bequemer geworden, sondern schreiben weiterhin in ihrem subjektiven Stil, behandeln Themen, die ihnen wichtig erscheinen, und lassen sich etwa in literaturtheoretischen Essays über den Weg aus, den ihre Literatur beschreiten soll. Der ehemals öffentliche Dialog um die Aufgabe der Kulturschaffenden und Lösung der Konflikte individueller Autoren mit dem Staat und seiner Ideologie hat sich, laut Tate, nun aber eher nach innen, in den Schriftstellerverband verlegt.

Thus an increasingly sophisticated dialogue continues, although the literary avant-garde - for its own good reason of creative authenticity as well as on grounds of political discretion - no longer provides the depth of immediate response to specific economic and political changes which it did in the aftermath of the 'Bitterfelder Weg'. ${ }^{9} 9$

Jäger, wie Tate, sieht die in der DDR verbliebenen Schriftsteller nicht als Duckmäuser. Sie bringen keine "bequemere, ideologisch gefällige Kunst und Literatur..."90 hervor, sondern erfüllen eine Aufgabe, die ihnen von den Lesern gestellt wird. "Bücher wirken heute weniger als Impulsgeber für grundsätzliche Veränderungen denn als Lebenshilfe für den einzelnen".91

$88_{\text {ebda }} 228$.

89 ebda 230.

90Jăger, 166.

$91_{\text {ebda }} 166$. 
Emmerich faßte zu Beginn der achtziger Jahre die Situation der Schriftsteller mit verhältnismässig positiven Worten zusammen. Er deutet darauf hin, daß trotz der teils gravierenden Maßnahmen gegen viele Autoren vieles gedruckt werden durfte, was in den ersten drei Jahrzehnten des Bestehens der DDR nicht veröffentlicht worden wäre.

Damit soll nicht gesagt sein, die DDR sei ein liberales, kritischer Literatur freundliches Land geworden. Trotzdem gilt, daß sich das Kräfteverhältnis zwischen Literatur und Staat nicht nur einseitig, zum Schlechten der Literatur, entwickelt hat. ${ }^{92}$

\section{INSTITUTE UND ORGANIZATIONEN}

Bestimmten Institutionen und Organisationen in der DDR steht die Aufgaben zu, die Ausführung kulturpolitischer Ziele des Staates zu unterstützen und zu übersehen. Da die Rolle des Schriftstellers in der DDR unmittelbar mit den politischen Zielen des Staates, und somit der Partei (SED) verbunden ist, wird die Literatur gesteuert. Marktzwänge bestimmen auch in der DDR zu einem wesentlichen Teil, was erscheint, doch der offizielle Einfluß, die kulturpolitischen Maßnamen, sind grundsätzlich richtungsweisend. Im folgenden werden die wichtigsten Institute und Organisationen besprochen, die entweder von offizieller Seite direkt damit beauftragt sind, die als Vermittlungsinstanzen zwischen Partei und Künstlern fungieren, oder die von den Künstlern selbst gegründet wurden: der Kulturbund der DDR, der Schriftstellerverband der DDR, das Institut für Literatur 'Johannes R. Becher', das Ministerium für Kultur und das Büro für Urheberrechte. 93

92Emmerich, 191.

93Vgl. DDR-Handbuch, Kulturpolitisches Wörterbuch BRD/DDR, A. Glückmann, Hrsg, Meyers Taschenlexikon Urheberrecht (Leipzig, 1975), Dokumente zur Kunst- Literatur- und Kulturpolitik der SED (Stuttgart: Seewald Verlag) Bd.1:1946-1970, hrsg. von Elimar Schubbe; Bd.2: 1971-1974, hrsg. von Gisela Rüß; Bd.3: 1975-1980, hrsg. von Peter Lübbe, erschienen 1984. 
Die Auffassung von Kultur in einem sozialistischen Land wie der DDR beinhaltet, daß sich Kultur von dem Volk angeeignet werden kann, sie ein Bildungsgut ist. Ahrends' Erläuterung des marxistisch-leninistischen Kulturbegriffes lautet:

Die Auffassung von Kultur als etwas Anzueignendem, als ein Bildungsgut ist noch deutlicher im Begriff der sozialistischen Kulturrevolution, die alle trennenden Schranken (z.B. das Bildungsprivileg) zwischen den Werktätigen und 'der Kultur' brechen soll, indem der soz. Staat seine 'kulturell-erzieherische Funktion' entfaltet und 'den Prozeß der kulturellen Entwicklung planmäßig' lenkt. Die 'Erhöhung des Kulturniveaus' der Werktätigen ist ihr wichtigstes Ziel.94

Die kulturelle Massenarbeit ist daher von großer Bedeutung und wird von der SEDPolitik mit besonderer Aufmerksamkeit verfolgt. Der "Kulturbund" ist eine solche Massenorganisation, die DDR-Bürger aller Schichten in Freundeskreisen, Fach- und Ortsgruppen und zahlreichen 'Klubs der Intelligenz' vereint. Am 3. Juli 1945 war dieser 'Kulturbund zur demokratischen Erneuerung Deutschlands', unter dem Vorsitz von Johannes R. Becher, in Berlin von Schriftstellern, Künstlern, Wissenschaftlern, Lehrern und Kulturvertretern gegründet worden. Die Aufgabe dieses, zunächst überparteilichen und humanistisch ausgerichteten Verbandes, war es, dem sogenannten antifaschistischen demokratischen Neuaufbau zu dienen und die kulturpolitische Linie der Sowjetischen Besatzungszone, der späteren DDR, zu formulieren. 1958 wurde er umbenannt und erhielt die Bezeichnung 'Deutscher Kulturbund', obwohl er nicht gesamtdeutscher Natur war, seit 1974 trägt er den Titel 'Kulturbund der DDR'. Heute ist der Kulturbund der DDR eine Organisation, die auf allen Gebieten der Kulturpolitik der DDR tätig ist, und seine Überparteilichkeit ist verschwunden.

Diese These befaßt sich mit Literaturproduktion in der DDR. Keinen direkten, jedoch einen nicht zu unterschätzenden indirekten Einfluß auf die eigentliche Produktion, hat der Leserkreis, der zum Teil unter starkem politischen Einfluß stehen kann. Durch die 
Arbeit der Massenorganisationen mit kulturell interessierten Teilen der Bevölkerung kann ihr Interesse teilweise gesteuert werden. Schriftstellerlesungen in Bibliotheken und Jugendklubs mit anschließenden Diskussionen etwa können eine Form von Beeinflussung darstellen. Auf diese Weise hat der Kulturbund einen Einfluß auf Meinungsäußerung und -bildung, der nicht zu unterschätzen ist. Eine Analyse des Einflusses der lesenden Bevölkerung in der DDR auf die Art der Literaturproduktion ist jedoch nicht Ziel dieser Arbeit.

Am 22.5.1952 wurde auf dem III. Deutschen Schriftstellerkongreß der 'Deutsche Schriftstellerverband' gegründet. Er ging als Vereinigung der Schriftsteller der DDR aus dem Kulturbund hervor. Der Schriftstellerverband verband nach Ende des zweiten Weltkrieges noch Berufsvertreter aus allen vier Besatzungszonen und sollte, zusammen mit dem Kulturbund, als gewerkschaftliche Verbindung der Berufsgruppe der Schriftsteller dienen. Seit November 1973 trägt der Verband den Namen 'Schriftstellerverband der DDR'. Wie der Vorsitzende der Berliner Bezirksorganisation des Verbandes, Günter Görlich, erläuterte, soll er auch heute noch eine gewerkschaftliche Funktion einnehmen:

Unser Verband hat die Funktion einer gesellschaftspolitischen Vereinigung, mit einer den Gewerkschaften entsprechenden, ihnen gleichberechtigten Stellung, darin selbstverständlich eingeschlossen die Interessenvertretung unserer Mitglieder in allen beruflichen Belangen, von der Nachwuchsförderung bis zur Altersversorgung. 95

Köhler-Hausmann bestreitet dies jedoch und weist darauf hin, daß schon 1952 "...die gewerkschaftliche Ausrichtung...aufgegeben wurde, [doch] sollte sie zumindest formal nach außen aufrechterhalten werden." 96

Der Verband ist keinesfalls nur eine Berufsorganisation, die ihre Mitglieder in ihren Interessen vertritt, sondern ein Bindungsglied zwischen Partei, Verbandsmitgliedern (1977): 157.

95Günter Görlich, "15\% Produktionssteigerung und immer noch zu wenig Bücher" Kürbiskern 2

96Reinhild Köhler-Hausmann, Literaturbetrieb in der DDR: Schriftsteller und Literaturinstanzen (Stuttgart: Metzler, 1984) 136. 
und Bevölkerung. Dem sowjetischen Modell folgend, und damit Stalins Forderung an die Schriftsteller der Sowjetunion, sie sollen sich als 'Ingenieure der menschlichen Seele' verstehen, sahen auch viele DDR-Schriftsteller ihre Aufgabe darin, sich am Prinzip des sozialistischen Realismus zu orientieren. "Parteilichkeit, Wahrheitstreue, Konkretheit, Volksverbundenheit und Volkstümlichkeit" sollten, folgte man Stalins Aufforderung, an die Stelle bürgerlicher Kunst gesetzt werden. Die Schriftsteller sollen auch heute noch nicht nur die Ziele der Partei dem Volk näherbringen, sondern auch die Verbundenheit des Volkes mit dem Staat darstellen. Dazu gehört,"dem Volke aufs Maul zu schauen" und widerzuspiegeln, was das Volk bewegt, was jedoch für Schriftsteller problematisch sein kann. Wie sich diese Problematik darstellen und zu welchen Konsequenzen das führen kann, soll in dieser Arbeit anhand Christa Wolfs Prosawerk Nachdenken über Christa T und Erich Loests Roman Es geht seinen Gang oder Mühen in unserer Ebene dargestellt werden.

Die Mitgliedschaft im Schriftstellerverband beschränkt sich nicht auf Autoren allein. "Schriftsteller im Sinne des Statuts sind die Verfasser, Übersetzer und Herausgeber schöngeistiger Werke sowie Literaturkritiker und Essayisten; Literaturwissenschaftler und Lektoren können auch Mitglieder werden".97 Der Präsident des Schriftstellerverbandes Hermann Kant ist der Auffassung, daß "die Mitgliedschaft in diesem Verband eine Angelegenheit der politischen Gemeinsamkeit" ist. ${ }^{98}$ Andere ehemalige Mitglieder sind jedoch anderer Meinung. Laut Joachim Seyppel, der 1979 vom Verband ausgeschlossen wurde, weil er mit sieben Schriftstellerkollegen den bereits erwähnten Protestbrief an

97 Bundesministerium für innerdeutsche Beziehungen, DDR-Handbuch Band 2M-Z (Köln: Verlag Wissenschaft und Politik, 2985) 1137.

98"Hanser, 53. 
Erich Honecker gerichtet hatte, ist der Schriftstellerverband ein Privilegienverband, eine "Ständeorganisation feudaler Natur."99

1983 betrug die Mitgliederzahl rund 900 . Unter den Mitgliedern sind jedoch weitaus weniger Schriftsteller zu finden, als dies noch in den fünfziger und sechziger Jahren der Fall war. Schmitt erklärt, seit 1973 seien immer mehr Nichtschriftsteller, Verlagsfunktionäre, Lektoren, Redakteure und Professoren Mitglieder. "Die Mehrheit, auf die sich die Partei immer gerne beruft, ist demnach nur per Mitgliedschaft 'Schriftsteller', aber Nutznießer sämtlicher Privilegien." 100 Zu diesen Privilegien zählen Darlehen, Stipendien, Reisen ins nichtsozialistische Ausland, Wohnungen, Alters- und Rentenversorgung, und in manchen Fällen ein Westauto.

Anzunehmen wäre leicht, je höher die Funktion, desto größer die Privilegien, doch dies scheint nicht unbedingt der Fall zu sein. Selbst die Mitglieder können oft nicht voraussagen, wie etwa eine Bitte um eine Forschungsreise in die Bundesrepublik gehandhabt wird. Bekannt ist mir ein Fall, in dem eine Schriftstellerin, die lange auf ein neues Auto gewartet hatte dieses prompt erhielt, nachdem sie sich schriftlich beim Verbandsvorstand beschwerte. Ihr Mann, nicht Mitglied im Schriftstellerverband, erhielt 1988 eine Reisegenehmigung zur mehrmaligen Ein- und Ausreise für ein Jahr, was äußerst ungewöhnlich ist. Wäre seine Frau nicht im Verband gewesen, hätte er dieses Recht eventuell nicht genießen können. Privilegien, die nach keiner offensichtlich deutlich festgelegten Regel verteilt werden, können dementsprechend auch entzogen oder niemals eingeräumt werden.

Bei Unbotmäßigkeit aber fallen alle diese Vergünstigungen weg, droht schließlich auch der Ausschluß aus dem Verband.... So hat die SEDParteiorganisation des Schriftstellerverbandes ihre Mitglieder wegen deren

${ }^{99}$ Hans-Jürgen Schmith, Die Literatur der DDR (= Hansers Sozialgeschichte der deutschen Literatur vom 16. Jahrhundert bis zur Gegenwart Band 11) Rolf Grimminger, Hrsg. (München: dtv, 1983) 53. 
solidarischen Eintretens für Biermann unterschiedlich gemaßregelt, um die Autoren untereinander zu verunsichern und zu spalten. ${ }^{101}$

Bekannte Unterzeichner wie Jurek Becker und Sarah Kirsch mußten bekanntlich die DDR verlassen, andere wie Stephan Hermlin und Christa Wolf wurden verhältnismäßig geringen Strafen ausgesetzt. Christa Wolf wurde aus dem Vorstand der Berliner Sektion des Schriftstellerverbandes ausgeschlossen, Stephan Hermlin, der den Anstoß für den Protest gegen die Ausbürgerung Biermanns gab, konnte sich schnell rehabilitieren und attakierte seine aus der DDR emigrierten Kollegen schon bald danach.

Der Schriftstellerverband der DDR verlegt die monatlich erscheinende Zeitschrift "Neue Deutsche Literatur", und zusammen mit dem Institut für Literatur "J. R. Becher" gibt er Werke junger Autoren und des 'Zirkels Schreibender Arbeiter' heraus. Hermann Kant, seit Mai 1978 Präsident des Verbandes, ist der Partei sehr verbunden, wie es auch seine 1981 verstorbene Vorgängerin, Anna Seghers. Beide waren, wie das für den Verband üblich ist, vom Vorstand gewählt worden. Der Vorstand wurde wiederum vom Kongreß gewählt, den Kongreß wählten die Mitglieder des Verbandes.

Von Bedeutung für Forschung auf dem Gebiet der DDR, besonders ihrer Kulturund Literaturpolitik, der gültigen, bzw. offiziell geförderten Literaturtheorien ist das Studium der Zeitschrift "Sinn und Form", veröffentlicht von der Akademie der Künste der DDR (AkD). Die AkD wurde am 24.3.1950 gegründet. In dem Statut der Akademie heißt es:

[Sie] hilft mit an der Entwicklung und Verbreitung einer parteilichen und volksverbundenen Kunst des sozialistischen Realismus, die zur Bildung sozialistischer Persönlichkeiten beiträgt, einer Kunst, die das geistige Leben des Volkes bereichert und als Bestandteil der kulturvollen Lebensweise im Sozialismus wirkt. Sie leistet einen wichtigen Beitrag zur Erforschung, Pflege, Erschließung und Verbreitung des kulturellen und künstlerischen Erbes. ${ }^{102}$

$101_{\text {ebda, }} 53$.

102 DDR-Handbuch Bd.1, 31. 
Die AdK ist in Sektionen aufgeteilt, unter denen sich der Aufgabenbereich Literatur und Sprachpflege befindet.

Staatliche Auszeichnungen spielen in der Kulturpolitik der DDR eine große Rolle. Von Bedeutung für die ökonomische Lage eines Schriftstellers kann die Auszeichnung durch einen Preis sein. Die Akademie überreicht eine Reihe von Preisen, die hoch dotiert sind. Sie zeichnet nicht nur offiziell diejenigen aus, die sich an die politischen Richtlinien gehalten haben, gibt also psychologische Unterstützung, sondern verhilft den Intellektuellen beruflich und finanziell aufzusteigen. Die höchste Auszeichnung, der Nationalpreis, wird jedoch vom Minister für Kultur vergeben. Damit verbundene Geldbeträge liegen in der Höhe von M 100 000, M 50000 und M 25 000, sind also von beträchtlicher Höhe. Der Johannes-R.-Becher-Preis wird alle zwei Jahre von der AkD vergeben "...für Werke der deutschen Lyrik, die im Geiste der großen Dichtung von Johannes R. Becher einen würdigen Beitrag zur sozialistischen deutschen Nationalliteratur bilden". ${ }^{103}$ Er beträgt $\mathbf{M}$ 20000 . Weitere kulturbezogene Preise, verliehen von der AkD, sind der Heinrich-HeinePreis und der Käthe-Kollwitz-Preis. Sogenannte nichtstaatliche Preise werden unter anderem von der Freien Deutschen Jugend (FDJ) verliehen, wie etwa die Erich-WeinertMedaille, die Alex-Wedding-Medaille für Kinderbuchautoren und der Kunstpreis der FDJ. Der Demokratische Frauenbund Deutschlands (DFD) verleiht einen Literaturpreis. Einzelne Städte vergeben außerdem Kulturpreise, wie etwa Karl-Marx-Stadt, Leipzig, Erfurt, Berlin, Weimar und Potsdam.

Das Institut für Literatur 'Johannes R.Becher" wurde am 3.2.1955 gebildet. Nicht das Schreiben an sich wird an dem Institut gelehrt. Die Festigung der ideologischen Orientierung der jungen Schriftsteller, die Schulung nach dem sowjetischen Vorbild des »Maxim Gorki Instituts« ist sein Ziel. Dem Schriftstellerverband unterlag die Aufgabe, 
die junge Autorengeneration zu fördern. Dies konnte auf einer breiten Basis geschehen, durch Arbeitkreise etwa und finanzielle Unterstützung. Das Literaturinstitut ist dagegen eine Schulungsstätte, in der in den ersten zwanzig Jahren 580 Autoren ausgebildet wurden. Erläutert Köhler-Hausmann:

Mit der Herausbildung einer solchen parteipolitisch organisierten Institution erhoffte man sich verstärkter als zuvor, die künstlerischen Werke bereits in der Entstehung in eine kulturpolitische Richtung lenken zu können, die für den sozialistischen Aufbau und die Bewältigung der nationalen Frage als systemintegrierende Kraft gebraucht wurden. ${ }^{104}$

Man kann in ein- bis dreijährigen Studiengängen unter anderem Kurse in marxistischer Philosophie, Literaturgeschichte, Stilistik und Ästhetik absolvieren. Im letzten Studienjahr wird die praktische Ausbildung geschult, zum Teil durch Zusammenarbeit mit Verlagslektoren und in Betriebszeitungen. Da es Ziel dieser Ausbildung ist, Schriftsteller zu schulen, die sich mit den Fragen des sozialistischen Aufbaus beschäftigen, und dies auf eine möglichst parteitreue Weise, verwundert es nicht, daß das Institut eng mit dem Ministerium für Kultur und dem Schriftstellerverband verbunden ist.

Es ist statuarisch fixiert, daß das Präsidium des Schriftstellerverbandes aus seiner Mitte die Mitglieder des künstlerischen Institutsbeirats benennt. Ihm obliegt gleichermaßen das Vorschlagsrecht für den Direktor, es trifft eine vorbereitende Auswahl für die Studentenzusammensetzung und stellt die Leiter für die schöpferischen Seminare, die in den drei klassischen Genres Lyrik, Drama und Epik abgehalten werden. ${ }^{105}$

Die Verordnung über seine Bildung erklärt:

Um die zeitgenössische deutsche Literatur im Geist der progressiven Traditionen und Errungenschaften der deutschen und Weltliteratur zu entwickeln und die ideologisch und künstlerische Ausbildung der Schriftsteller zu fördern, ist die Schaffung eines Instituts für Literatur notwendig. 106

${ }^{104}$ Köhler-Hausmann, 140.

$105_{\text {ebda, }} 141$.

${ }^{106}$ DDR-Handbuch. Bd.1, 654/655. 
Nicht jeder Studienbewerber kann jedoch an dem Institut studieren, sondern nur solche, die besonders qualifiziert sind. Oft gingen sie aus Arbeiterschriftstellerzirkeln hervor, z.B. in den späten fünfziger und frühen sechziger Jahren als Teil des Bitterfelder Weges. Eine abgeschlossene Berufsausbildung ist heue noch Voraussetzung, der Nachweis über literarisches Talent, aktives gesellschaftliches Engagement und die Unterstützung des Schriftstellerverbandes oder einer anderen kulturellen Einrichtung. ${ }^{107}$ Trotz der anscheinend strengen Auswahl der Studenten, der gezielten Ausbildung anhand marxistisch-leninistischer Ideologie in dem parteipolitisch organisierten Institut scheinen sich die Studenten und Absolventen nicht weniger eigen in ihrer Themenwahl und Ausführung ihrer Werke zu verhalten als Schriftsteller, die keine derartige Schulung genossen haben. Das Literaturinstitut ist, einem Gespräch mit Studenten des Instituts nach zu urteilen, nicht in der Lage, den Drang nach Individualität aufzuhalten. ${ }^{108}$ Wie KöhlerHausmann betont, wird der Wunsch nach Unabhängigkeit in Ausdruck und Leseerfahrung, der Weg zur Selbstfindung einen Einfluß auf den Literaturbetrieb haben, denn aus diesen Studentenkreisen kamen meist diejenigen, denen literaturpolitisch schwierige Stellen anvertraut wurden, sei es als Verlagslektor oder Vorstandsmitglied des Schriftstellerverbands.

Das äußerst mächtige Ministerium für Kultur, seit 1973 geleitet vom Minister für Kultur Hans-Joachim Hoffmann, ist offiziell für die Planung und Leitung der einheitlichen Kulturpolitik verantwortlich. Es besteht seit 1954 und verwaltet unter anderem die Literatur, den Buchhandel und das Verlagswesen, indem es konkrete Aufgabenstellungen für die einzelnen kuturellen Bereiche festlegt. Verlage müssen z.B. ihre Perspektiv- und

${ }^{107}$ Köhler-Hausmann, 142. K-H weist daraufhin, daß sie weder das Statut noch genauere Lehrplanausführungen erhalten konnte. Sie bezieht ihre Information aus einer dreiseitigen hektographischen Informationsbroschüre, die das Institut an Interessierte verteilt.

108 Kơhler-Hausmann, 143/44. Darin: 1979 führte Joachim Novotny ein Gespräch mit Studenten des Instituts aus dem 3. Studienjahr, das in "Weimarer Beiträge" veröffentlicht wurde. 
Jahrespläne dem Ministerium vorlegen. Gagen, Honorare und Urherbervergütungen aller kulturellen Berufe werden vom Ministerium geregelt. Druckgenehmigungen werden nur vom ihm erteilt, und ohne diese Genehmigung kommt kein Buch auf den Markt.

Unter Verwaltung des Ministeriums für Kultur steht weiterhin ein Kuratorium, das über den Kulturfonds der DDR und dessen Einsatz verfügt. Dieser Kulturfonds der DDR, obwohl keine Institution oder Organisation, ist eine kulturpolitisch einflußreiche Einrichtung. Aus einer Künstlerhilfe in Höhe von M150 000 , die 1949 von der Verwaltung für Volksbildung, dem 'Kulturbund zur demokratischen Erneuerung Deutschlands' und dem Gewerkschaftsbund gemeinsam erstellt wurde, ging der Kulturfonds der DDR hervor. Die finanzielle Ausstattung stammt heute aus den Mitteln der Kulturabgabe, eine 5-Pfennig Abgabe beim Kauf einer Theaterkarte, 10-Pfennig einer Schallplatte, die dem Kulturfonds zufließt. Durch Auftragswerke oder Stipendien etwa werden Künstler gefördert, die neue sozialrealistische Werke schreiben, oder auf eine andere Art künstlerisch für den Sozialismus arbeiten. Geleitet wird das Kuratorium des Kulturfonds von den Präsidenten und Vorsitzenden des Kulturbundes, der Akademie der Künste, der Gewerkschaft Kunst sowie Personen, die vom Minister für Kultur speziell dazu ausgewählt wurden. Der Direktor des Kulturfonds wird vom Minister für Kultur ernannt. Laut 'Kulturpolitisches Wörterbuch BRD-DDR' umfaßte 1983 der Kulturfonds etwa 2 Mrd. M, ${ }^{109}$ eine unglaublich hohe Summe für eine Bevölkerung, in Höhe von 17 Millionen Menschen.

Das Büro für Urheberrechte ist allein berechtigt, den Lizenzverkehr mit dem Ausland vertraglich zu genehmigen. "Nach Art. 11 Abs. 2 der Verfassung vom 6.4.1968 i.d.F. vom 7.10.74 (GBl. I, S. 432) genießen die Urheber den Schutz des sozialistischen 
Staates"..10 Das Ministerium für Kultur überprüft Musterverträge, die vom Büro für Urheberrechte verfaßt werden, denn das Büro unterliegt der Aufsicht des MfK (AO vom 23.10.1956, GBl. II, S.365). Besonders wichtig ist diese Prüfung, wenn es sich um geplante Auslandsverträge handelt. Als Ausland gilt selbstverständlich auch die Bundesrepublik Deutschland. "Die Verlage müssen alle Manuskripte der 'Hauptverwaltung Verlage und Buchhandlungen' des Ministeriums für Kultur zur Erteilung einer Druckgenehmigung vorlegen. Ob Lizenzen ins Ausland gegeben werden, entscheidet das 'Büro für Urheberrechte.' 111" Bevor ein Autor ein Manuskript oder Buch etwa einem Verlag in der Bundesrepublik anbietet, wird von ihm verlangt, daß die Nutzungsrechte zuerst einem Verlag in der DDR angeboten werden. Falls der Autor dagegen verstößt und sein Manuskript 'unter Umgehung der Rechtsvorschriften' dem Ausland anbietet, kann ihm eine Ordnungsstrafe erteilt werden. Seit 1979 wird ein solches Vergehen sogar noch strenger geahndet, und zwar als ein Devisenvergehen, und kann mit einer Freiheitsstrafe bis zu fünf Jahren bestraft werden.

Um die kulturpolitischen Maßnahmen der DDR zu verstehen ist eine Kenntnis der genannten Institute und Organisationen notwendig. Mit Hilfe dieser werden Richtlinien gegeben, Verstöße dagegen geahndet und Zensurmaßnahmen ausgeführt. Im Folgenden wird eine kurze literarische Interpretation zweier Werke geleistet, die sich Produktionsund Rezensionsschwierigkeiten ausgesetzt sahen, die charakteristisch für die DDR gesehen werden könne.

110 DDR-Handbuch, Bd.2, 1401.

${ }^{111}$ Gisela Helwig, Hrsg., Die DDR-Gesellschaft im Spiegel ihrer Literatur (Köln: Verlag Wissenschaft und Politik, 1986) 20, Fußnote 47. 


\section{KAPITEL III}

\section{"NACHDENKEN" ÜBER DIE MÖGLICHEN ANGRIFFSPUNKTE IM WERK WOLFS UND LOESTS: EINE GEZIELTE NACHERZÄHLUNG}

\section{DIE ROLLE DES AUTORS}

"Keine andere Epoche deutscher Literatur ist mit dem kulturpolitischen Programm einer Partei in einer so ambivalenten Verbindung zu sehen, wie die Literatur der DDR." 112 Von dieser Voraussetzung ausgehend läßt sich schließen, daß Autoren der DDR-Literatur eine besondere Rolle zugeteilt wird, oder sie sich diese Rolle selbst zuteilen. Befaßt man sich mit DDR-Literatur muß die Frage gestellt werden, was jedoch DDR-Schriftsteller als solche auszeichnet? Wodurch unterscheidet sich ein DDR-Autor von einem Autor, dessen Berufsbeschreibung nicht sofort durch geographische Gebundenheit und eine bestimmte politische Ideologie festgelegt wird?

Die Bezeichnung "DDR-Autor" bezieht sich in dieser Arbeit auf die Autoren, die in der DDR schrieben, also dort seßhaft waren, als sie schrieben. Einige dieser Autoren leben noch in der DDR, andere sind vor Jahren oder vor kurzer Zeit ausgereist oder wurden ausgebürgert. Zu den DDR-Autoren zählen auch jene, die in der DDR schrieben, dort jedoch nicht veröffentlicht wurden, darum zuerst in der Bundesrepublik ihre Werke verlegten und zu einem späteren Zeitpunkt auch in der DDR gedruckt wurden. Selbstverständlich zählen auch Autoren dazu, die weder in der DDR noch in der Bundesrepublik publiziert wurden. "Der Schriftsteller muß Chronist seiner Zeit sein. Seine Arbeiten sollen nach fünfzig, nach zweihundert Jahren Auskunft geben, wie bestimmte Leute zu

112 Hans-Jürgen Schmith, Vorbemerkung, Hansers Sozialgeschichte der deutschen Literatur. Band 11 (München: dtv, 1983) 10. 
bestimmten Zeiten gelebt und gefühlt haben." ${ }^{113}$ So sah Sarah Kirsch ihre Aufgabe als Schriftstellerin im Jahre 1975. Diese Feststellung zeichnet sie nicht unbedingt als DDRSchriftstellerin aus. Ihre Auffassung hat vieles gemein mit Schriftstellern aus aller Welt.

"Literatur leistet hier [in der DDR], was sie immer und überall kann. Sie beteiligt den, der mit ihr umgeht, an anderer menschlicher Erfahrung und vertieft seine eigene, sie macht empfindsam, sie übt Phantasie, sie vermenschlicht." 114

So bezeichnet Wolfgang Kohlhaase, stellvertretend für viele DDR-Schriftsteller, aber auch Schriftsteller allgemein, ohne starke geographische und politische Bindung, was er darunter versteht, Schriftsteller zu sein. ${ }^{115}$ Die Einstellung Günter Kunerts, der im Herbst 1979 ausgebürgert wurde, ist jedoch besonders bezeichnend für eine Anzahl DDRSchriftsteller, die nicht unbedingt linientreue Parteianhänger, aber überzeugte Sozialisten sind.

"Einerseits finde ich, daß die Funktion der Literatur immer die gleiche ist, andererseits hat aber die Literatur in dieser Gesellschaft eine besondere Funktion bekommen. In dieser Gesellschaft...ist die Literatur plötzlich in die Lage versetzt worden eine Rolle zu spielen, die für sie vielleicht zu groß ist, das heißt, sie soll Fragen beantworten, die sie eigentlich garnicht beantworten kann."116

DDR-Autoren nehmen demnach, und das sei bei der Betrachtung ihrer Werke, ihres Handelns und Denkens nicht zu vergessen, eine Rolle ein, die sie zum Teil nicht spielen wollen, zum Teil nicht spielen können. Es müssen darum Konflikte daraus entstehen.

DDR-Autoren unterscheiden sich nicht schon seit dem Jahre 1945 derart voneinander. Die DDR-Autoren der sechziger und siebziger Jahre, mit denen sich diese

113 Kirsch in: Richard A. Zipser und Karl-Heinz Schoeps, DDR-Literatur im Tauwetter (Bern: Peter Lang, 1985) Bd.3, 20. Zipser und Schocps stellten einer Reihe bekannter DDR-Autoren berufsbezogenen Fragen.

114 ebda 20.

$115_{\text {Kohlhaases Antwort wird hier angeführt, stellvertretend für viele andere Befragte, deren }}$ Antwort ahnlich formuliert waren. 
Arbeit besonders befaßt, unterscheiden sich in ihren Hoffnungen und Zielen deutlich von denjenigen, die sich nach dem Ende des Zweiten Weltkrieges in der DDR ansiedelten und ein gemeinsames politisches Ziel im Auge hatten. Damals war man sich einig, gemeinsam mit der Partei ein neues, besseres Leben für alle in der DDR aufzubauen. ${ }^{117}$ Man hatte sich vereint gefühlt, stellt Schmitt fest:

Später, als sozialistische 'Prognostik' weder dem Wachstum der Produktivkräfte noch dem Bild vom 'neuen' Menschen entsprach, wurde bei nicht wenigen Autoren ein Schriftstellerbewußtsein immer stärker spürbar - marxistisch unterkellert bei Volker Braun und Heiner Müller, humanistisch-sozialistisch bei Christa Wolf und Günter de Bruyn, existentiell bei Günter Kunert und Reiner Kunze. ${ }^{118}$

Keinesfalls waren es nur innenpolitische, DDR spezifische Ereignisse die halfen, das Selbstverständnis der DDR-Autoren zu verfeinern und zu differenzieren. Unterschiedliche Ideologien westlich und östlich der innerdeutschen Grenze trugen auch zur Definition der DDR-Literatur und ihrer Autoren bei. Schon bevor Willy Brandts Ostpolitik Anfang der siebziger Jahre die Einstellung der beiden deutschen Staaten zueinander auf einen neuen Pfad leitete, schon als andere Länder weltweit begannen, die DDR als einen eigenen Staat anzuerkennen, änderte sich mit dem wachsenden Selbstbewußtsein des Staates auch das seiner Bürger. Die Literatur, laut Helwig besonders die Belletristik der DDR, ist, und war damals schon, "...als 'Seismograph von gesamtgesellschaftlichen Problemen und Bewußtseinslagen' zu apostrophieren." ${ }^{119}$ Und Leser in der Bundesrepublik begannen Interesse an dieser Belletristik zu zeigen. Einige suchten gewiß nach Bestätigungen ihrer Vorurteile dem anderen Deutschland gegenüber, andere Leser genossen es, endlich einen besseren Einblick in diesen ihnen fremd gewordenen

${ }^{117}$ Schmitt weist auf die Titel in der Anthologie > Menschen und Werke $<$ hin, die optimistisch klangen. In: Hansers Sozialgeschichte der deutschen Literatur. Band 11 (München: dtv, 1983) 15.

118 ebda 16.

${ }^{119}$ Gisela Helwig, Hrsg., Die DDR Gesellschaft im Spiegle ihrer Literatur (Köln: Verlag Wissenschaft und Politik, 1986) 14. 
Teil ihrer Heimat gewinnen zu dürfen. Manche DDR-Autoren, die sich ihrer Verantwortung dem Staat und der Gesellschaft gegenüber bewußt waren, fanden sich in einer neuen Rolle vor. Sie berichteten nicht etwa nur vom entwickelten Sozialismus, sondern auch von den Schwierigkeiten, die sie damit verbunden sahen, von den

Widersprüchen und Ärgernissen, auf dem großen Hintergrund einer sich entfaltenden neuen Welt, während [ihre] Gesellschaftswissenschaftler zwar vom realen Sozialismus sprechen, aber in ihren konkreten Beschreibungen der Realität so oft der Neigung zur Schönfärberei verfallen. ${ }^{120}$

Ein Hauptaspekt dieser These ist die Zensur in der DDR. Charakteristisch für die DDR-Literatur und ihre Autoren ist der Einfluß, der diese Zensur auf sie hat. ${ }^{121}$ Die unterschiedlichen Zensurmaßnahmen, die dem Staat zur Verfügung stehen und von denen er zu bestimmten Zeiten Gebrauch macht, verhilft DDR-Autoren zum Teil zu einem perversen Status. Interviews im Westen über politische Praktiken im Osten, Ausschlüsse aus dem Schriftstellerverband oder offene Briefe an DDR-Staatsfunktionäre die in der westlichen Presse veröffentlicht wurden, vergrößerten etwa das Renomée solcher Autoren wie Bernd Jentzsch, Stefan Heym, Joachim Seyppel und Rudolf Schneider. Es ist für den Erfolg und das Image hilfreich, ob beabsichtigt oder nicht, als DDR-Autor mit dem Staat auf eine Weise in Konflikt zu geraten, der eventuell in der Bundesrepublik als Zeichen von Unzufriedenheit interpretiert werden kann. Erläutert Christa Wolf:

Solange es Arbeitsteilung gibt, sind Schriftsteller Spezialisten zur Herstellung eines Selbst-Bewußtseins, eines Selbst-Gefühls ihrer Zeit, ihrer Gesellschaft, ob sie sich so sehen mögen oder nicht, ob sie so verstanden werden oder nicht. Auch wir Autoren in der DDR stehen in einem historischen und sozial bedingten Spannungsfeld, sind gebunden an die Bedingungen von Geschichte, Ort und Zeit. Auch hier hat Literatur zu leisten, was sie seit mehr als zweitausend Jahren im 'Abendland' tut: sie drückt die Spannung zwischen den Ansprüchen, Bedürfnissen,

$120_{\text {ebda }} 14$.

${ }^{121}$ Der Gebrauch des Wortes 'Zensur' in der DDR wird im folgenden Kapitel genauer behandelt. 
Hoffnungen, Sehnsüchten des einzelnen und seiner Gesellschaft aus.

Vollkommen zufriedene Menschen bedürfen nicht der Kunst. ${ }^{122}$

\section{NACHDENKEN ÜBER NACHDENKEN ÜBER CHRISTA T.}

Nachdenken über Christa T., Christa Wolfs bedeutendes Werk, das in der DDR und der Bundesrepublik Aufsehen erregt hat, ist eine Art Entwicklungsroman, in dem Sinne, daß er den inneren und äußerlichen Werdegang der Christa T. von ihren Anfängen als junges Mädchen bis zu ihrem Tod darstellt. Ihre Entwicklung, ihre Reifung in eine Persönlichkeit war noch nicht abgeschlossen, wäre wahrscheinlich auch niemals ganz gelungen, wäre sie am Leben geblieben.

Zwei Hauptpersonen, Christa T. und die Ich-Erzählerin, werden zum Teil gemeinsam, zum Teil getrennt, zu erwachsenen Menschen in den Nachkriegsjahren, während des Aufbaus der DDR. Hilzinger erläutert jedoch: "Das Leben der Christa T., so wie es Inhalt des Nachdenkens der Erzählerin ist, hat die Tendenz, sich der offiziellen Version von Lebensläufen in dieser Zeit, dem Ankommen im Sozialismus, zu widersetzen". 123

In der DDR-Literatur, besonders den Werken der sechziger Jahre, war die 'Ankunftsliteratur' von Bedeutung, denn in ihr sollte der Wandel des Helden vom unpolitischen zum politischen Menschen dargestellt werden."Die 'Ankunft' des neuen Menschen im Sozialismus, seine Identifikation mit der bestehenden Sozialordnung und seine Integration darin..."124 verdeutlichen. Christa Wolfs 1963 erschienenes Prosawerk Der geteilte Himmel wäre ein Beispiel dafür.

122Zipser, Bd 3., 31.

${ }^{123}$ Hilzinger, Sonja: Christa Wolf (Stuttgart: Metzler, 1986) 35.

${ }^{124}$ Gero von Wilpert, Sachwörterbuch der Literatur (Stuttgart: Kömer, 1979) 28. 
Christa T., die 1927 im heutigen Polen geboren wurde, lernt auf der Schule die zweite Hauptperson kennen. Dies ist die Ich-Erzählerin des Romans, ihre ehemalige Klassenkameradin und Freundin, über die wir im Verlaufe des Buches aus stilistischen und, so wird von Kritikern oft vermutet, politischen Gründen, sehr wenig erfahren. Nur kurze Zeit kennen sie sich als Kinder, als das Ende des Krieges naht. Während der Flucht vor der Roten Armee verlieren sie sich aus den Augen und treffen sich erst beim gemeinsamen Germanistikstudium im Jahre 1951 wieder. Christa T. hat in der Zwischenzeit nach Kriegsende auf dem Land als Lehrerin gearbeitet und geht nun nach Leipzig, um zu studieren. 1954, nachdem sie ihr Studium mit einer Arbeit über Theodor Storm mit sehr gut abgeschlossen hat, unterrichtet sie wieder als Lehrerin. Sie übt diesen Beruf jedoch nicht lange aus, sondern heiratet Justus, einen Tierarzt, mit dem sie aufs Land zieht. In Mecklenburg bauen sie sich ein Haus, sehr abgelegen an einem See, sie gebärt drei Kinder während ihrer siebenjährigen Ehe, hat eine kurze Liebesaffäre mit einem Jäger und versucht sich als Schriftstellerin. Ihrem Leben wird im Frühjahr 1963 ein Ende gesetzt. Sie stirbt an Leukämie. Ihre Freundin, die Ich-Erzählerin, beginnt kurz nach Christas Tod mit Hilfe von Dokumenten aus Christas Nachlaß eine Aufzeichnung ihres Lebens.

Die achtzehn Jahre, die, bis zum Todesjahr 1963, betrachtet werden, entsprechen den Anfangsjahren der DDR und damit auch dem Weg einer ganzen Generation.... Christa T. ist aber 'als Beispiel nicht beispielhaft, als Gestalt kein Vor-Bild' [NT 57], denn ihr Nutzen ist nicht eine Verwendbarkeit im Sinne der 'schrecklichen schreienden Helden' [NT 72] der Anfangsjahre, sondern die Thematisierung ihres Bezuges zur Wirklichkeit. ${ }^{125}$

Christa T. stirbt zwar physisch an Leukämie, psychisch stirbt sie jedoch an ihrem eigenen Scheitern in dem neuen deutschen Staat. Der sich entwickelnde sozialistische

125 Marc Silberman, "Soll und Haben. Überlegungen zum Roman der DDR" in Deutsche Gegenwartsliteratur. Ausgangsposition und aktuelle Entwicklungen, Manfred Durzak, Hrsg.(Ditzingen: Reclam, 1981) 513. 
Staat mit seinem Ideal des neuen sozialistischen Menschen stellt Erwartungen an sie, denen sie nicht gewachsen ist. Umgekehrt ist der Staat ihrem idealsten Bürger nicht gewachsen. Der Staat gestattet ihr nicht, sich individuell zu entfalten. Sie versucht, die Schritte zu ihrer Selbstverwirklichung in einem Land zu gehen, in dem sie auf unsichere Menschen in einem System stößt, welches selbst noch nicht selbstsicher ist und dadurch um so er- und unterdrückender auf sie wirkt. Wittstock faßt Christa T.s Problem zusammen:

Während sich ihre Mitmenschen darauf beschränken, die Umwelt neu zu benennen, also durch eine veränderte intellektuelle Kennzeichnung in eine neue rationale Ordnung zu bringen, bezweifelt sie, daß man damit der Wirklichkeit vollends gerecht wird. Da sie aber nie definitiv formuliert (formulieren kann), welche Bereiche der Wirklichkeit durch diese rationale Neuordnung ausgespart werden, entwickelt sie sich mehr und mehr zu einer Außenseiterin, der man mit Unverständnis begegnet. ${ }^{126}$

In dieser Außenseiterrolle verbleibt sie bis an ihr Lebensende.

Die "...zentrale Problemstellung..." des Romans, laut Stephan, lautet:

Wie und unter welchen Umständen ist es dem Einzelnen innerhalb einer geplanten, straff organisierten Gesellschaft möglich, seine privaten, individuellen und damit ungenormten Lebenserwartungen zu erfüllen und gleichzeitig als tätiges Mitglied der Gemeinschaft produktiv zu sein. ${ }^{127}$

Die Autorin Christa Wolf und die Ich-Erzählerin berichten in zwanzig Kapiteln die Lebensgeschichte der Christa T., ein nicht unbedingt aufregender, doch von der Autorin absichtlich so dargestellter Lebenslauf, der in vielem typisch ist für Christa T.s und Wolfs Altersgenossen. Als Jugendliche erlebten sie, teilweise bewußt, den Zweiten Weltkrieg mit, fühlten sich betroffen und mitverantwortlich an den Geschehnissen. Durch ihre Unerfahrenheit und Naivität konnten sie sich eventuell entschuldigen, verspürten aber eine Mitschuld, sind verunsichert in bezug auf ihre eigene Charakterstärke.

${ }^{126}$ Uwe Wittstock, Über die Fähigkeit zu trauern: das Bild der Wandlung im Prosawerk von Christa Wolf und Franz Fühmann, 92.

${ }^{127}$ Alexander Stephan, 60. 
Wir könnten uns fragen, warum wir verschont geblieben waren, warum uns die Gelegenheiten nicht zugetrieben waren. Welche denn hätten wir ergriffen: Alle, keine? Und was wußten wir von uns, wenn wir das nicht wußten? Diese entsetzliche Dankbarkeit über den Mangel an Gelegenheit wird man nicht vergessen. ${ }^{128}$

Christa T. will sich nun, nachdem sie ihre Tagebücher nach dem Krieg verbrannt hat, in ihrem Leben als Erwachsene beweisen, daß sie sich und den Mitmenschen trauen kann.

Offiziell war in der DDR die Vergangenheit kurz nach Kriegsende bewältigt worden. Der Staat war entnazifiziert, so hieß es, und heißt es auch heute noch. Ende der vierziger Jahre sprach sich der neu gegründete Staat DDR von aller Mitschuld an den Kriegsverbrechen der Nazis frei. Wie schon in Der geteilte Himmel kommt die Autorin, Christa Wolf, jedoch wieder auf den Charakter der Menschen zu sprechen, seien sie Nazis oder DDR-Bürger, die sich dem Staat unterordnen. Nicht alle taten und tun das aus den selben Gründen, einige aus Angst, andere aus Sucht nach Macht. Welche Motive sich dahinter verbergen ist unbedeutend. Der Typ Mensch, der an der nationalsozialistischen "Revolution" mitwirkte und sie unterstützte, existiert noch und wird, das scheint Christa T. zu befürchten, vielleicht auch in dem neuen sozialistischen Staat demjenigen vorgezogen, der durch Mitdenken und konstruktive Kritik dem Staat in seiner Entwicklung helfen könnte. In Blasing sind beispielsweise die unattraktiven Ausartungen des imperfekten DDR-Bürgers darstellt.

In Anekdoten aus ihrer Kindheit, Jugend und Studienzeit illustriert Christa T. diese Menschen und ihre Furcht vor ihnen. Sie hat Angst auch vor sich selbst, denn auch sie hatte daran teilgenommen, wenn auch nicht aktiv.

Da beginnt das Radio über ihr zu dröhnen: Noch einmal, auch in der Hölle noch, diese fanatische, sich überschlagende Stimme, Treue dem Führer bis in den Tod. Sie aber, Christa T., noch ehe sie den Mann verstanden hat, fühlt sich kalt werden. Ihr Körper hat, wie auch sonst, eher begriffen als ihr Kopf, dem nun allerdings die schwere Aufgabe des Nacharbeitens bleibt, den Schreck aufzuarbeiten, der ihr in den Gliedern sitzt. (NT 25) 
Und mit diesem 'Nacharbeiten' verbringt sie den Rest ihres Lebens.

Ein in ihren Gedanken an die Kindheit immer wiederkehrendes Bild ist das des Katzenmörders, der ihren Kater an der Stallwand zu Tode schlägt.(NT 26). An einen Nachbar- und Hitlerjungen, der seinen Vater "wegen Abhörens feindlicher Sender" (NT 34) anzeigt, erinnert sie sich. Und sie selbst fühlt sich an dem Tod eines Kindes schuldig, das ihr auf der Flucht in einer Nacht, als sie aus Erschöpfung eingeschlafen war, vom Schoß rutschte und im Schnee erfror. Wenn sich auch der Hiltlerjunge bei Kriegsende erschoß, und auch der Katermörder nicht mehr leben sollte, die neue Gesellschaft hat sich ihre Mitglieder nur bedingt aussuchen können, oder ausgesucht. Diese sind jedoch gewillt, das Alte hinter sich zu lassen und am Aufbau des jungen Staates teilzunehmen.

Doch während die anderen...mit Hilfe dieses Entschlusses beinahe übergangslos Hoffnungslosigkeit und Illusionsverlust in Begeisterung, Lernkollektive, Selbstverpflichtungen und die Hebung von Durchschnittsnoten zu verwandeln verstand, heilt die 'Wunde' (NT 37) der Christa T. nur langsam: '...die Angst, einem selbst könnte zustoßen, was gang und gäbe war: spurlos zu verschwinden.'(NT 38) ${ }^{129}$

Um dieses Nicht-verschwinden-wollen bemüht sich Christa T. auf unterschiedliche Weise bis an ihr Lebensende. Sie hegt nie den Gedanken, sich eine andere Heimat zu suchen, eventuell im Westen. Das ist für sie keine Alternative. "Unter den Tauschangeboten ist keines, nach dem auch nur den Kopf zu drehen sich lohnen würde...." (NT 55) Und doch geht sie immer wieder weg, wechselt ihren Wohnort, ihren Einflußbereich, nicht weil sie vor etwas wegläuft, sondern weil sie auf etwas zuläuft.

Sie hat diesen Vorgang - wegzugehen - später noch öfter wiederholt, dahinter verbirgt sich ein Muster, schon ablesbar beim erstenmal: hinter sich lassen, was man gut kennt, was keine Herausforderung mehr darstellt. Neugierig bleiben auf die anderen Erfahrungen, letzten Endes auf sich selbst in den neuen Umständen. Die Bewegung mehr lieben als das Ziel.(NT 46) 
Ein drastisches Beispiel für das, was sie an ihren Kommilitonen und der neuen Generation bedrückt und woran sie verzweifelt, ist der Mangel an Bemühung um Wahrheit. Die Generationen, so wie sie es sieht und bedauert, entwickeln sich nicht mehr. Sie setzen sich nicht weiter in Diskussionen mit den Zielen und der Ideologie des neuen Staates auseinander, sondern sie passen sich an. Beispiel dafür sind zuerst ihre Kommilitonen an der Universität und später ihre Schüler, die sich über Christa T.s Lebensphilosophie lustig machen. So behauptet einer ihrer ehemaligen Schüler, den sie trifft, als sie schon verheiratet ist, "Überleben sei das Ziel der Menschheit immer gewesen und werde es bleiben. Das heißt, ihr Mittel zu jeder Zeit: Anpassung. Anpassung um jeden Preis."(NT 112) Doch Christa T. kann sich immer noch nicht damit zufrieden geben. "Was fehlt der Welt zu ihrer Vollkommenheit"(NT 64) und "was braucht die Welt zu ihrer Vollkommenheit?"(NT 57) Diese Fragen versuchte sie schon während ihrer Studienzeit zu beantworten. Als mögliche Antwort auf sie tauchen zuerst Hoffnung und Liebe auf, "die vollkommene Liebe".(NT 64) Diese suchte sie und fand sie kurz bei Kostja, einem Kommolitonen, der ihr unterstellte, sie sei 'unzeitgemäß'.(NT 65) "Ja, sagt sie. Das kann sein. Dann werde ich nicht lange leben."(NT 65) Und somit manifestiert sich ihre Krankheit.

Im achten Kapitel erscheint dieses Wort zum erstenmal, »Krankheit«. (NT 73) Der offizielle Befund eines Arztes, den sie aufsucht, lautet:

Todeswunsch als Krankheit. Neurose als mangelnde Anpassungsfähigkeit an gegebene Umstände.... Am besten, mein Fräulein, Sie kommen zu mir in die Therapie, Sie werden begreifen müssen, worauf es ankommt. Bei Ihrer Intelligenz...Sie werden sich anpassen lernen.(NT 75)

Doch sie geht nicht in die Therapie, sondern flüchtet sich in das ihr Vertraute, in ihr Dorf, zu den Pappeln, den Kirschen, den Fröschen, dem Teich, verbringt einen Sommer dort.

Hier 'entdeckt' sie auch, daß sie sich selbst heilen muß und glaubt, dies auch zu können.

Da Sehnsucht von »sehen « kommt: die Sucht, zu sehen, hat sie zu sehen angefangen und gefunden, daß ihre Sehnsucht, wenn sie nur ruhig und 
gründlich genug hinsah, mit den wirklichen Dingen auf einfache, aber unleugbare Art übereinstimmte."(NT 90)

Bei diesem Heilungsprozeß helfen ihr Schriftsteller des neunzehnten Jahrhunderts wie Keller und Storm, die sie nun mit Genuß liest. "Feste, klare Umrisse, nichts in Gefühl aufgelöst, nichts in Gedankenspiel gebrochen,"(NT 95) das findet sie bei ihnen.

Am Ende des Sommers kehrt Christa T. nach Leipzig zurück, schreibt ihre Examensarbeit über Theodor Storm und beginnt wieder zu lehren. Täglich trifft sie nun wieder mit den Menschen zusammen, die nicht eifrig an der Entwicklung des Sozialismus teilnehmen, wie sie es sich vorstellt, sondern die engstirnig, verbissen und enttäuscht sind. Sie sind illusionslos, schon so bald nach der Gründung ihres neuen Staates. Christa T. will sie jedoch als mitdenkende, notfalls kritische Mitglieder der sozialistischen Gemeinschaft sehen. Stattdessen illustriert die Erzählerin anhand der Krötengeschichte, wie weit außerhalb der Gesellschaft Christa T. steht. Einer ihrer Schüler, Hammurabi genannt, beißt, wegen einer Wette, bei einem Schulausflug einer Kröte den Kopf ab. Christa T. ist ungemein betroffen von dem Vorfall, sieht sich wieder mit den brutalen, gefühlskalten Mitmenschen ihrer Jugend konfrontiert. "Fleißig und roh ist er.... Er hat nur Glück, daß er hier lebt. Anderswo wäre er - sonstwas. Sein Typ ist noch gefragt."(NT 111) Verständnis für ihre Betroffenheit findet sie auch nicht bei Kollegen. Diese wundern sich nur über ihre emotionale Reaktion und verurteilen sie wegen Mangel an korrektem Verhalten.

Christa T. stellt fest, daß sie die Rolle, die sie sich bis jetzt selbst geschrieben hat, nicht spielen kann. Sie wollte aktiv an der Entwicklung der jungen, neuen Gesellschaft teilnehmen, erkennt jedoch, daß sie nicht die richtigen Voraussetzungen mitbringt. So schreibt sie sich eine andere Rolle, die der Ehefrau und Mutter, zu, "sie nimmt den Vorteil wahr, eine Frau zu sein."(NT 122) In Kapitel vierzehn, als Sechsundzwanzigjährige, "schuf" sie "sich noch mal neu, von Grund auf, für Justus."(NT 123) Stephan bezeichnet es als 
einen letzten Versuch..., ihrem Leben einen privaten und öffentlichen Sinn zu geben. Ein Familien- und Landleben also als Alternative zu den überspannten Ansprüchen der Anfangs- und Lehrjahre: der Versuch, sich nach der Sturm- und Drangzeit der Aufbauperiode mit der 'Ankunft im Alltag' der DDR-Gesellschaft abzufinden. ${ }^{130}$

Und wieder scheitert sie, kann sich keine passende Aufgabe auf den Leib schneidern. Auch ihrem Mann ist es nicht möglich später zu erklären, "in welchem Sinn Christa T. sich immer für unzureichend, in welchem anderen dagegen sie sich für zureichend hielt, vielleicht sogar für überlegen."(NT 137) Doch für die Erzählerin, ihre Freundin, ist soviel sicher: "Niemals kann man durch das, was man tut, so müde werden wie durch das, was man nicht tut oder nicht tun kann. Das war ihr Fall. Das war ihre Schwäche und ihre geheime Überlegenheit." (NT 138)

Christa $T$. versucht ihrem Leben wieder etwas zu geben, was sie vermißte. Vielleicht fühlt sie sich unwohl in der Frauen- und Mutterrolle, zu der sie sich verpflichtet hat und der sie nicht so leicht entweichen kann, wie das früher bei ihren anderen Rollen möglich war. Sie hat eine Affäre mit einem Jäger und bringt dadurch ihre Ehe in Gefahr. Sie gesteht ihrer Freundin, "daß sie sich nicht mehr zu helfen wisse." (NT 154) Sie ist nicht nur ihrem Mann und ihren Freunden, sondern auch sich selbst fremd geworden. (NT155) Ende 1962 besuchen die Erzählerin, andere Bekannte und ihr ehemaliger Freund und Studienkollege Günter Christa T. In Gesprächen zu Silvester über die Rolle und Aufgabe des Schriftstellers und die Macht des Schreibens äußert sich Christa T. "Da haben wir sie, Christa T., von ihren Schwierigkeiten reden hören, ein einziges Mal." (NT

166) Endlich, so glaubt die Erzählerin, versteht sie Christa T. .

Ihr Geheimnis, auf das ich aus war, seit wir uns kannten, war gar kein Geheimnis mehr. Was sie im Innersten wollte, wovon sie träumte und was zu tun sie seit langem begonnen hatte, lag offen vor mir, unbestreitbar und unbezweifelbar. Jetzt schien mir, wir hätten es immer gewußt. Sie hatte es ja nicht besonders ängstlich behütet, nur eben nicht aufgedrängt. Ihr langes Zögern, ihre Versuche in verschiedenen Lebensformen, ihr Dilettieren auf manchem Gebiet deuten in dieselbe Richtung, wenn man nur Augen hatte 
zu sehen. Daß sie ausprobierte, was möglich war, bis ihr nichts mehr übrigblieb - das wäre wohl zu verstehen. (NT 168)

Doch sie hat keine Zeit mehr, ihre Depressionen, die sich durch ständige Müdigkeit bemerkbar gemacht hatten, zu bekämpfen. Durch den Entwurf ihres Hauses und den Hausbau, das Sammeln von Geschichten aus der Umgebung die sie zu Papier bringen wollte, hatte sie ihre Selbstentfremdung bekämpfen wollen, hatte sie begonnen, sich einen Weg zur psychischen Heilung zu bahnen. Sie erkrankt an Leukämie, kann ihre dritte Tochter noch gesund zur Welt bringen, und stirbt kurze Zeit später, im Februar 1963. Silberman beschreibt Christa T.s raison d'etre:

Sie ist die Figur, die in ihrem Leben, in ihrer Ehe, in ihren fragmentarisch gebliebenen dichterischen Schriften und in ihrer Examensarbeit über Theodor Storm am bewußtesten fragt, ob überhaupt und unter welchen Umständen es dem einzelnen möglich ist, sich in ihrer Gesellschaft als Individuum und als Mitglieder einer Gemeinschaft zu entwickeln. ${ }^{131}$

"Schreib doch, Krischan. Warum schreibst du nicht?" (NT 169) Mit dieser Frage hatte die Erzählerin Christa T. am Ende noch einmal ermutigen wollen, endlich den Schritt zu gehen, zu dem sie schon so lange angesetzt hatte. Und beinahe hätte sie es geschafft, ihre Suche nach sich selbst zu beenden, ihre Frage nach der Aufgabe in dieser Welt zu beantworten. Christa T.s Schreibversuche ziehen sich leitmotivartig durch den ganzen Roman. Schon als zehnjähriges Mädchen hatte sie geschrieben: "Ich möchte gerne dichten und liebe auch Geschichten." (NT 22) In der geschriebenen Sprache glaubt sie, sich gegen die Welt abschirmen zu können. "Dichten, dicht machen, die Sprache hilft." (NT 23) Je mehr sie jedoch über Sprache lernt und lehrt, sie studiert Germanistik und lehrt Deutsch, desto gespannter ist ihr Verhältnis zur von ihr geschriebenen Sprache. Den Trost, den sie einmal darin zu finden hoffte, scheint ihr erst kurz vor Lebensende gespendet zu werden. Da verfaßt sie ein Gedicht. "Endlich! schreibt sie an den Rand, und das heißt soviel wie: Jetzt stirbt man nicht."(NT 108) Zeit ihres Lebens brachte sie nichts 
auf Papier, was sie für wertvoll oder wichtig genug hielt von anderen gelesen zu werden.

Mit Hilfe von Tagebucheintragungen und Notizen, die sie dann später auf lose Zettel aller Art schreibt, hilft sie sich jedoch, "über die Dinge zu kommen." (NT 39) Und doch macht sie sich auch das zum Vorwurf, daß sie es nicht anders schafft, daß sie auf das geschriebene Wort zurückgreifen muß, um sich helfen zu können. Sie hat Angst, "...einem selbst könnte zustoßen, was gang und gäbe war: spurlos zu verschwinden." (NT 38) Veröffentlichen will sie aber keine ihrer Gedichte oder Erzählungen, da ihre Selbstzweifel zu groß sind. "Schreiben ist groß machen," (NT 167) glaubt die Erzählerin sie einmal sagen gehört zu haben. Doch gewiß meinte sie nicht nur den Schriftsteller, der sich damit groß macht, wie etwa Blasing, ein Bekannter von ihr. Gemeint war auch das Geschriebene selbst, dem, sobald man es aufs Papier bringt, eine Bedeutung gegeben wird, die nicht verdient sein könnte.

Sie hatte Angst vor den ungenauen, unzutreffenden Wörtern. Sie wußte, daß sie Unheil anrichten, das schleichende Unheil des Vorbeilebens, das sie fast mehr fürchtete als die großen Katastrophen. Sie hielt das Leben für verletzbar durch Worte.(NT 169)

Darum verstummt sie auch jahrelang, schreibt immer weniger als sie Frau und Mutter ist. Dann beginnt sie die "wahren" Erlebnisse ihrer Mitmenschen zu sammeln, das, was nicht erfunden zu sein schien, sondern in dem sich die von ihr so lang gesuchte Wahrheit verbarg. "Die Einsicht, daß das Leben durch große Wort verletzbar sei,"...bringt sie "endgültig dazu, die großen Entwürfe, den unmäßigen Anspruch auf die unmittelbare Konkretisierung der offiziellen und privaten Utopien aufzugeben. ${ }^{.132}$ Denn Tatsachen brauchte sie, realistisch wollte sie sein. "Tatsachen! An Tatsachen halten. Und darunter stand in einer Klammer: Aber was sind Tatsachen?" (NT 170) Da sie auch diese Frage nicht beantworten kann, gibt sie den neuen Schreibversuch wieder auf. Laut Stephan findet sie nie das in der Kunst, in ihren "schriftstellerischen Versuchen" was sie suchte, 
ein "Mittel zur Selbstverteidigung, zur Ich-Findung und zur Klärung der unauflösbar scheinenden Lebenswidersprüche." 133

\section{NACHDENKEN ÜBER ES GEHT SEINEN GANG}

Das zweite Werk, mit dem sich diese These befaßt, ist ein Roman ganz anderer stilistischer Art, nämlich Erich Loests Es geht seinen Gang oder Mühen in unserer Ebene. Auch er setzt sich mit Problemen und Zügen der jüngeren DDR-Generation auseinander, jedoch in einem Stil, der sich von Christa Wolfs 'Nachdenken', Christa T.s Suche nach sich selbst, unterscheidet. Loests Held sucht nicht nach einer Möglichkeit als sensibles Individuum, wie Christa T., als Teil der DDR-Gesellschaft an deren Entwicklung teilzunehmen. Seine sehr ironische Darstellung der teilweise äußerst spießigen DDRBürger erlaubt einen Einblick in den DDR-Alltag der siebziger Jahre.

Günter Gaus, Leiter der Ständigen Vertretung der Bundesrepublik in der DDR, schickte Diplomatenkollegen in aller Welt, die ihn nach seinem Wirkungsbereich fragten, dieses Buch; aus ihm...könnten sie die DDR erkennen wie aus keinem noch so genauen Bericht. ${ }^{134}$

Wolfgang Wülff ist Ingenieur in Leipzig. Er ist der 'Held' in Loests Buch Es geht seinen Gang oder Mühen in unserer Ebene, obwohl er kein Held im Sinne des Sozialismus ist. Wülff, Mitte zwanzig, mit Jutta verheiratet, ist Vater einer noch nicht schulpflichtigen Tochter, Bianca, lebt mit seiner Familie in einem Neubaugebiet und besitzt, was viele Mitbürger in seinem Alter nicht zu ihrem Eigentum zählen können, ein Auto, eine Schrankwand, eine Couch, einen Fernseher mit dem er Westfernsehen empfangen kann. Er ist ein Durchschnittsbürger, lebt in bürgerlichen Verhältnissen in der DDR. Er ist ein Bourgeois, wie man ihn auf beiden Seiten der deutsch-deutschen Grenze

133 ebda 76.

${ }^{134}$ Erich Loest, Der Vierte Zensor. Vom Entstehen und Sterben eines Romans in der DDR (Köln: Edition Deutschland Archiv im Verlag Wissenschaft und Politik, 1984) 76. 
finden könnte, "...ein Mann wie viele: Ein brauchbarer Ingenieur, ohne brennenden Ehrgeiz, zufrieden, wenn es ihm ordentlich geht." 135 Mit diesen Worten beschreibt Loest seinen Wolfgang Wülff. Wolfgang will ein Durchschnittsbürger sein, kein Aufsteiger. Er will sein kleines Glück im trauten Heim genießen. Jutta hingegen hat anderes für ihn geplant. Ihr liegt sehr viel daran, daß ihr Mann sich weiterbildet, und dadurch in ihrem und dem Ansehen anderer steigt und sich dann in der Gesellschaftsschicht befindet, aus der sie selbst stammt. Wolfgang ist der Sohn einer Fabrikarbeiterin, deren Mann sich in die Bundesrepublik absetzte, als ihr Sohn noch klein war. Jutta stammt aus einer Familie mit Besitz und Geld. Sie brachte 43,576 Mark und 56 Pfennig mit in die Ehe. Ihr Bruder ist Arzt, ihr Vater war vor dem Krieg ein Geschäftsmann. Sie möchte in gehobeneren Kreisen verkehren und einen Mann haben, der in diesen Kreises akzeptiert würde. Das wäre der Fall, wenn Wülff sich durch ein Fernstudium zum Diplomingenieur weiterbilden würde, wenn er der oberen Schicht beweisen würde, daß er, trotz proletarischer Herkunft, aufzusteigen vermag. Doch Wolfgang Wülff hat absolut kein Interesse daran. Ihn zieht es nicht nach vorn, er meint "...es sei besser, im zweiten oder dritten Glied zu stehen, als im ersten Glied aufzufallen." ${ }^{136}$ Loest weist möglicherweise mit dieser Metapher auf den Militarismus in der deutschen Gesellschaft hin, ein überhistorisches Phänomen, daß sich in der neuen Gesellschaft fortsetzt.

Wiederholt erinnert Wülff sich an einen Vorfall, der einen starken Einfluß auf die Entwicklung seines Charakters hatte. Als Gegenargument führt er diesen wiederholt an, wenn Jutta von seinem Desinteresse enttäuscht ist. Wie viele seiner Freunde in den Jugendjahren war er von den Beatles und Beatmusik begeistert gewesen. Entgegen den Warnungen seiner Lehrer fand er sich eines Tages zu einer Protestversammlung auf dem 
Leipziger Leuschnerplatz ein. Während der Sympathiekundgebung für die DDR-

Beatgruppe Old Kings, die in eine regelrechte Schlacht ausartete, wurde er wütend. Was ihn zuerst zum Lachen bewegt hatte, die Lautsprecherwagen, Wasserwerfer, LKWs und Jeeps der Polizei, verwandelte sich schnell in Macht, die Macht, die ihm das Gefühl gab, er sei auf einmal ein Staatsfeind. Das Lachen und die danach verspürte Demütigung schlug in Wut um, Wut auf die Polizei, deren Hunde, den Staat. Er verstand auf einmal, wie er diese Gegenaktion zu interpretieren hatte: "Wer nicht für uns ist, ist gegen uns; es gibt keinen dritten Weg." 137 Die harmlose Kundgebung, die sich laut Wolfgang aus Langeweile nach einer Stunde wieder verlaufen hätte, wäre die Polizei nicht derart agressiv eingesetzt worden, wurde am kommenden Morgen von seinem Lehrer namens Bauerheld als eine "konterrevolutionäre Ansammlung" mit "Rädelsführern" bezeichnet. Schlagringe habe man gefunden, und eventuell sogar Pistolen. Während Bauerheld nach Teilnehmern unter den Schülern sucht, sitzt Wolf unruhig auf seinem Stuhl, nicht nur, weil er fürchtet ertappt zu werden, sondern weil er Schmerzen hat. Ein Polizeihund hatte ihm in das Gesäß gebissen. "Ich haßte dieses Hundevieh und hatte die Gesichter der Polizisten nicht vergessen, aufgeheizt und rot und wütend."(EG 22) In Wolfgang war eine Veränderung vor sich gegangen, die auf seine Lebensphilosophie einen bedeutenden Einfluß hatte. Wülff beteuert:

Einmal, hab ich mir vorgenommen, rächst du dich. Vor der Schlacht auf dem Leuschnerplatz war für mich die Welt sauber eingeteilt. Der Feind stand im Westen; die Amerikaner bombardierten Vietnam, Kiesinger war ein Faschist. Nun biß mich einer unserer Hunde, der eigentlich einen Ami hätte beißen sollen, der Bomben auf Vietnam ausklinkte. Ich schmiß kein Napalm, nach mir hatte gefälligst kein DDR-Hund zu schnappen. Also Rache. Wie? (EG 23)

Seine Rache beginnt zwei Jahre später vor der Musterungskommission, die ihm eine Karriere bei der Armee schmackhaft machen will. Offizier könne er dort werden, das

${ }^{137}$ Erich Loest, Es geht seinen Gang oder Mühen in unserer Ebene (München: dtv, 1978; im folgenden zitiert mit dem Kürzel EG und den entsprechenden Scitenzahlen) 21. 
wird ihm angeboten. Wolfgang erkundigt sich, wie lange es dauern würde, General zu werden. Die Kommissionsmitglieder amüsieren sich darüber.

Da wurden in meinem Gehirnklappenschrank computerflink Verbindungen geschaltet: der General, der auf dem Leuschnerplatz gesiegt hatte, der Offizier, der seiner Hundestaffel den Befehl geben durfte oder mußte, die Beißkörbe abzunehmen, da war es auf einmal, als ob zwischen ihnen und mir der Strahl des Wasserwerfers rauschte. Sie boten mir Macht, und ich wollte diese Macht nicht haben. (EG 24)

Wolfgang will sich rächen, indem er ihr Machtangebot ablehnt. Aber nicht nur rächen will er sich, sondern einer Furcht ist er sich bewußt geworden, der Furcht "...jemals jemandem befehlen zu müssen, Beißkörbe abzunehmen. (EG 24) Zum erstenmal scheint er sein Problem zu begreifen, an dem er auch als Sechsundzwanzigjähriger noch zu arbeiten hat. Er hat Angst sich mit den Mächtigen zu solidarisieren, hat Angst vor der Verantwortung mächtig zu sein. Anna Seghers hatte Ende der vierziger Jahre den Helden ihres Romans Die Toten bleiben jung das Problem der Macht, und der eng damit verbundenen Angst, erläutern lassen: "Mit Angst hat es vor zehn Jahren angefangen: mit Angst hört es auf. Aus Angst wird befohlen, aus Angst wird gehorcht." 138 Anstatt Berufssoldat zu werden, absolviert Wülff seine Pflichtzeit bei der Volksarmee, wo ihm ein Macht ausübender Vorgesetzter sechs Stunden vor Ende der Wehrzeit noch einmal das Haareschneiden verordnet, wird Werkzeugmacher und hält sich anfangs unter der Gruppe Menschen auf, die er von zuhause aus gewöhnt ist, die Arbeiter. Er "fand es männlich und möglich, jedwede Meinungsverschiedenheit bei einem Bier zu lösen.... Ich glaubte, mit einem Schluck unter Männern ließe sich aller Ärger aus der Welt schaffen." (EG 24)

An Kapitel eins anschließend eröffnet sich in neun weiteren Kapiteln das Ende der Wülffschen Ehe. Rückblickend vollzieht der Ich-Erzähler Wülff das Brüchigwerden seiner Beziehung zu Frau und Freunden. Anhand von Begebenheiten, die den endgültigen

${ }^{138}$ Silberman, 497. Zitiert aus Anna Scghers, Die Toten bleiben iung (Berlin/Frankfurt a.M., 1949): .604 
Bruch zwischen ihm und seiner Frau, und dadurch mit deren Lebenszielen, herbeiführen, illustriert der Erzähler seine Enttäuschung über den Staat und die Gesellschaft und seine Rebellion gegen den von ihm verspürten Leistungsdruck. ${ }^{139}$ Der Leistungsdruck in der BRD-Gesellschaft ist ein Thema der Kritik aus DDR-Kreisen, eines der Übel der kapitalistischen Klassengesellschaft. Wülff wird diesem Druck auch in der DDR unterworfen, womit Loest wiederum auf die bürgerliche Tugend hinweist, die in der DDR aufrecht erhalten wird.

'Wölfchen, Wolfi, Wolf', 'Partytime', 'Nicht aus der Hüfte raus', 'Das Waschen des älteren Säuglings', 'Ein Leipziger im Arzgebirge', 'Ich sagte: »Sie verdammter Faschist! «', 'Es gibt keine Maikäfer mehr', 'Mein Albatros', 'Ach Jutta, ach Brischidd!' und 'Schrankwand', so lauten die Titel der zehn Kapitel, in denen Loest immer wieder den 'kleinbürgerlichen Spießer' Wolfgang erläutern läßt, warum er nicht als aktives Glied dem real existierenden Sozialismus zum Erfolg verhilft oder verhelfen kann.

Anfangs versucht Wolfgang, dem Druck seiner Frau auszuweichen. Er schiebt das Einreichen der für die Weiterbildung nötigen Formulare vor sich her, findet immer wieder Ausreden dafür, traut sich jedoch nicht, seiner Frau zu unterbreiten, daß ihre Ziele tatsächlich nicht die seinigen sind. Andeutungen machen beide, zu einer offenen Aussprache kommt es aber nicht. Klärende Gespräche scheinen die Ehepartner nie während der Ehe zu führen. Als Wolfgang sich endlich durch eine Notlüge aus der Klemme helfen will, diese aber bald von Jutta aufgedeckt wird, wird der Ehezwist offensichtlich. Während Biancas Schwimmstunde entsteht der endgültige Bruch. Wülff bezeichnet den Vater eines kleinen Jungen als Faschisten, nachdem dieser den verängstigten Sohn zwingt, einen Kopfsprung zu machen. Mit dem Sohn, einem Versager in den Augen des Vaters, kann sich Wülff identifizieren. Da Wolfgang nicht gewillt ist,

${ }^{139}$ Leitmotivartig für den Zcrfall der Ehc sind dic Schlafzimmerszenen des Ehepaars Wülffs. Anfängliches Interesse an Geschlechtsverkchr cndet nach fortlaufender Erkühlung des Sextriebes in Einstellung der sexuellen Beziehung. 
sich für diese Beleidigung eines "vorbildlichen Bürgers der DDR"140 zu entschuldigen, wird er von einem Gericht zu einer geringen Geldstrafe verurteilt. Loest verdeutlicht in seiner Beschreibung des Richters die Differenziertheit der Mächtigen in der DDR. Jedoch entwickelt er diese Person nicht, sodaß er, einem Trostpreis ähnlich, dem Leser angeboten wird.

Weitaus folgenschwerere Konsequenzen hat diese Episode aber für die Familie Wülff. Die Eheleute trennen sich, Wolfgang zieht zu seiner Mutter, die Scheidung wird eingereicht und Wolfgang und Jutta gehen getrennt ihren Zielen entgegen. Jutta lernt einen Röntgenarzt kennen, einen Bekannten ihres Bruders, der ihr zum erwünschten gesellschaftlichen Aufstieg verhelfen kann. Wolfgang freundet sich mit einer Postangestellten an, einer alleinstehenden Mutter mit unehelichem Sohn. Wülff ist zufrieden mit sich und der Tatsache, daß er nun nichts mehr vorzutäuschen braucht. Vielleicht ist er ein 'Spießer', ist 'faul', ein 'Frührentner'. So ist er zumindest von Bekannten und Verwandten tituliert worden. Er gibt sich endgültig zufrieden und erläutert dies seinem Freund Huppel mit den Worten:

So war mein letztes Jahr, aufregend und klärend und bitter und fröhlich und unwiederholbar, und wie du auch immer darüber und über mich in dieser Zeit urteilst, eins steht fest: Keiner kann kommen und behaupten, es wäre anders gewesen.(EG 222)

Wülff hat sich emanzipiert, hat für sich selbst einen Weg durchs Leben entdeckt, den er selbstbewußt und zufrieden schreiten kann. Er hat der Bevormundung durch andere ein Ende gesetzt und weiß sich selbst zu entscheiden.

Erich Loests Anti-Held Wolfgang Wülff bewegt sich in Es geht seinen Gang oder Mühne in unserer Ebene zwischen Spießigkeit und seiner Abkehr von der Gesellschaft und deren Forderungen. In seinem zum Teil in einem sehr ironischen aber trotzdem leichten Ton verfaßten Buch befaßt sich Loest mit der im DDR-Staat aufgewachsenen 
und dort erzogenen Nachkriegsgeneration. Wülff lebt in Leipzig, Loests Heimatstadt. Er kennt diese Stadt, das Milieu, die Leute, denen er 'auf's Maul geschaut hat'. Wird über den Roman geschrieben so wird die Sprache oft liebevoll als 'schnodderig' bezeichnet. Wülff, der Erzähler, scheint wirklich nur zu erzählen. Der Autor 'verfaßt' keinen Roman, sondern läßt seinen Helden scheinbar ungelenkt losreden, als erzähle er seine Geschichte einem anderen aus seinem Milieu. Die Prämisse ist, daß er seinem Freund und Kollegen, der Vaterfigur Huppel, zu erklären versucht, wie ihn die vergangenen Jahre geformt haben. Er möchte, daß Huppel ihn und seine Denk- und Handlungsweise begreifen kann, denn Huppel ist Wülff ein Vorbild. Er ist ein sozialistischer Held, ein alter Kommunist, Mitglied der Partei, ein DDR-Bürger, der 'im ersten Glied' steht. Er hat die verschiedenen Phasen des Aufbaus der DDR mitgemacht, war auf der Arbeiter- und Bauernfakultät und hat studiert, um Schriftsteller zu werden, versuchte sich als Autor eines Theaterstückes, wie so viele Arbeiter während des Bitterfelder Weges, und glaubt an seine Aufgabe als Sozialist. Gerade von ihm erhofft Wolfgang Verständnis, denn dieser überzeugte Sozialist scheint für ihn und sein Selbstverständnis eine große Rolle zu spielen. Auch Huppel übt wiederholt sehr scharfe Kritik an der damaligen und heutigen DDR-Gesellschaft, kann sich jedoch nicht von seiner politischen Überzeugung freisprechen. In ihm verkörpert sich möglicherweise auch eine Seite Loests, der Kommunist ist, aber auch mit offenen Augen die Mühen seiner Gesellschaft erkennt. Doch wird Wülff am Ende auch ohne Huppels Zustimmung weiterleben, auch wenn er nicht den erwarteten 'sozialistischen Gang' gegangen ist.

Huppel, alter Huppel, alles war anders zu deiner Zeit, du mußt das nicht betonen. Natürlich habt ihr keine kalten Platten aufgetafelt und keinen Hemus getrunken, aber habt ihr euch vielleicht nach Fleisch und Wein gesehnt ? Habt ihr dafür gekämpft, oder wofür? Und warum beschimpfst du mich, daß ich zufrieden bin, ist nicht Zufriedenheit das beste überhaupt? Ich mache meine Arbeit - ach, lassen wir das, guter Huppel, wenn du mich bis jetzt nicht begriffen hast, nutzen alle Worte nichts mehr. (EG 222) 
Wolfgang Wülff ist Jahrgang 49, wurde also im Gründungsjahr der DDR geboren, und 'klärt' für sich im Jahr des 30. Jubiläums, daß seine Rache an dem Staat aus seinem Rückzug in die hinterern Ränge besteht. Er hat als Staatsbürger dem Staat gegenüber seine Pflichten erfüllt, war bei der FDJ, beim Militär, setzt sich als Erwachsener in seinem Betrieb ein, genießt seine Arbeit sogar ab und zu, wenn es ihm gestattet ist kreativ zu sein, ist ein aktives, produktives Mitglied seiner Gesellschaft von morgens bis abends. In seiner Freizeit jedoch genießt er es, mit Bekannten aus der alten Nachbarschaft ein Bier zu trinken und über Fußball zu sprechen, verhält sich direkt 'kleinbürgerlich'. Er geht seinen Pflichten seiner Mutter gegenüber nach, wenn auch nicht übereifrig, fragt nie nach seinem Vater in der Bundesrepublik, denkt kaum darüber nach wie sein Leben ausgefallen wäre, wäre seine Mutter ihrem Mann in den Westen gefolgt. Wülff will sein Leben nicht komplizierter machen als es ist, voller Fragen, die er sich doch nicht zufriedenstellend beantworten könnte.

Freude bringt ihm der routinemäßige Spaziergang am Samstagmorgen mit seiner Tochter Bianca, fünf Lieder, die er auf der Zither spielen kann, hier und da ein Flirt mit einer Frau, ein begutachtender Blick auf weibliche Rundungen und gut geformte Beine, ein paar Flaschen Bier oder einige Gläser Hemus mit Freunden, Westfernsehen, Schachspielen, regelmäßiger Geschlechtsverkehr mit seiner Frau.

'Es geht eben alles seinen Gang'141, war "eine Redewendung, die Anfang der siebziger Jahre aufkam". ${ }^{142}$ Loest erläutert dies in einem "Hinweis für räumlich und

141 Ahrends, 72: Gang gehen: daß eine Angelegenheit ihren Gang gehe, meinte wohl ursprünglich, daß man ihrem Gang durch die Behörden zuversichtlich entgegenblicken könne. Die Wendung "Das geht seinen Gang « fand in der Umgangssprache weite Verbreitung als Bestätigung eines Auftrages etwa im Sinne von »wird gemacht«, »wird erledigt«, »geht in Ordnung«. Eine deutlich ironische Färbung hat die Formel "Das geht seinen sozialistischen Gang", die entweder Vorgänge bezeichnet, die auf spezifisch realsozialistische Weise schiefgehen oder die gängige Selbsthilfe auf Staatskosten.

${ }^{142}$ Schmitt, 327. 
zeitlich Entfernte," 143 den er seinem Buch voranschickt. Der Untertitel Mühen in unserer Ebene bezieht sich auf Brecht, der auf die Mühen der Gebirge die Mühen der Ebene folgen sah. In diesen 'Mühen der Ebene' scheint sich der nun dreißig Jahre alte DDR-Staat zu befinden, und Loest, durch Wülff, erzählt, wie es wirklich ist, nicht wie der Staat es vorgibt. Wülff erwartet nicht viel Aufregendes vom Leben. Er weiß, daß die Einflußreichen, die entweder Macht, Geld, oder beides besitzen, die ausschlaggebenden Kräfte in seinem Staat sind. Die Machtlosen führen deren Anordnungen aus, arbeiten angeblich für das Gemeingut, sind sich jedoch fortwährend ihrer Ohnmacht bewußt. Seien es die Ingenieure, bei denen Loest hospitierte, die die sorgfältig ausgearbeiteten Pläne für ein Projekt in den Papierkorb werfen müssen, da es ihnen so befohlen wird, oder seinen es die Leute, die von der Redewendung gebrauch machen, sie nehmen es nicht zu ernst, verzagen nicht darüber.

Es geht seinen Gang sagten die Leute, wenn sie ausdrücken wollten, daß es bei der Besorgung eines Autoreifens, eines Sacks Zement, eines Kastens guten Bieres und eines Klempners zwar nicht kalkulierbare Schwierigkeiten geben werde, aber irgendwie werde man es schon hinkriegen. Er vermutete, in diesem Satz liege auch die Hoffnung, man werde sich trotz aller Last und Mühe zu einem erträglichen Sozialismus durchwursteln. L. wollte Heiterkeit und Kraft, Gelassenheit und Findigkeit heraushören und fand den Satz sächsisch, nicht preußisch, beileibe nicht stolz." 144

Beispielhaft, für das von offizieller Seite vertretene paradiesische Weltbild, dem Staat auf dem Weg zur idealen Gesellschaftsform, ist ein Bildband, den die Partei Huppel als Auszeichnung überreichte . Darin befinden sich Fotos, die den DDR-Alltag übertrieben glücklich und zufrieden, und dadurch unglaubwürdig darstellen. Es gibt viele "Versager" wie Wolfgang, die wie er "...nicht in der gesellschaftlich vorgegebenen

${ }^{143}$ Dort heißt es: in der anfangs der siebziger Jahre in der DDR verbreiteten Redewendung »Es geht seinen Gang« lagen gleichermaßen die Gewißheit geschichtlichen Fortschritts wie die Kapitulation vor der Robustheit des Schlendrians. 
Rollenzuweisung" aufgehen. Sie "verweigern sich der Aufstiegs- und LeistungsIdentität". 145 "Machtverweigerung" betreiben diese "mittleren Helden". ${ }^{146}$

Die Beschreibung eines Lebensabschnittes von Wolfgang Wülff dient Loest dazu, mit dessen vermeintlichem beruflichen und politischen $>$ Versagen< die DDR-Gesellschaft so zu zeigen, wie sie heute nach Auffassung des Autors weitgehend im Alltag ist: spießig und muffig, leistungsorientiert und unsolidarisch, autoritär und selbstgerecht. ${ }^{147}$

Doch frage ich mich, ob diese Machtverweigerung als schädlich empfunden werden soll, oder eher als menschlicher Zug in einer oft allzu unmenschlichen Zeit, die nicht auf die DDR begrenzt ist.

145 Blumensath, 64 .

146 ebda 65.

147 ebda 65. 


\section{KAPITEL IV}

\section{"DER VIERTE ZENSOR": DARSTELLUNG DER REZEPTION}

\section{AUCH EIN LINIENTREUER AUTOR BRAUCHT GELD}

Aufgabe dieser These ist die Analyse gewisser Aspekte der Literaturproduktion in der DDR und des Einflusses, den die Zensur auf diesen Prozess hat. Nachdem die gesetzlichen, ideologischen, und bedingt auch die gesellschaftlichen Voraussetzungen betrachtet wurden, soll die ökonomische Seite analysiert werden. Dieser Analyse wurde eine gezielte Nacherzählung beider Werke vorausgestellt, da diese zum Verständnis der Angriffspunkte der Zensoren notwendig ist. Wie in Kapitel fünf dieser Arbeit gezeigt wird, liefern die oben besprochenen Protagonisten und deren Handeln und Gedanken die Hauptangriffspunkte für die Zensoren. Wolf und Loest hatten in ihren Werken, größtenteils durch die Darstellung ihrer Helden, gewagt, was sich viele DDR-Autoren noch nicht zugemutet hatten. Inwieweit darauf seitens der Zensur eingegangen wurde, wie sich demnach die Reaktion darauf seitens der Literaturinstanzen, Rezensenten und des Publikums bemerkbar machte, ist ein Ziel dieser These.

Die ökonomische Lage eines DDR-Autoren wird von verschiedenen Kriterien beeinflußt, wovon das wichtigste ist, die Möglichkeit Bücher zu veröffentlichen. Gesetzlich festgelegt sind finanzielle und gesellschaftliche Privilegien, die KöhlerHausmann als eine "...Form von sozialer Bestechung..." bezeichnet. ${ }^{148}$ Die Schriftsteller genießen teilweise einen Status, der staatlich nicht klar definiert ist, der jedoch 
gesellschaftlich hoch und respektabel ist, solange sie politisch nicht in Ungnade gefallen sind. Erläutert Hausmann:

Die Art der gesellschaftlichen Einbindung des Intellektuellenstatus beruht auf einer unklaren Standortsbestimmung zwischen der Klasse der Arbeiter und Angestellten einerseits und den Genossenschaftsbauern und handwerkern andererseits, sowie der kleinen Schicht der Selbständigen. ${ }^{149}$

Der Zutritt zum Schriftstellerberuf wird in einer Weise geregelt, die uns fast unvorstellbar ist. Um als Schriftsteller tätig zu sein, bedarf der "freischaffende" Autor einer Berufserlaubnis, die er in Form einer Zulassungsnummer erhält. Auch benötigt er eine Steuernummer. Falls sich ein Autor straflich macht und/oder seiner Mitgliedschaft in einem Verband behoben wird, wird ihm die Berufserlaubnis entzogen, wodurch er arbeitslos wird. Anspruch auf Arbeitslosenunterstützung kann er jedoch nicht erheben. Weiterhin spielt die Mitgliedschaft im Schriftstellerverband eine bedeutende Rolle, obwohl ein Autor auch veröffentlichen kann, ohne Mitglied im Verband zu sein. Laut Günter Görlich, dem Vorsitzenden der Berliner Bezirksorganisation im Schriftstellerverband der DDR, ist "die übliche Entwicklung...sogar die, daß ein Autor zunächst ein Buch oder mehrere macht, ehe er in den Verband aufgenommen wird." 150 Das Ziel dieses Verbandes ist die ideologische Ausrichtung, die dann immerhin durch soziale und wirtschaftliche Vorteile attraktiver gestaltet werden kann. Für die soziale Absicherung seiner Mitglieder sorgt der Verband, indem er unter anderem zinslose Kredite für Hausbau oder Renovierung gibt, Ferienbetreuung und Kurbetrieb anbietet, Stipendien an junge Autoren verteilt, bei Reiseerleichterungen und Autokauf behilflich ist und eine Rentenversicherung anbietet. Renate Feyl, eine Schriftstellerin und Mutter, verheiratet mit einem Schriftsteller, der kein Verbandsmitglied ist, zahlt zum Beispiel M 2400 jährlich für ihre

149 ebda, 129.

${ }^{150}$ Günter Gorrlich, "15\% Produktionssteigerung und immer noch zu wenig Bücher," Kürbiskern 2 (1977): 157. 
Rentenversicherung, um später im Rentenalter von 60 Jahren eine Monatsrente von M1 100 zu erhalten. Diese Rentenregelung gilt nur für den Schriftstellerverband und nicht für andere Künstlerverbände. ${ }^{151}$ Hilfe bei der Genehmigung für Auslandsreisen ist von großem finanziellen Vorteil, da viele Autoren ihre Forschungen außerhalb ihrer Grenzen durchführen müssen, um Zugang zu wichtigen Materialien zu haben oder einfach Ideen zu sammeln. Diese liefern Stoff für ihre Bücher und infolgedessen ein Einkommen.

Die Partei ist der Meinung, eine gesunde finanzielle Basis müsse gegeben sein, um künstlerisch arbeiten zu können, und diese versucht der Staat zu garantieren. Da den Kulturschaffenden eine wichtige politische Funktion zugeteilt wird, fühlt sich der Staat darin gerechtfertigt, dieser Intellektuellenschicht Lebensbedingungen zu bieten und Freiheiten zuzugestehen, die vielen anderen DDR-Bürgern nicht gewährt sind. Selbstverständlich beschränkt sich dieses Recht auf Künstler, die politisch nicht in Ungnade gefallen sind, oder, falls dies einmal der Fall war, rehabilitiert wurden, was jedoch selten vorkommt. In einem Staat, der sich auf dem Weg zu einer klassenlosen Gesellschaft befindet, erscheint diese Behandlung der Intellektuellen philosophisch problematisch.

Versichert sind die Künstler mit den Ärzten in der FDGB-Versicherung, besteuert werden sie jedoch wie nach den Steuersätzen für Arbeiter und Angestellte. Sie zahlen somit keine Umsatzsteuer, ihr Einkommensteuer-Tarif ist reduziert. ${ }^{152}$ Bis zum 20. März jeden Jahres muß die Steuererklärung mit der Jahreserklärung für 'Einkünfte aus freiberuflicher Tätigkeit' ausgefüllt und eingereicht sein. Darin wird nach der Mitgliedschaft in einem Verband gefragt, nach der Bèrufserlaubnis und der Zulassung. " 'Erteilt durch' steht im Fragebogen der Jahreserklärung; daß schließt die Möglichkeit der Nichterteilung

${ }^{15} 1_{\text {Information erhalten als persönliche Frage an R. Feyl, übermittelt durch E. Stenzel }}$ ${ }^{152}$ Köhler-Hausmann, 120. 
automatisch ein", ${ }^{153}$ was laut Seyppel ein Mittel zur politischen Kontrolle der Kunst darstellt.

Ein Autor muß im Höchstfall zwanzig Prozent seines Bruttoverdienstes als Steuer zahlen. Der Verlag zieht dies vor der Überweisung direkt von seinem Honorar ab. Das Honorar erhält der Autor in zwei oder drei Raten, je nach vertraglicher Vereinbarung. 1015\% der Hälfte des Buchpreises, der im Durchschnitt bedeutend unter bundesrepublikanischen Preisen liegt, macht meist dieses Honorar aus. Falls in zwei Raten gezahlt wird, erhält der Autor die erste nach Abschluß des Vertrages. Sie ist abhängig von der Höhe der Auflage. Die zweite Rate wird nach dem Erscheinen gezahlt. Peter Kaeding, Schriftsteller und Ehemann der Schriftstellerin Renate Feyl, schrieb ein Buch über Knigge. Die erste Rate bei Abschluß des Vertrags betrug M 3000.

Als Erich Loest endlich seinen Vertrag für Es geht seinen Gang erhielt, den Vertrag, auf den er ein ganzes Jahr gewartet hatte, war darin festgehalten:

Das Werk soll folgenden Bedingungen entsprechen. Es wird die Geschichte des Ingenieurs Wolfgang Wülff in der Sprache unserer Tage erzählt. Dabei werden gesellschaftliche Zusammenhänge aufgedeckt, wie der einzelne die gebotenen Möglichkeiten wahrnimmt bzw. wie W. an keiner Weiterentwicklung interessiert ist."...Die Nebenrechte werden im Verhältnis 75 zu 25 zugunsten des Autors geteilt.... Verbreitung ab 1977 ... Die Auflagenhöhe: 12000 Exemplare... Das Honorar sollte 15\% vom Ladenpreis betragen, also den höchstmöglichen Satz. ${ }^{154}$

Eine versprochene zweite Auflage des Romans in einer Höhe von 22000 Exemplaren hätte ihm M 21120 gebracht, Netto.

Ähnlich beschreibt Seyppel den Vertrag für eines seiner Bücher. Der AufbauVerlag verpflichtete sich zu einem Honorar von $15 \%$.

Einnahmen aus der Vergabe von Drittrechten flossen zu fünfundsiebzig Prozent mir, zu fünfundzwanzig Prozent dem Verlag zu. Das Honorar wird

${ }^{153}$ Joachim Seyppel, Ich bin ein kapulter Typ. Bericht über Autoren in der DDR (Wiesbaden/München: Limes, 1982) 231.

${ }^{154}$ Erich Loest, Der Vierte Zensor. Vom Entstehen und Sterben eines Romans in der DDR. (Köln: Verlag Wissenschaft und Politik, 1984) 25. 
gezahlt wie folgt: erstes Drittel bei Vertragsabschluß, zweites Drittel bei Annahme des Manuskripts, letztes Drittel bei Erscheinen des Werkes »nach Maßgabe der Abrechnung « (die vierteljährlich erfolgt). ${ }^{155}$

Kündigungen des Vertrages sind, zumindest auf Papier, sowohl dem Autor als auch dem Verlag gestattet. Falls der Verlag " »wesentlichen Pflichten« nicht nachkommt oder wenn er »auf Änderungen besteht, die dem Verfasser nicht zumutbar sind «"156 kann der Autor kündigen. "Wenn »das Werk seine gesellschaftliche Wirksamkeit verloren hat " 157 ist dies dem Verlag erlaubt.

Nicht unbedingt jeder Schriftsteller arbeitet eng mit einem Verlag zusammen oder hat einen Vertrag, bevor er sein Werk schreibt oder beendet. Doch da das Verlagswesen nach 1945 in die zentrale Wirtschaftsplanung integriert wurde, kann er sich dem Einfluß der Partei nicht entziehen. Da es kein festes Monatseinkommen für Autoren gibt, sind diese nicht selten finanziell auf sich gestellt, besonders wenn sie keinem Verband oder keiner Organisation angehören, die ihnen mit Geldern unter die Arme greifen kann. Sie laufen Gefahr, Geschichten oder Bücher zu schreiben, die dann von Verlagen abgelehnt werden, da sie politisch zu umstritten sein könnten oder einfach von minderer Qualität sind. Es besteht auch die Gefahr, daß sie sich unkritisch mit Themen befassen, um ein gesichertes Einkommen zu haben. Einige Autoren verbinden das Schreiben literarisch anspruchsvoller Werke mit der Produktion unanfechtbarer Materialien.

\section{DER WIEVIELTE ZENSOR? DIE ROLLE DES VERLAGS}

Es stellt sich darum die Frage, auf welche Weise ein Verlag beurteilt, inwiefern er ein möglicherweise sozial- oder systemkritisches Werk veröffentlichen kann, soll oder darf. Diese soll weiter unten beantwortet werden, anhand Erich Loests Erfahrungen. Kein

155 Seyppel 232.

156 ebda 233.

157 ebda 233. 
Verlag möchte Gefahr laufen, dafür zur Rechenschaft gezogen zu werden, oder schlimmstenfalls ein Werk auf den Markt zu bringen, das sich nach seinem Erscheinen als kontrovers auszeichnet.

Ein Einblick in das Verlagswesen kann aufgrund verschiedener Publikationen vollzogen werden, die sich mit dem Thema DDR befassen und somit ein Bild des offiziellen Publikationsprozesses vermitteln. Wie sich jedoch das Verhalten gegenüber gewissen Autoren und deren Werken 'hinter den Kulissen' abspielt, welche Kriterien tatsächlich bei der Beurteilung eines Werkes angewandt werden, und wer nun tatsächlich in welcher Instanz Urteile fällt - das ist weitaus schwieriger zu belegen.

Führt man sich den Publikationsprozeß einmal vor Augen, so könnte man davon ausgehen, daß folgende Information einem angehenden Schriftsteller zu Verfügung steht. Die Erläuterungen anhand eines Beispiels beziehen sich auf Belletristik und nicht auf Fachliteratur. Ein Autor reicht ein Manuskript oder die Idee zu einem Buch beim Verlag ein. Laut DDR-Handbuch (1985) waren im Jahre 197978 Verlage an der Buchproduktion beteiligt ${ }^{158}$, wovon 60 'volkseigen' oder 'organisationseigen', d.h. im Besitz der Partei oder anderen Massenorganisationen, waren. Davon befaßten sich 22 mit Belletristik, Kinder- und Jugendliteratur. Zu diesen 22 gehören der Aufbau-Verlag, (Eigentum des Kulturbundes der DDR), der Hinstorff-Verlag, der Tribüne-Verlag, (Eigentum des Freien Deutschen Gewerkschaftsbundes), der Verlag Neues Leben, (Eigentum der FDJ [Freie Deutsche Jugend]), der Mitteldeutsche Verlag, der Verlag der Nation, (Eigentum der NDPD), Koehler und Amelang und Union Verlag, (Eigentum der CDU). Der AufbauVerlag ist mit circa 450 Titeln pro Jahr der größte, sich mit Belletristik befassende Verlag der DDR.

${ }^{158}$ Andere Quellen, wie etwa Emmerich, Köhlcr-Hausmann und Kulturpolitisches Wörterbuch geben andere Zahlen an, die aber nicht bedeutend vom DDR-Handbuch abweichen. 
Da dem DDR-Autor das DDR-Handbuch nicht zur Verfügung steht, macht er von anderen Quellen gebrauch. Er kann sich an die Verlage selbst wenden, Schriftstellerkollegen fragen, sich an den Schriftstellerverband richten oder an das Ministerium für Kultur. Dies ist wahrscheinlich nicht notwendig, da er wahrscheinlich schon als Jugendlicher mit seinem literarischen Talent aufgefallen war, oder auf sein Interesse am Schreiben aufmerksam gemacht hatte. Möglichkeiten gibt es genügend dafür, sei es in der FDJ, in der Schule oder im Betrieb. Vielleicht ist er Mitglied des »Zirkels schreibender Arbeiter«, oder er ist einem Mitglied des Schriftstellerverbandes aufgefallen, dem er in einer Arbeitsgemeinschaft Junger Autoren begegnete. ${ }^{159}$ Nachdem er Kontakt aufgenommen hat, reicht er sein Manuskript bei einem Verlag ein, der sich auf Belletristik oder Gegenwartsliteratur spezialisiert. Ein Lektor, und seit wenigen Jahren ein Außengutachter, überprüfen, ob das Buch ideologisch problemfrei ist.

Im Durchschnitt betreut ein Lektor zehn bis zwölf Autoren. Lektoren werden durch das Leipziger Institut für Verlagswesen während eines einjährigen Fernstudiums ausgebildet. Der Lektor ist von großer Bedeutung für den Autor, denn ihre Beziehung zueinander kann der Publikation des Buches helfen oder sie verhindern. Er ist, laut Christa Wolf, noch vor dem Schriftsteller selbst und seiner 'Selbstzensur' ${ }^{160}$, der wichtigste Zensor, mit dem sich der Schriftsteller auseinandersetzen muß. Wolf beschrieb 1974 die Selbstzensur mit folgenden Worten:

Der Mechanismus der Selbstzensur, der dem der Zensur folgt, ist gefährlicher als dieser: Er verinnerlicht Forderungen, die das Entstehen von Literatur verhindern können, und verwickelt manchen Autor in ein unfruchtbares und aussichtsloses Gerangel mit einander ausschließenden Geboten: daß er realistisch schreiben soll zum Beispiel und zugleich auf 130-132.

${ }^{159}$ Für einen ausführlichen fiktiven Lebenslauf cines jungen Autors siehe: Köhler-Hausmann, 160 Jurek Becker, "Ja, wenn Stalin cin großer Mann war ...," Spiegel 10 (1980): 212. 
Konflikte verzichten, daß er wahrheitsgetreu schreiben soll, aber sich selbst nicht glauben, was er sieht, weil es nicht 'typisch' sei. ${ }^{161}$

Wolfgang Schreyer, ein bekannter Abentenerromanautor, stellt die Selbstzensur, im Gegensatz zu Wolf, an erste Stelle.

Es hat bei uns schon immer eine tief, nämlich dreifach gestaffelte Kontrolle literarischer Äußerungen gegeben: die Selbstzensur der Autoren, von vielen verinnerlicht und verdrängt; die Vorprüfung der Verlagslektorate und schließlich - dies beides ständig aktivierend - die Kompetenz der HV [Hauptverwaltung Verlage und Buchhandlung im Ministerium für Kultur], Druckgenehmigungen zu erteilen oder nicht. ${ }^{162}$

Selbstverständlich gibt es laut DDR-Quellen keine Zensur in ihrem Land. Bemerkt das Kulturpolitische Wörterbuch: "Obwohl in der DDR die Tatsache einer Zensur offiziell bestritten und allenfalls von Maßnahmen zur Ausschaltung feindlicher Einflüsse gesprochen wird, gibt es eine direkte staatliche Meinungskontrolle". ${ }^{163}$

Da die Verlage dem Ministerium für Kultur unterstellt sind, von ihm geleitet und demnach auch kontrolliert werden, müssen sie sich dem Kulturminister, seit 1973 HansJoachim Hoffmann, oder dem stellvertretenden Minister Klaus Höpcke, gegenüber rechtfertigen. Dem Ministerium für Kultur obliegt es, "die Entwicklung einer vielseitigen, sozialistischen, schöngeistigen Literatur zu orientieren und insbesondere jene literarischen Werke zu fördern, die die Gegenwart in fortschrittlichem Geiste darstellen." 164 Dies wird in seinem Statut von 1964 festgehalten. Diese Aufgabe führt das Ministerium sehr ernsthaft durch, das 'fördern' wirkt sich in einer direkten Kontrolle der Verlage aus. Die Hauptabteilung Verlage und Buchwesen des Ministeriums für Kultur lizensiert die

${ }^{161}$ Christa Wolf in Weimarer Beiträge 6 (1974): 102.

${ }^{162}$ Loest, Der Vierte Zensor 48.

${ }^{163}$ Wolfgang R. Langenbucher, Ralf Rytlewski und Bcrnd Weyergraf, Hrsg., Kulturpolitisches Wörterbuch Bundesrepublik Deutschland/Deutsche Demokratische Republik im Vergleich (Stuttgart: Metzler,1983) 764.

${ }^{164}$ Bundesministerium für innerdeutsche Bczichungen, DDR-Handbuch Band $2 \mathrm{M}-\mathrm{Z}$ (Köln: Verlag Wissenschaft und Politik, 1985) 1430. 
Verlage und überprüft deren Jahres- und Perspektivplanung. Die von den Verlagen selbst zusammengestellten Die Verlagspläne müssen aufweisen, welche Werke sie im kommenden Jahr verlegen möchte. Notfalls muß die Wahl begründet werden, was durch Gutachten geschieht. Der Verlagsleiter, vom Ministerium eingesetzt, trägt zusammen mit seinen Cheflektoren dem Ministerium gegenüber die Verantwortung. Da die wichtigsten Verlagsstellen mit parteitreuen Genossen besetzt sind, macht sich die Kaderpolitik, und dadurch die Zensur, auch in dieser Instanz sehr bemerkbar. Jedoch haben die Lektoren und Gutachter kein Interesse daran, Werke ohne kulturpolitische Bedeutung auf den Verlagsplan zu setzen, und leisten dementsprechend ihre Vorarbeit.

Erst nachdem sämtliche Manuskripte auf dem Verlagsplan angenommen werden, erteilt das Ministerium die Druckgenehmigung. Diese-Genehmignt Atermit Auflagen diese »Anordnung über das Genehmigungsverfahren für die Herstellung von Druck- und Vervielfältigungserzeugnissen« festgehalten. Seit 1975 stellt die Abteilung Kultur beim Rat des Bezirks die Genehmigungen aus. Angeordnet wurde diese Änderung "Im Einvernehmen mit dem Minister des Inneren und Chef der Deutschen Volkspolizei." 165 Die erteilte Druckgenehmigung kann eingeschränkt oder mit Auflagen verbunden werden. Ist dieser Genehmigungsprozeß abgeschlossen, so hat das Ministerium für Kultur durch die Hauptverwaltung Verlag und Buchhandel entschieden, was an Büchern erscheinen darf oder auch nicht.

Laut Statut gewährleistet der Kulturminister »...eine einheitliche politischideologische Arbeit des gesamten Verlagswesens und die ökonomische Leitung der Verlage, eine bedarfsgerechte Buch- und Broschürenproduktion in hoher ideologischer und künstlerischer Qualität bei gleichzeitiger Entfaltung einer zielstrebigen vielseitigen Literaturpropaganda, bestätigt die thematische Perspektiv- und Jahrespläne der Verlage und die Verteilung der Kontingente polygraphischer Erzeugnisse auf Grundlage einer langfristig orientierten Kulturpolitik,

$165_{\text {Elimar Lübbe, Hrsg., Dokumente zur Kunst-. Literatur- und Kulturpolitik der SED Band } 3}$ (Stuttgart: Seewald Verlag, 1984) 30; dort befindet sich der gesamte Wortlaut des Gesetzes. 
entscheidet über die Lizenpolitik, und erteilt die Druckgenehmigung für die lizenzpflichtigen Druckerzeugnisse «. ${ }^{166}$

Ist dem Verlag die Druckgenehmigung erteilt worden, eventuell mit Gutachten, in denen die Einwände festgehalten und die Änderungswünsche ausdrückt wurden, werden die druckgenehmigten Manuskripte an die Druckerei weitergeleitet. Bei Vertragsabschluß zwischen Autor und Verlag waren aus Planungsgründen der Abgabetermin und die Seitenzahl festgelegt worden, von der der Schriftsteller bis zu 10\% abweichen darf. Nun liegt die Ausführung des eigentlichen Druckprozesses an der Druckerei, die ihre Ware oft nach langen Wartezeiten liefert. Wiederholt gibt es zwei Hauptgründe für diese Wartezeiten: Papiermangel und fehlende Druckkapazitäten. Da die DDR-Druckereien aufgrund von Devisenbedarf in zunehmendem Maße für Westverlage drucken, müssen oft DDRAutoren auf ihre Werke warten. Das Verfahren kann jedoch beschleunigt werden, falls ideologisches Interesse einer höheren Instanz besteht oder eine Westlizenz vorhanden ist.

Mit der Druckgenehmigung wird bei den Herausgaben lizensierter Verlage eine Prüfung der Qualität vorgenommen. Im Prinzip gilt dasselbe für die nichtlizensierten Druckerzeugnisse, wobei die Erteilung der Erlaubnisse entscheidend durch die zur Verfügung stehende Papiermenge bestimmt wird. ${ }^{167}$

Als Beispiel sei noch einmal Peter Kaedings Knigge-Buch zu betrachten. Ein Jahr dauerte das Gutachten, 1988 gab er das Buch beim Verlag ab. Voraussichtlich soll es 1992 erscheinen, also nach vier Jahren. Da im Moment kein Westverlag in Sicht ist, ist mit einem früheren Erscheinen nicht zu rechnen.

Nehmen wir einmal an, daß das von einem Autor eingereichte Manuskript vom Verlag nicht angenommen wird, sei es aus ideologischen oder künstlerischen Gründen. Da er von dem literarischen Wert seines Werkes überzeugt ist, es nicht 'für die Schublade' schreiben will, und auch Geld damit verdienen möchte, überlegt er sich in wieweit eine

166 Langenbucher 722. Dort ziticrt er aus dem GBI. der DDR I, 1977, S. 361.

${ }^{167}$ Köhler-Hausmann 95. Sic zitiert aus: Kullurpolitisches Wörterbuch, 2. Auflage, Berlin 1978, 
Chance bestehen könnte bei einem Westverlag verlegen zu können. Falls er sich in Schriftstellerkreisen auskennt, weiß er, daß er damit gesetzeswidrig handeln würde. Jedoch garantiert ihm das 1966 in Kraft getretene Urheberrechtsgesetz das Recht auf Eigentum seines Werkes. Er könnte sich an das Büro für Urheberrechte in Berlin wenden (1956 eingerichtet), das dem Ministerium für Kultur unterliegt, und beantragen, sein Manuskript einem Verlag in der Bundesrepublik anzubieten. Wie vom Büro verlangt hat der Autor das Nutzungsrecht zuerst einem Verlag in der DDR angeboten, der es jedoch abgelehnt hat. Wie Köhler-Hausmann darlegt, ist der Urheber jedoch von den staatlichen Instanzen anhängig, und kann nicht frei über sein Werk verfügen. Es heißt:

Das Urheberrecht ermöglicht eine breite Wirkung und Nutzbarmachung aller literarischen, künstlerischen oder wissenschaftlichen Werke, die dem gesellschaftlichen Fortschritt, der Verbreitung humanistischer Ideen und der Sicherung des Friedens und der Völkerfreundschaft dienen. Es steht also eine Verbindung der persönlichen Interessen der Urheber mit den gesellschaftlichen Interessen dar. ${ }^{168}$

Falls ein Werk diesen Kriterien nicht entspricht, so kann auch kein Anspruch auf Urheberrechte gestellt werden.

Die Tatsache, daß das Manuskript unseres fiktiven Autors vom Verlag nicht angenommen wurde, zeichnet es demnach schon als 'nicht den gesellschaftlichen Interessen entsprechend' aus. Im Paragraph 1 des Gesetzes wird darauf indirekt hingewiesen.

Die Leiter der Staats- und Wirtschaftsorgane, der kulturellen und wissenschaftlichen Einrichtungen, der Verlage und Betriebe und die Leistungen anderer Organisationen sorgen dafür, daß die Rechte der Urheber in ihrem Verantwortungsbereich verwirklicht werden. ${ }^{169}$

Ein von den Kulturinstitutionen nicht sanktioniertes Werk eines DDR-Autoren soll in den meisten Fällen nicht im Westen veröffentlicht werden. Das Verhindern einer

$168_{\text {ebda }} 34$. 169 ebda 134. 
Veröffentlichung untersteht in einer Hinsicht dem Büro für Urheberrecht, da ihm das Werk, daß der Autor im Ausland publizieren will, vorgelegt werden muß. Eine weitaus wichtigere Instanz ist jedoch das Ministerium für Kultur, genauer der Minister selbst. In den »Verfügungen und Mitteilungen des Ministeriums für Kultur« werden die Bestimmungen veröffentlicht, die sich mit dem westlichen Ausland befassen. Doch laut KöhlerHausmann sind diese weder im Buchhandel noch in den Bibliotheken erhältlich. Aus eigener Erfahrung bemerkt sie, daß auch innerhalb der DDR nur ein begrenzter Personenkreis Zugang dazu hat. ${ }^{170} \mathrm{Da}$ die wichtigen Bestimmungen zum Honorar-, Lizenz- und Vertragswesen so schwer zugänglich sind, dürfte kein Zufall sein. Dieses Informationsdefizit läßt vermuten, daß eine Diskrepanz zwischen offiziellem Anspruch und Praxis besteht. ${ }^{171}$

Erich Loest wies zynisch auf diese 'Rechtsbestimmungen' hin, als er von der neuen Tauwetterperiode nach dem VII. Parteitag sprach.

Stefan Heyms bisher nur unter Verletzung von Rechtsbestimmungen im Ausland erschienene Bücher ïber Lassalle und Defoe wurden in der DDR aufgelegt, Kunert, Hermlin, Kunze galten als keine Bösewichter mehr, sondern wurden wieder zum vielgestaltigen, handschriftenreichen kulturellen Leben gezählt.

\section{EINFLUSS DER BUNDESREPUBLIK}

Es wäre angebracht, sich an dieser Stelle die offizielle Einstellung zur nationalen und internationalen Rolle der DDR-Literatur vor Augen zu führen, denn diese hat einen bedeutenden Einfluß auf das Selbstverständnis, mit dem die Zensur in der DDR ausgeführt wird. Seit ihrem Bestehen war die DDR bemüht, sich so unabhängig wie möglich von dem westlichen Teil Deutschlands zu entwickeln. Dies galt nicht nur für die politische Ebene, sondern, aufgrund der Aufgabe, die die Literatur in der DDR zu erfüllen

170 ebda 96. Dazu siche man auch Fußnote 86, in der sic über persönliche Erfahrung berichtet. $171_{\text {ebda }} 96$. 
hat, auch auf literarischem Gebiet. Die DDR- und die bundesrepublikanische Literatur wird unter anderem aus politischen Gründen von vielen Literaturwissenschaftlern, Politikern und Schriftstellern selbst in zwei Gruppen gespalten.

Viel ist geschrieben worden über die philosophischen Voraussetzungen der sozialistischen Literatur. Literaturwissenschaftler und -kritiker in sozialistischen Ländern befassen sich mit diesem Thema seit Bestehen ihres Staates, einige bekannte Wissenschaftler, Lukacs zum Beispiel, sind der Debatte zum Opfer gefallen. Eine Reihe bekannter westdeutscher Kritiker und Wissenschaftler, die zum Teil aus der Ostzone oder der DDR stammen, hatten sich der Debatte auf westlicher Seite angeschlossen, und man kann behaupten, sie würden diese heutzutage sogar bestimmen. Marcel Reich-Ranicki, Manfred Jäger und Gerhard Zwerenz gehören zu den prominentesten Vertretern. Ihr indirekter Einfluß auf die Literaturpolitik der DDR ist nicht zu unterschätzen. Haase und sein Autorenkollektiv weisen in ihrer Literaturgeschichte der DDR indirekt darauf hin. Allein die Tatsache, daß sie sich verpflichtet fiihlen, sich mit diesem Thema auseinandersetzen zu müssen, weist auf den Einfluß der bundesrepublikanischen Literaturwissenschaftler auf DDR-Gebiet hin. Auch wird der Versuch einer Rechtfertigung vieler Zensurmaßnahmen aufgrund bundesdeutschen Einflusses wiederholt unternommen. Das Kollektiv erläutert, sich auf den Anfang der siebziger Jahre beziehend:

Die Erfolge im Kampf für den Frieden und Sozialismus ließen den imperialistischen Gegner zu neuen Formen des ideologischen Kampfes greifen. Er versuchte, sich den neuen historischen Bedingungen anzupassen und seine Politik des Antikommunismus und der ideologischen Unterwanderung des Sozialismus mit verschiedenartigen Methoden durchzusetzen. Gegenüber der DDR verfocht der Imperialismus in der BRD weiterhin besonders die These von der einheitlichen "Kulturnation".... Die zu beginn der siebziger Jahre erscheinenden diversen Darstellungen über die DDR-Literatur zeugen davon, daß selbst diese dafür in Anspruch genommen werden sollte. ${ }^{172}$

172 Autorenkollektiv unter der Leitung von Horst Haase u.a., Geschichte der Literatur der Deutschen Demokratischen Republik ( $=$ Geschichte der deutschen Literatur von den Anfängen bis zur Gegenwart. Bd.11 (Berlin: Volk und Wissen, 1976) 783. 
In einer Fußnote weisen die Verfasser besonders auf Konrad Franke, Fritz J. Raddatz, Werner Brettschneider, Gregor Laschen und Hans Dietrich Sander hin.

Bei allen, zum Teil erheblichen Unterschieden in der Darstellung und Bewertung der DDR-Literatur durch diese Autoren aus der BRD, bei allen politischen und konzeptionellen Gegensätzen im Herangehen, kann in diesen und anderen Arbeiten von einer sachlichen Behandlung des Gegenstandes nicht oder nur vereinzelt die Rede sein. Die vorliegende Darstellung versteht sich als eine Korrektur von Entstellungen und Verleumdungen in diesen Publikationen, ohne daß sie direkt daraufhin geschrieben wurde. ${ }^{173}$

Obwohl sich die Spannung zwischen beiden Deutschen Staaten in den vergangenen Jahren gelockert hat, kann keine Rede von einer bedeutenden ideologischen Annäherung sein. Da es, trotz relativ offener Grenze, immer noch schwierig ist, einen Einblick in den ostdeutschen Alltag zu gewinnen, scheint die DDR-Literatur für bundesrepublikanische Leser und Literatur-kritiker eine besondere Aufgabe zu erfüllen. Sie scheint den Außenstehenden einen Blick 'hinter den Vorhang', einen Blick in die Psyche und die alltäglichen Begebenheiten des anderen deutschen Staates zu erlauben. Dadurch wird der DDR-Literatur von westlichen Lesern eine Rolle zugeteilt, die sie weder erfüllen kann noch will.

Die Konflikte zwischen DDR-Schriftstellern und ihrer Partei sind offenkundig und spielen sich zu einem großen Anteil in den bundesrepublikanischen Medien, bei Besuchen oder nach Ausreisen auch auf deren Boden ab. Aufgrund dessen besteht die Tendenz von westlicher Sicht, die Autoren in die Kategorien 'systemtreu' und 'oppositionell' einzuordnen. Westliche Leser und Kritiker finden oft Interesse an einem Werk aus der DDR nicht aufgrund seines literarischen Wertes, sondern aufgrund seines 
vermeintlichen oder wirklichen politischen Inhalts. Ein als systemkritisch empfundener DDR-Schriftsteller kann demnach damit rechnen, eher in der Bundesrepublik gelesen und diskutiert zu werden. Eine bemerkenswerte Erscheinung dieser Tatsache ist folgendes Phänomen: in der DDR ist es gang und gäbe geworden, aus finanziellen Gründen Werke in der Bundesrepublik zu veröffentlichen, die aus politischen Gründen in der DDR selbst nicht erscheinen dürfen. Der Staat kann dadurch westliche Devisen erhalten. ${ }^{174}$

In der DDR ist man sich der Rolle ihrer Literatur selbstverständlich bewußt und steht darum unter einem gewissen moralischen und ideologischen Druck. Einerseits erwartet der Staat von den sozialistischen Berufsschriftstellern, daß sie ihren Beruf zufriedenstellend und zuverlässig ausführen. Sie sollen sich ihrer Aufgabe der Gesellschaft gegenüber bewußt sein und als Verbreiter sozialistischer Standpunkte wirken, wozu Mitglieder des Schriftstellerverbandes sogar durch ihr Statut verpflichtet sind. Wie bereits erwähnt wird seit Bestehen der Ostzone auf Schriftstellerkongressen und Parteitagen durch Verbandsvertreter und Parteifunktionäre die Rolle des sozialistischen Schriftstellers definiert, gedacht als Anleitung für die Themenwahl und Konkretisierung der Werke. Einerseits ist sich der Staat demnach bewußt, daß gewisse Erwartungen von 'imperialistischer Seite' an die DDR-Autoren gestellt werden. Andererseits kann kritischen Autoren in der DDR jedoch unterstellt werden, sie spielten den westlichen Systemkritikern in die Hand, oder sie seien Opportunisten, die ihren Staat wegen Valuta kritisieren würden. Derart ließen sich etwa Bekannte, wahrscheinlich Kollegen Loest über

Heiduczek nach Veröffentlichung dessen Buch aus:

Da hat sich auch ein Genosse wie Heidu aufgemacht, der bisher im

Geschirr gestapft ist, denkt doch bloß an Abschied von den Engeln, so was

${ }^{174}$ Es stellt sich die Frage, ob der erhøhte Kontakt mit ostdeutschen Staatsbürgern einen Einfluss auf die Rolle der Literatur haben wird. Im Jahre 1988 machten 7 Millionen DDR-Bürger gebrauch von einer Besuchserlaubnis und reisten in die Bundesrepublik. Durch mündliche Kommunikation kann darum der Blick in die DDR akkurater und schneller geschehen als durch Bücher. 
von Unbedarftheit! Jetzt zerrt er an seinen Ketten. Oder, warf jemand ein, will er nur auf einen Zug aufspringen, der da gerade fährt? ${ }^{175}$

Ob ein literarisches Werk in der DDR von hoher oder minderwertiger literarischer Qualität ist, ist nicht das einzig Ausschlaggebende in bezug auf seine Chance, veröffentlicht und gepriesen zu werden. Veröffentlichungen während des "Bitterfelder Weges" zeigten zum Beispiel teilweise mangelhaftes Talent der Autoren, wurden jedoch aus politischen Gründen veröffentlicht. Ausschlaggebend sind andere, von der Kulturpolitik bestimmte Faktoren. Wie bereits erläutert, durchschritt die Kulturpolitik der DDR seit ihrem Entstehen mehrere Phasen. Mit zunehmendem politischen Selbstbewußtsein änderte sich auch die den Kulturbehörden zugeteilten Rolle. Verstärktes Selbstbewußtsein bedeutete jedoch keinesfalls eine automatische Lockerung der kulturinstitutionellen Kontrolle. Eine Beurteilung der Kulturpolitik der DDR muß darum während unterschiedlicher Phasen verschieden ausfallen. Unbestritten bleibt jedoch, daß unter anderem die Kulturbehörden, die Zeitungen, die Verlage, die Schriftsteller selbst, egal zu welchem Zeitpunkt, die Kulturpolitik stark beeinflussen. Die Rolle und die Auswirkung der Literatur mag sich demnach geändert haben, ihre Gewichtigkeit im sozialistischen Staat ist jedoch unumstritten.

Wie das Autorenkollektiv unter Leitung Horst Haases in seiner 1976 (Redaktionsschluß war der 31. Oktober 1974) erschienenen Geschichte der Literatur der Deutschen Demokratischen Republik erläutert, hat die DDR-Literatur in den Jahren seit ihrer Entstehung "...auch international immer mehr Anerkennung..." 176 gefunden. Unter dem Titel "Entwicklungstendenzen der DDR-Literatur in den siebziger Jahren", mit denen dieser gewichtige Band schließt, faßt das Kollektiv die Entwicklung der Literatur

${ }^{175}$ Erich Loest, Der Vierte Zensor. Vom Entstchen und Sterben eines Romans (Köln: Edition Deutschland Archiv, Verlag Wissenschaft und Politik, 1984) 31, im folgenden zitiert mit dem Kürzel VZ und den entsprechenden Seitenzahlen. 
zusammen und, typisch für viele lininentreue Literaturwissenschaftler der DDR, unterstellt es dem 'imperialistischen Gegner' , er führe weiterhin den ideologischen Kampf, um die "...These von der einheitlichen 'Kulturnation' "177 zu gewinnen.

In ihrer literaturhistorischen Wertung durch mißgünstige Kritiker ließen sich zwei Tendenzen erkennen. Einerseits wurden jene antikommunistischen Konzeptionen beibehalten, die schon in den fünfziger Jahren darauf ausgingen, den sozialistischen Gehalt der DDR-Literatur zu verleumden und ihren Realismus abzuwerten. Andererseits bildete sich eine Richtung heraus, die das Material anscheinend objektiv ausbreitete und den Rang einzelner Schriftsteller und Werke unterstrich. Dieses Neben- und Miteinander verschiedener Darstellungsweisen und Wertungen der DDR-Literatur entsprach durchaus der imperialistischen Strategie des ideologischen Kampfes in dieser Zeit. Mit dieser Methode suchte die Literaturgeschichtsschreibung der BRD vor allem einen unüberbrïckbaren Gegensatz zwischen den Künstlern und der Kulturpolitik der SED zu konstruieren sowie die Schriftsteller, besonders die verschiedener Generationen, gegeneinander auszuspielen. ${ }^{178}$

Haase und seine Kollegen gestehen der Bundesrepublik durch diese Stellungnahme und Unterstellung mehr Macht zu, als ihnen lieb sein könnte. Die Verfasser gehen auf die 'bürgerliche Ideologie' und den 'imperialistischen Gegner' ein. Ob dieses "gegeneinander ausspielen" jedoch gelang, das lassen sie unbeantwortet. Fest steht, daß auch nach fünfundzwanzigiährigem Bestehen der DDR die Bundesrepublik noch Einfluß auf die Literaturpolitik und das Literaturverständnis der DDR hatte. Dieser Einfluß sollte, wie oben nachvollzogen wurde, nach Biermanns Ausbürgerung noch deutlicher zum Vor-

177 ebda 783 .

178 ebda 783. 
schein treten. Im Brennpunkt standen die Kunstschaffenden, die nach 1976 auswanderten, ausgebürgert wurden, oder mit einem mehrjährigen Visum in den Westen übersiedelten.

\section{DER WEG EINES LINIENTREUEN MANUSKRIPTS}

Es fragt sich, inwieweit anhand von offiziellen Dokumenten der Kulturpolitik der DDR Schlüsse zur Literaturproduktion in der DDR gezogen werden können, und die Antwort ist eine positive. Seit Anfang der siebziger Jahre, seit Honeckers Amtsantritt, sind Parteitagsbeschlüsse und Informationen anderer Art eher zugänglich gemacht worden. Diese offiziellen Quellen gestatten einen Blick in die Kulturpolitik der DDR, aus dem sich wichtige Schlüsse ziehen lassen. Durch den Exodus vieler Literaturschaffender nach 1976 ist auch aus westlichen Quellen viel Material an die Öffentlichkeit geraten, welches äußerst hilfreich bei der Beurteilung der Literaturpolitik sein kann. Zu beachten ist jedoch, daß die meisten, im Westen veröffentlichten, Quellen, wie etwa Loests Der Vierte Zensor, aus der Feder der DDR-Autoren stammen, die von der Kulturpolitik, und besonders deren Zensur, direkt betroffen waren, und denen man unterstellen könnte, sie seien nicht fähig, unvoreingenommen zu urteilen. Sobald man sich mit Materialien und Informationen einer direkt betroffen Person befaßt, läuft man Gefahr, sich von diesen manipulieren zu lassen. Um werkspezifische Information über Produktionsschritte zu erhalten, mußte ich mich jedoch auf persönliche Erfahrungen einiger Autoren stützen. Ich fühle mich darin gerechtfertigt, denn diese Autoren haben meines Erachtens das Recht, sich über ihre Erfahrungen zu äußern. In den meisten Fällen sind sie sich bewußt, daß sie sich unterstellen lassen müssen, sich aus sehr persönlichen Gründen, aus Boshaftigkeit und Verbitterung oder aus ökonomischen Gründen derart nachteilig über die DDR auszulassen. Was diese Autoren zu ihren Werken motiviert hat, das wissen nur sie selbst mit Gewißheit. Seyppel schreibt "Zum Geleit", er "lege hier Aufzeichnungen vor, die sich 
mit dem Leben eines Schriftstellers drüben beschäftigen". ${ }^{179}$ Die autobiographischen Aufzeichnungen seiner Jahre in der DDR führt er mit einem Augustin Zitat ein: "Immer wieder sprachen sie mir von Wahrheit, und doch war sie niemals in ihnen". ${ }^{180}$ Erich Loest hingegen fühlt sich von Brecht motiviert: "Wo ein Unrecht ist, da muß ein Aufstand sein". ${ }^{181}$ Zumindest konnten diese Autoren, einmal im Westen angekommen, zu Papier bringen, was sie bedrückt, verärgert, enttäuscht.

"Seinen Zorn über die Macht der Bürokraten ließ Erich Loest...[schon]... in seinen Roman Es geht seinen Gang oder Miihen in unserer Ebene einfließen". 182 Eventuell ist es dieser Zorn, der ihn auch dazu verleitete, Der Vierte Zensor zu schreiben, seinen aufschlußreichen Bericht, über das Entstehen und Sterben eines Romans in der DDR, wie der Untertitel erläutert. Wie Maaß in seinem im Herbst 1978 in Leipzig geführten Interview mit Loest erfuhr, war es immer noch Loests Ziel "als Schriftsteller...weiter wie schon damals nach dem 17. Juni 'Konflikte zu beschreiben, ohne die es in keiner Gesellschaft eine Entwicklung gibt; gegen die anschreiben, die so tun, als ob alles im Lot wäre'."183,184 Darunter befinden sich auch die Dogmatiker, die die Kulturpolitik der DDR bestimmen.

Es stellt sich die Frage, wie sich der Einfluß der institutionalisierten Kulturpolitik auf Schriftsteller im besonderen bemerkbar macht. Werden Schriftsteller unterschiedlich

179 Joachim Seyppel, Ich bin ein kaputter Typ. Bericht über Autoren in der DDR (Wiesbaden/München: Limes, 1982) 6.

$180_{\text {cbda } 5 .}$.

${ }^{181}$ Winfried Maas, "Ein Kommunist sichert scine Spur. Der mühevolle Weg des Leipziger Schriftstellers Erich Loest,"in: Die Fünfrigjährigen (Hamburg: Hofrmann und Campe, 1980) 169.

$182_{\text {ebda }} 179$.

$183_{\text {ebda }} 182$.

184 "Spurensicherung" soll der Titcl eincr bis jetzt unveröffentlichten Lebensgeschichte sein, in der Loest, wie er Maas erläutert, autobiographisch der jüngeren Gencration bei der Suche nach dem richtigen Weg durchs Leben helfen will. 
behandelt? Welche Kriterien werden bei der Zensur eines Buches angesetzt? Nach welchen Richtlinien wird entschieden, was veröffentlicht wird und was nicht? Wovon lebt ein Autor, der in der DDR veröffentlicht und einer, dessen Werk nicht veröffentlicht wird? Und wer veröffentlicht Werke?

\section{DAS 'LINIENTREUE' WERK}

Gibt es einen typischen Gang für ein linientreues Werk? Für ein nicht linientreues? Wohl kaum, weder in der DDR noch in nicht-sozialistischen Ländern. Das Werk eines Schriftstellers in der Bundesrepublik etwa, einem Land mit freier Marktwirtschaft, geht zwar andere Wege wie das eines DDR-Schriftstellers, jedoch nicht unbedingt einen einfacheren Weg. Doch gibt es Einflüsse neben denen der schon genannten Literaturinstanzen und Organisationen, die nicht übersehen werden dürfen, um das Denken und Handeln unterschiedlicher Schriftsteller beurteilen zu können.

Da das Alter eines Autors für die Themenwahl und Ausführung seines Themas von Bedeutung.ist, soll zuerst zusammenfassend auf die Thesen und Ereignisse eingegangen werden, die deutend und bedeutend für sie waren. Die Autoren, die etwa den II. Weltkrieg miterlebten, wurden von einer politischen Zeit beeinflußt oder geprägt, die sich oft direkt in ihrem Werk widerspiegelt, wie es etwa in Christa Wolfs Kindheitsmuster der Fall ist. ${ }^{185} \ddot{A} u ß e r s t ~ e i n f l u ß r e i c h$ auf ihre Werke und ihr Verhalten ist auch ihre Teilnahme an der Gründung des neuen deutschen Staates, falls sie im entsprechenden Alter waren und daran bewußt teilnahmen. Einige Künstler wie etwa Brecht, Seyppel, Heym, das Ehepaar Wander, Wolf Biermann zogen in der Gründerzeit in die DDR, da sie meist, wie viele Künstlerkollegen, an einen besseren neuen deutschen Staat glaubten und an dessen Erfolg mitarbeiten wollten. Jüngere Schriftsteller hingegen, die in der DDR geboren 
wurden, und deren Erfahrenskreis sich hauptsächlich auf die DDR beschränkt, befassen sich in ihren Werken meist mit anderen Themen als die älteren Schriftsteller, setzen sich mit politischen Problemen und persönlichen Aufgaben als Kunstschaffende anders aus als die Älteren.

\section{WER SETZT DIE RICHTLINIEN? DIE SCHRIFTSTELLER SELBST?}

Eine bedeutende Rolle spielt weiterhin, zu welchem Zeitpunkt Schriftsteller ihre Werke schrieben, während welcher Phase der Kulturpolitik. Selbstverständlich soll dies die Themenwahl und Ausführung des Schreibprozesses beeinflussen. Nach welchen Gesichtspunkten etwa Literatur während des Bitterfelder Weges produziert und veröffentlicht wurde, unterscheidet sich sehr von denen der siebziger oder achtziger Jahre.

Bedeutende Wegweiser für die politischen Tendenzen und Phasen, und darum das Verhalten einzelner Künstler, sind, neben den Aufgaben der kulturellen Institutionen und Organisationen, vor allem die Schriftstellerkongresse und SED-Parteitage. Auf ihnen wird zum einen festgelegt, welche Ziele die Kulturschaffenden in den kommenden Jahren anzustreben haben, zum anderen verdeutlicht sich durch ihre Reden, ihrer Teilnahme oder auch Abwesenheit, wie viele der Kulturschaffenden selbst zu den politischen Gegebenheiten stehen.

Der erste Schriftstellerkongreß fand im Oktober 1947 in Berlin statt. An ihm nahmen, als Teil einer internationalen Delegation, noch über 300 Schriftsteller aus allen vier Besatzungszonen Deutschlands teil. Elisabeth Langgässer hielt das Einleitungsreferat mit dem Titel "Schriftsteller unter der Hitlerdiktatur". Schon damals machte sich jedoch die ideologische Spaltung zwischen Ost und West bemerkbar, die unterschiedliche Auffassung der Rolle des Schriftstellers und seiner Sprache. Langgässer "...forderte, auf 
die Zeit des Mißbrauchs und der Schändung der Sprache durch die Faschisten eine Zeit des Schweigens folgen zu lassen". 186

Das bedeutete nichts anderes, als die Literatur im Kampf für den Frieden und für die demokratische Erneuerung der Kultur zur Wirkungslosigkeit zu verurteilen. ${ }^{187}$

So lautet das Urteil der offiziellen DDR-Literaturgeschichte. Die Kluft zwischen 'imperialistischer' und real-sozialistischer Einstellung zu ästhetischen und literarischen Fragen war auf diesem ersten Schriftstellerkongreß aufgerissen worden und sollte sich nicht mehr schließen. Unterschiedliche Einstellungen zur literarischen Verarbeitung des Nationalsozialismus und zur neuen Rolle des Schriftstellers in der Nachkriegsperiode führten zu scharfen Auseinandersetzungen. Dem ersten Schriftstellerkongreß waren 1946 die erste zentrale Kulturtagung der KPD und 1947 die erste Bundestagung des Kulturbundes vorausgegangen. "Die Umerziehung des deutschen Volkes konnte nur gelingen, ...wenn die Pädagogen, ...wenn die Geistlichkeit und die Schriftsteller dafür gewonnen werden konnten". ${ }^{188}$ So hatte sich Johannes R. Becher schon 1944 über die Rolle des Schriftstellers ausgelassen.

Der II. Schriftstellerkongreß vom Juli 1950 stand unter dem Motto "Das neue Leben verlangt nach Gestaltung", und rief die Schriftsteller auf, die großen landwirtschaftlichen und industriellen Entwicklungen des jungen Staates in ihrer Literatur widerzuspiegeln. Die noch 1947 von einigen empfundene Gemeinsamkeit mit den westlichen Kollegen war nun jedoch größtenteils in Feindlichkeit umgeschlagen, die sich deutlich in Bechers Schlußwort widerspiegelt, das an westliche Kollegen gerichtet war.

Wir wollen nichts mehr wissen von Euch, Euch weder sehen noch hören. Zwar müssen wir vorerst von Euch noch Kenntnis nehmen, aber wir

${ }^{186}$ Haase, 59.

187 ebda 59.

${ }^{188}$ Manfred Jäger, Kultur und Politik in der DDR. Ein historischer Abriß (Köln: Edition Deutschland Archiv, Verlag Wissenschaft und Politik, 1982) 3. 
nehmen Kenntnis von Euch nur in dem Sinne, wie man von einem

Geschwür Kenntnis nimmt, das darauf wartet, operiert zu werden. ${ }^{189}$

Die ehemals proklamierten gemeinsamen Ziele der gesamtdeutschen Schriftsteller hatten sich mit Hilfe der politischen Entwicklungen des kalten Krieges und der Trennung beider Deutschen Staaten binnen weniger Jahre gewandelt, waren zu Gegensätzen geworden.

Auf dem III. Parteitag der SED, der im gleichen Monat wie der II. Schriftstellerkongreß stattfand, befaßte sich die Partei mit den Kulturaufgaben. Offiziell wurde die Kultur in den Fünfjahresplan eingeordnet. Schon im darauffolgenden Jahr befaßte sich eine besondere Tagung des SED-Zentralkomitees mit "Problemen von Literatur und Kunst. Hier wurde die berüchtigte Entschließung »Der Kampf gegen den Formalismus in Kunst und Literatur, für eine fortschrittliche deutsche Kultur« gefaßt". ${ }^{190}$ Der Schriftstellerverband kam unter Beschuß und wurde neuen bürokratischen Zwängen ausgesetzt. Am 1. September 1951 wurde das Amt für Literatur und Verlagswesen ins Leben gerufen, dessen Aufgabe darin bestand, "...Verlagslizenzen [zu] genehmigen, geplante Bücher [zu] begutachten und Papierkontingente zu[zu]teilen". ${ }^{191}$

Auf dem III. Schriftstellerkongreß im Mai 1952 und der darauffolgenden II. Parteikonferenz verfestigte sich der Begriff des 'Sozialistischen Realismus'. Orientiert wurde die Kulturpolitik daraufhin immer mehr nach sowjetischen Richtlinien und Beschlüssen, die zum Teil direkt in den kulturpolitischen Alltag der DDR übernommen wurden. Getadelt wurden die Literaturkritiker zum Beispiel:

${ }^{189}$ ebda 29.

190 ebda 30.

${ }^{191}$ ebda 31. 
Die Erfahrungen der großen russischen revolutionären Demokraten auf dem Gebiet der Literaturkritik und besonders die Lehren aus der

Literaturkritik der Sowjetunion werden mangelhaft beherzigt. ${ }^{192}$

In den darauffolgenden Jahren lief die Debatte um die Rolle der Schriftsteller weiter, Stalin starb, am 16. und 17. 1953 Juni gab es einen Arbeiteraufstand. Das kulturpolitische Klima wurde durch die gesellschaftlichen Ereignisse beeinflußt, doch traten keine bedeutenden Änderungen ein, die liberalisierend auf die Schriftsteller gewirkt hätten. Die Kunst- und Kulturschaffenden hatten zwar versucht, die Situation zu nutzen und Forderungen an die Partei zu stellen, die ihnen mehr Freiheit in ihrer Arbeit gewährleistet hätten. Das Resultat war die Einführung einer neuen Zensurinstanz, die Gründung des Ministeriums für Kultur mit dem Schriftsteller Johannes R. Becher als Kulturminister, dem späteren Kulturminister Alexander Abusch als erster Stellvertreter. Das Ministerium übernahm unter anderem die Aufgaben des Amtes für Literatur und Verlagswesen.

Der Kampf gegen den Formalismus steigerte sich zu diesem Zeitpunkt.

Formalismus war "ursprünglich eine Richtung der russischen Literaturtheorie und Literaturgeschichtsschreibung" 193 der 20 er Jahre. Er war der Kulturpolitik Stalins zum Opfer gefallen und wurde in der DDR ab 1951 als Gegenbegriff zu dem des sozialistischen Realismus gebraucht, als eine Weltanschauung verstanden, die sich in der Kunst ausdrückte und nicht den parteipolitischen Vorstellungen entsprach. Der Begriff wird benutzt um alles "... Reaktionäre, Nichtsozialistische, Bürgerlich-Dekadente in der Kunst" 194 zu bezeichnen. Künstler und ihre Werke fielen nun diesem Kampf zum Opfer. Sogar Brecht blieb davon nicht verschont. Veröffentlichungsverbote wurden beispielsweise erlassen und Bücher eingestampft.

192 ebda 65.

${ }^{193}$ DDR-Handbuch Bd.1 A-L, 423.

${ }^{194}$ Martin Ahrends, Hrsg., Trabbi, Telespargcl und Tränenpavillon. Das Wörterbuch der DDRSprache (München: Heyne, 1986) 63. 
Der IV. Schriftstellerkongreß (9.-14.1.1956) wird in Haases DDR-

Literaturgeschichte als nicht sehr zufriedenstellend dargestellt, da die Debatte um den Einfluß der Partei auf die Schriftsteller weitergefuihrt wurde und unbefriedigend ausfiel. Die Debatte lief darauf hinaus, in wieweit sich Autoren frei zu Themen äußern könnten, die sie sich selbst gestellt hatten, selbstverständlich als Autoren, die den Aufbau des sozialistischen Realismus unterstïtzen. Stefan Heym erläuterte in seiner Kongreßrede die Schwierigkeiten mancher Schriftsteller, die ihnen gestellte Aufgabe verantwortungsbewußt zu erfüllen,

[da] die neue Zeit noch gar so neu und ungewohnt ist, und daß der verschlungene Weg vor uns sich gar zu oft gabelt und kreuzt und überschneidet. Und in solchen Augenblicken mag die Verantwortung, die auf uns liegt, zu schwer erscheinen und die Versuchung, nichts zu sagen oder nichtssagend zu werden, tritt an uns heran. ${ }^{195}$

Schon wieder, diesmal also 1956, debattierte man den Einfluß der Partei auf die Rolle der Schriftsteller. Heym kritisierte nicht nur, daß die "schädlich süßlichen und scholastischen Werke offenbar von oben gewünscht"werden ${ }^{196}$, sondern auch, daß ihren Autoren durch Produktion dieser vorgeschriebenen literarischen Ausführung hohe Auflagen und Ehrungen garantiert sind. Die Freiheit der Schriftsteller, das zu schreiben, was sie selbst als wichtig empfinden, steht also immer noch zur Debatte. Laut Heym gehört Mut dazu.

Auch Anna Seghers sprach sich gegen die Unmündigkeit aus, in der die Schriftsteller gehalten werden, wenn auch in einer weniger offenen Weise als Heym. Noch gesteht man den Schriftstellerkollegen zu, daß sie eventuell aus gerechtfertigter Unsicherheit noch nicht das zu produzieren wagen, was sie wirklich schreiben wollen. Ulbrichts Stellungnahme zu Heyms Äußerungen unterstreichen, daß der parteiliche 
Vormund bestehen bleiben wird, denn der Kampf gegen die "kleinbürgerlichen Gewohnheiten" und "die Einflïsse der bürgerlichen Ideologie, ... die uns hauptsächlich hindern, noch größere Aufgaben zu lösen"197, wird noch geführt. Der Versuch, sich von der Wirkungslosigkeit zu befreien, schlägt fehl. Die Angst vor 'revisionistischen Tendenzen' unter den Intellektuellen ist zu groß. Schriftsteller und Funktionäre fordern die Durchsetzung des sozialistischen Realismus, doch auf unterschiedliche Weise.

Im Mai 1961, drei Monate vor dem Bau der Mauer, tagte der V. Schriftstellerkongreß. Es lohnt die Teilnahme einiger westdeutscher Schriftsteller festzuhalten, darunter Günter Grass. Die Einladung an die Schriftsteller der Bundesrepublik wurde durch ein gemeinsames Interesse an der Ablehnung der "Atombewaffnung in Westdeutschland" von Walter Ulbricht begrïndet. "Die »klerikal-militaristische Reaktion in Westdeutschland « sei der Gegner, laut Ulbricht. ${ }^{198}$ Dieser Kongreß wird in der offiziellen Literaturgeschichte der DDR nicht erwähnt. Grund dafür könnte die Auseinandersetzung sein, die zwischen west- und ostdeutschen Schriftstellern entfachte. Kritisiert wurden die Schriftsteller der Bundesrepublik wegen ungenïgender politischer Macht in der Bundesrepublik. Günter Grass konterte, indem er sich über die Zensur in der DDR ausließ.

Keines meiner Bücher, die ich geschrieben habe, hätte ich in diesem Staat veröffentlichen könne, und so geht es meinen Kollegen auch. Was fehlt diesem Staat nach meiner Meinung? Ein Lyriker wie Enzensberger dürfte hier gar nicht seinen Mund aufmachen, wenn er Bürger der DDR wäre. ${ }^{199}$

Acht Jahre verstrichen, bevor der nächste, der VI. Schriftstellerkongreß stattfand.

197 ebda, 75 .

$198_{\text {ebda }} 102$.

199 ebda 103. 


\section{"SIE IST IHRER ZEIT VORAUS". CHRISTA WOLF UND CHRISTA T.}

An die Behandlung der Produktionsspezifischen Mittel, der ökonomischen, ideologischen und damit verbundenen kulturpolitischen Voraussetzungen anschließend, soll zu diesem Zeitpunkt anhand der Rezeptionsgeschichte der Werke Christa Wolfs und Erich Loests die werkspezifischen Auswirkungen der Zensur dargestellt werden.

Laut Jäger war der VI. Schriftstellerkongreß im Mai 1969 "...der farbloseste in der Geschichte des Verbandes. Kaum ein Autor von Bedeutung ergriff das Wort, wirkliche Diskussion blieb aus". ${ }^{200}$ Christa Wolf hatte ihn gewiß nicht als solchen empfunden, denn ihr im vorherigen Jahr erschienenes Buch »Nachdenken über Christa T.« wurde von Max Walter Schulz und Eberhard Röhner scharf kritisiert. "Die ideologische Offensive zum Anlaß eines heftigen Ausfalls gegen Christa Wolf (der ihm höheren Orts nachträglich ins Manuskript diktiert worden sein soll)..." 201 fand auf dem VI. Schriftstellerkongreß statt. Dieses Werk hatte immerhin schon vor seinem Erscheinen Aufmerksamkeit auf sich gezogen, nicht nur in der DDR seines Stils und Inhalts wegen, sondern auch in der Bundesrepublik aufgrund der unmittelbaren Rezeption in der DDR. Wie Hans-Jürgen Schmitt bemerkt "...geschieht es nicht selten, daß wir uns gegenseitig unsere Feindbilder bestätigen". ${ }^{202}$ Sobald die westdeutsche Presse gewahr wird, daß das Werk eines DDR-Schriftstellers dort ungewöhnlich strengen Zensurmaßnahmen unterzogen wird, oder es so erscheint, wird ihm besondere Aufmerksamkeit geschenkt. Schmitt unterstellt sogar: "...der Krieg der Kritiker in der Bundesrepublik erzwang zumindest

200 Manfred Jäger, Kultur und Politik in der DDR. Ein historischer Abriß (Köln: Edition Deutschland Archiv im Verlag Wissenschaft und Politik, 1982) 134.

${ }^{201}$ Hans-Jürgen Schmitt, Hrsg., Die Literatur der DDR (=Hansers Sozialgeschichte der deutschen Literatur vom 16. Jahrhundert bis zur Gegenwart, Bd.11) (München: dtv, 1983) 32.

202 ebda 29. 
eine halböffentliche Diskussion in der DDR". ${ }^{203}$ Eine erst Fassung für »Nachdenken über Christa T.« war schon 1965 fertig und sollte nicht lange danach erscheinen. Im Oktober 1966 las Christa Wolf im ostberliner Rundfunk aus ihrem Manuskript. Eventuell nahm Wolf Veränderungen am Manuskript vor, was jedoch nicht belegt ist. Fest steht, daß nach Ankündigung des Mitteldeutschen Verlages Halle, das Buch solle zur Herbstmesse 1968 erscheinen, der Veröffentlichung eines Auszuges aus dem Buch in Sinn und Form im Februar 1968, und der Veröffentlichung eines weiteren Abschnitts in der Münchner Monatszeitschrift »Kürbiskern« im April 1968 das Buch schon vor seinem eigentlichen Erscheinen heftig diskutierte wurde. Christa Wolf war auf Angriffe gefaßt gewesen und hatte sich, ihr Leserpublikum, sowie die Kritiker darauf vorbereitet. Im "Kürbiskern" war, dem Textauszug folgend, in Form eines Selbstinterviews eine Selbstanalyse gefolgt, in der sie eine Eigeninterpretation anbot. Unter dem Titel "Nachdenken über Christa T." erschien Wolfs Interview im "Kürbiskern"; es ist seitdem als "Selbstinterview" bekannt. Hier deutete sie an, daß es diese Christa T. wirklich gab, sie hatte demnach die Charakterzüge, Gedanken und Aufzeichnungen der sich in der Gesellschaft untergehenden Person nicht aus der Luft gegriffen. "Ein Mensch, der mir nahe war, starb zu früh. Ich wehre mich gegen diesen Tod. Ich suche nach einem Mittel, mich wirksam wehren zu können". ${ }^{204}$ So begründet Wolf ihr Buch, ihre Suche durch das Schreiben. Die spätere Debatte um die Authenzitität dieser Freundin wurde jedoch nicht durch diese Aussage verhindert. In ihrem Werk, so deutete Christa Wolf schon in diesem Selbstinterview an, befinden sich autobiographische Zïge. "Ich stand auf einmal mir selbst gegenüber, das hatte ich nicht vorhergesehen". ${ }^{205}$ Auch weist sie hier auf einen Vorgang hin, der typisch

$203_{\text {ebda }} 30$.

${ }^{204}$ Manfred Behn, Hrsg., Wirkungsgeschichtc von Christa Wolfs 'Nachdenken über Christa T' (Königstein: Athenäum, 1978) 25. Darin der Abdruck des Intervicws aus Kürbiskern 4 (1968): 555-558.

$205_{\text {ebda }} 25$. 
für viele Autoren ist. Ihre Helden entwickeln sich oft während des eigentlichen Schreibprozesses. Sie sind meist nicht vorher in ihrer ganzen Persönlichkeit entworfen. Loests Wülff etwa erhält Form und Charakter beim eigentlichen Schreiben. ${ }^{206}$

Unterstützt durch den Erzählstil bleiben an vielen Stellen die Grenzen zwischen der Autorin, der Erzählerin und Christa T. verschwommen. Seyppel äußert sich folgendermaßen zum Stil und der Verantwortung des Schriftstellers sich und seinen Lesern gegenüber:

Ich glaube, dies ist es wohl, was neben anderen Dingen einen Schriftsteller au coeur ausmacht: nicht leichter, besser, schöner zu schreiben als andere (ihm fällt ja das Schreiben eher schwerer), sondern aufzuschreiben, was andere verschweigen oder wovor sie verstummen, und wozu die Nichtschreibenden dann beim Lesen sagen: »Ja, so ist es! «. ${ }^{207}$

"Nachdenken, ihr nach - denken. Dem Versuch,man selbst zu sein". ${ }^{208}$ Mit diesen Worten beginnt diese Suche nach der Freundin, die Suche zu sich selbst, die Suche, die in der Literatur der DDR neu war und eventuell auf Kritik stoßen würde. Wolf fragte sich, einer zu erwartenden Frage der Kritik vorausgreifend, im Selbstinterview: "Sie betonen die subjektiven Elemente in Ihrer Erzählung. Können Sie trotzdem so etwas wie eine Idee angeben"?209

Darum rechtfertigt sich Wolf, die überzeugte Sozialistin, mit den Worten:

Es ist ein großer Gedanke, daß der Mensch nicht zur Ruhe kommt, ehe er zu sich selber gefunden hat. Die tiefe Wurzel der Übereinstimmung zwischen echter Literatur und der sozialistischen Gesellschaft sehe ich eben darin: Beide haben das Ziel, dem Menschen zu seiner

Selbstverwirklichung zu verhelfen. Die Literatur nimmt sich, wie unsere Gesellschaft, gerade der Unruhigen an. Menschen darzustellen, denen

${ }^{206}$ Erich Loest, Der Vierte Zensor (Köln: Edition Dcutschland Archiv im Verlag Wissenschaft und Politik, 1984) 8.

207 Joachim Seyppel, Ich bin ein kapuller Typ (Wiesbaden/München: 1982) 42.

${ }^{208}$ Christa Wolf, Nachdenken über Christa T (Darmstadt: Luchterhand, 1987) 9.

${ }^{209}$ Christa Wolf, Die Dimension des Autors. Essays und Aufsätze. Reden und Gespräche. 1959: 1985 (Darmstadu/Neuwied: Luchterhand, 1987) 32. 
diese Unruhe fremd ist: Selbstzufriedene, Platte, allzu Anpassungsfähige das erscheint mir langweiliger und unergiebiger. ${ }^{210}$

Hiermit distanzierte sich Wolf persönlich von den Erwartungen an die sozialistischen Schriftsteller, ohne diese zu verwerfen. Sie vertrat die Auffassung, es solle einem Schriftsteller, dessen Ideologie im Sozialismus verankert ist die Möglichkeit gegeben werden, seine Charaktere und seinen Stil selbst zu entwickeln.

Die absurde Meinung, die sozialistische Literatur könne sich nicht mit den feinen Nuancen des Gefühlslebens, mit den individuellen Unterschieden der Charaktere befassen; sie sei darauf angewiesen, Typen zu schaffen, die sich in vorgegebenen soziologischen Bahnen bewegen: diese absurde Meinung wird niemand mehr vorbringen. Die Jahre, da wir die realen Grundlagen für die Selbstverwirklichung des Individuums legten, sozialistische Produktionsverhältnisse schafften, liegen hinter uns. Unsere Gesellschaft wird immer differenzierter. Differenzierter werden auch die Fragen, die ihre Mitglieder stellen - auch in Form der Kunst. 211

Und doch wurden diese Meinungen vorgebracht. Was sie schon als absurd bezeichnete war noch, und ist auch heute zum Teil noch, fest verankert in der sozialistischen Ideologie. Noch immer, wie sich im März 1989 wieder bewiesen hat, fühlt sich der DDR-Staat weiterhin unsicher in bezug auf seine Stellung in der Welt, und besonders der Bundesrepublik gegenüber. Es wird weiterhin versucht die Differenziertheit auch zwanzig Jahre nach Wolfs Selbstinterview noch zu unterdrücken. Wolf sei ihrer Zeit Jahre voraus gewesen, meint Stephan.

Fünf Jahre verstrichen bis zum Erscheinen von Christa Wolfs zweitem Roman - Jahre, in denen sich die Schriftstellerin in vielem schneller entwickelte als ihre Gesellschaft... Immer noch war sich die politische Führung der DDR trotz aller Fortschritte ihrer selbst nicht sicher genug, um Weg und Ziel der gesellschaftlichen Entwicklung von ihren Schriftstellern kritisch iiberpriifen und grundsätzlich in Frage stellen zu lassen. 212

${ }^{210}$ Behn 26.

$211_{\text {ebda }} 27$.

${ }^{212}$ Alexander Stephan, Christa Wolf (München: Beck, 1987) 59. 
Damit wird zum Teil begründet, warum das Prosawerk auch erst weitere fünf Jahre später, nachdem Honecker als Staatsoberhaupt übernommen hatte, neu aufgelegt und akzeptiert wurde. Führt man sich vor Augen, während welcher politischen, und besonders welcher literaturpolitischen, Phase das Werk auf den Markt kam, verwundert die Reaktion darauf nicht übermäßig. Behn gibt folgende Gründe für die angespannte Situation an: außenpolitisch die Nichtanerkennungspolitik der Bundesrepublik und die SED Einstellung zu den Vorgängen in der CSSR, innenpolitisch die Neue Ökonomische Politik der Planung und Leitung, die 1963 in Kraft getreten war. ${ }^{213}, 214$

Behn erläutert:"Unter den Vorzeichen der sich stürmisch entwickelnden wissenschaftlich-technischen Revolution und der damit auf der Ebene der ideologischen Auseinandersetzungen zwischen den beiden Gesellschaftsordnungen sich intensivierenden Diskussion über eine Konvergenz der Systeme ergab sich auch für die Literaturpolitik der SED die Notwendigkeit, ihren Standort den neuentstandenen Problemen gegenüber zu umreißen und von dort aus literaturpolitische Entscheidungen zu fällen. ${ }^{215}$

Auch Stephan erwähnt den Mangel an Vertrauen in das neue Wirtschaftssystem. Man bleibt beim Alten und wartet ab.

Ängstlich versteckten sich Kritiker, Literaturwissenschaftler und Schriftstellerkollegen lieber noch einmal hinter den längst ausgeleierten Prinzipien und Schlagwörtern des sozialistischen Realismus:

'Perspektivebewußtsein', 'intellektualistischer Pseudo-Internationalismus', 'Innenweltschau'. ${ }^{216}$

Unter Schriftstellern und Kulturfunktionären war die Definition der Gegenwartsliteratur schon seit der Konzeption einer eigenen Literatur diskutiert worden. Die

${ }^{213}$ Behn, 1.

${ }^{214}$ Das NÖS, Neue Ökonomische System der Planung und Leitung der Volkswirtschaft beinhaltete die Dezentralisicrung, durch dic das ökonomische System flexibler und lcistungsfähiger gemacht werden sollte. GröBerc Selbstverwaltung und -vcrantwortung Volkscigener Betriebe, Leistungsanreize durch Prämien z.B. sollten ein "cinhcitliches System der ökonomischen Hebel"bilden. Vgl. Georg Lehmann, Chronik der DDR (München: Beck, 1987) 84.

$215_{\text {Behn, } 2 .}$

216 Stephan, 60 . 
Orientierung auf die Gestaltung der Gegenwart, den Arbeiter als Helden, das Leben der Werktätigen in den Betrieben und Genossenschaften, dies war die Definition der Gegenwartsliteratur auf dem Bitterfelder Weg. Mit einer derart engen Definition hatten sich Autoren schon auseinandergesetzt, doch wurden diese, laut Behn, nicht ausgezeichnet, und fanden oft zuerst Anklang in der Bundesrepublik.

Immer größer wurde dann auch die Zahl der Autoren, die an das BrechtWort: "Wir haben allzu früh der unnittelbaren Vergangenheit den Rücken zugekehrt, begierig uns der Zukunft zuzuwenden. Die Zukunft wird aber abhängen von der Erledigung der Vergangenheit' erinnern. "217

Doch die Politik setzte stärkere Grenzen, denn der Partei war an der literarischen Darstellung des "Entwickelten gesellschaftlichen Systems des Sozialismus" gelegen. "Werke, die sich einer derartigen Funktionsbestimmung entzogen, mußten folgerichtig mit den normativen Wertungskriterien von Kultur- und Literaturkritik kollidieren". 218

Behn nimmt an, Christa Wolfs Prosastiick sei jedoch in dieser Zeit veröffentlicht worden, da "...die jeweils Verantwortlichen sehr wohl von der Annahme ausgingen, die neue Prosa Christa Wolfs ließe sich der oft beschworenen 'Weite und Vielfalt des sozialistischen Realismus' zuordnen". 219

Es können nur Annahmen gemacht werden darïber, was den Verleger des MDV dazu veranlaßte, »Nachdenken über Christa T.« zu veröffentlichen. Im Gegensatz zu Erich Loest hat sich Christa Wolf bis heute nicht ausführlich über den Publikationsprozeß ihres Buches ausgelassen. Sie verhielt sich nach der Veröffentlichung von den Streitigkeiten um ihr Buch entfernt, und hatte sich auch der Selbstkritik ihres Verlegers nicht angeschlossen. Für ihre Weigerung sich zu rechtfertigen wurde sie in gewissem Sinne belohnt, als das Buch mehrere Jahre nach der ersten Auflage auch in der DDR zu

${ }^{217}$ Behn, 2.

$218_{\text {ebda } 3 .}$

219 ebda 4. 
einer Art 'Bestseller' wurde. In der Bundesrepublik war die erste Auflage schon ein 'Bestseller' geworden. Auch sie hatte es also in "Bestseller country" weit gebracht, doch war sie nicht, wie so viele andere in den Jahren danach, dorthin gegangen. Auch kann man ihr gewiß nicht unterstellen, sie habe dieses Buch aus finanziellen Gründen derart systemkritisch gehalten.

Über die Details des Vorgangs von Veröffentlichung und Unterdrückung [des Buches] gibt es mehr Mutmaßungen als exakte Nachrichten. [...] Meine Bitte um authentische Auskunft hat der Mitteldeutsche Verlag nicht beantwortet. [...]"220

Von einem 'quasi-Veröffentlichungsverbot' spricht Stephan, denn es ist ja bekannt, daß Christa Wolf ihr Manuskript schon eine Weile beendet hatte, bevor sie es dem Verlag anbot.

Doch sie bot es an, und das gewiß nicht aus Naivität, denn sie war eine erfahrene, intelligente Sozialistin. Seit 1955 war sie Mitglied des Vorstandes des Deutschen Schriftstellerverbandes gewesen, in der Zeit zwischen 1963 und 1967, also vom VI. bis zum VII. Parteitag der SED war sie Kandidatin des ZK der SED. Ihre Kandidatur hatte sie 1967 wegen ihrer Verteidigung eines Schriftstellerkollegen, Werner Bräunig, auf dem 11. Plenum des ZK der SED verloren. Um ihren 1963 veröffentichten Roman »Der geteilte Himmel« hatte es auch Debatten gegeben, denen sie sich widersetzen konnte und für den sie den Heinrich-Mann-Preise der Akademie der Künste der DDR , 1964 den Nationalpreis III. Klasse der Akademie der Künste der DDR erhielt. Erich Loest zählte sie zu den Schriftstellern der DDR, die sich "Achtung" und "Selbstachtung" und "vielleicht sogar den Respekt der Funktionäre errungen" hatten, ohne "Lieblingskinder der Staatsmacht" zu sein, ohne "auf Geheiß von oben Kollegen in den Rücken zu fallen".221 Trotz ihres Rufes hatte auch sie Schwierigkeiten bei der Veröffentlichung ihres neuen Romans. Über die 
Jahre hatte sich gezeigt, und sollte sich auch weiterhin zeigen, daß sogar parteitreue Schriftsteller den unberechenbaren Schwankungen der Zensur nicht gewachsen waren, und es auch heute noch nicht sind. Sogar ein zuverlässig linientreuer Autor wie Hermann Kant etwa hatte Veröffentlichungsschwierigkeiten gehabt. Ein Vorabdruck seines Romans Das Impressum war gestoppt worden, und bevor sein Verlag das Buch auf den Markt brachte, mußte er es umarbeiten.

Auch in Christa Wolfs Verlag, dem Mitteldeutschen Verlag Halle, hatte man versucht hauptsächlich Werke zu veröffentlichen, die Publikationserfolge würden, was bedeutet Werke, die sich dem Bitterfelder Weg anpaßten und, laut Hans Sachs in 'Neues Deutschland' "...auf vielfältige Weise Antwort auf die Fragen der Lebensweise im Sozialismus" 222 gaben.

Im Mai 1969 erschien nun Nachdenken über Christa $\Upsilon^{223}$ Allein die Auflagehöhe machte im westlichen Teil Deutschlands von sich reden. Der bekannte Literaturkritiker Fritz Raddatz sprach in seiner Rezension des Buches im "Spiegel" von einer Auflage in Höhe von 800 Exemplaren. Diese seien an vom Verlag ausgewählte Priviligierte geschickt worden, darunter Kritiker und Funktionäre. Bissig bezeichnet er sie als "Auflage für die Wölfe"224. Im selben Monat, im Juni 1969, sprach Heinz Kersten in der Frankfurter Rundschau von einer Auflage in Höhe von 4000 Exemplaren. Stephans Angabe beträgt 15000 Exemplare, Schmitt gibt eine Auflage von 20000 an, davon waren durch ein "Lizenz- und Mitdruck-Geschäft" 5000 Exemplare an den Luchterhand Verlag verkauft worden. 225 Im Mai 1969 erschienen die DDR-Exemplare auf dem Markt,

${ }^{222}$ Behn, 54.

${ }^{223}$ Verschiedene Quellen gcben auch 1968 oder $1968 / 69$ an

${ }^{224}$ Der Spiegel, 2.6.1969

${ }^{225}$ Schmitt, 30. Schmitt erläutcrt die unterschicdlichen Angaben für das Erscheinungsjahr dadurch, das die in der DDR verbliebenen Bücher erst Anfang 1969 auf den Markt kamen. 
jedoch in weitaus reduzierter Anzahl da, wie Raddatz korrekt vermerkt hatte, bevorzugte

Personen zuerst beliefert worden waren. Nun entfachte eine Ost-West Debatte um das Buch, aus dem sich die Autorin entfernt hielt. Wolf hatte nicht nur im Kürbiskern zu ihrer Arbeit Stellung genommen, sondern sich auch intensiv mit der Funktion von Literatur in Essays befaßt, welche sie 1968 geschrieben hatte. Christa Wolf, die gelernte Germanistin, gewissenhafte, scharfsichtige sowie einsichtige (insightful) Autorin hatte sich das Schreiben sowie ihre Rolle als Schriftstellerin in der DDR nie leicht gemacht. Sie mußte sich ihrer Gefühle und Gedanken bewußt gewesen sein, die sie auf Papier gebracht hatte. Sie schien überzeugt davon zu sein, daß die Zeit für eine neue Prosa gekommen war, eine Prosa, die nicht nur an den sozialistischen Realismus oder den Bitterfelder Weg gebunden war.

Die Prosa kann sich nur mit gedanklichen Strömungen und gesellschaftlichen Bewegungen verbinden, die der Menschheit eine Zukunft geben, die frei sind von den jahrhundertealten und den brandneuen Zauberformeln der Manipulierung und selbst das Experiment nicht scheuen. ${ }^{226}$

Eventuell überließ sie es nun der Öffentlichkeit, diesen ideologisch fortgeschrittenen Punkt zu erreichen, an dem sie schon angekommen war. Ihr Essay-Band kam aber erst drei Jahre nach Nachdenken über Christa T, auf den Markt, sodaß er Ende der sechziger Jahre noch keinen Einfluß auf die Rezeptionen und Reaktionen haben konnte.

Auf dem VI. Schriftstellerkongreß verurteilte dann Schulz Christa Wolfs neues Werk, und weitete gleichzeitig in eine Ost-West Debatte aus, in der er, offensichtlich erbost, auf die westliche Resonanz auf das Werk einging.

Wir lassen uns unser Urteil nicht vom Gegner diktieren. Wenn aber ein Mann wie Reich-Ranicki, der Anna Seghers' neuen großen Roman aufs niederträchtigste beschimpfte und besudelte, gleichzeitig des Nachdenken über Christa T. so kommentiert: 'Sagen wir klar, Christa T. stirbt an Leukämie, aber sie leidet an der DDR' - dann muß uns das auch zu denken

${ }^{226}$ Christa Wolf, Lesen und Schreiben. Aursiilze und Prosasüicke (Darmstadt: Luchterhand,1972) 208. 
geben, um so mehr, als eine alte Methode wieder einmal praktiziert wird:

Die DDR-Schriftsteller sind gegeneinander auszuspielen.... Wir wären

Prügel wert, wenn wir die diversante Absicht nicht durchschauten. ${ }^{227}$

Nicht verwunderlich war die Resonanz auf » Nachdenken über Christa T.« in der

DDR überwiegend negativ, in der Bundesrepublik positiv. Heinrich Mohr nennt den

Roman "erregend vielschichtig und mehrdeutig. Er ist nicht aufzulösen in der

Interpretation; es bleibt etwas Rätselhaftes, das reizt oder Ärgernis erregt." ${ }^{228}$ In Horst

Haases Geschichte der DDR-Literatur wird der Roman zwar besprochen, doch steht ihm

Haase Jahre später immer noch skeptisch gegenüber. Seine "ambivalente Wertung", wie

Behn Haases Kritik in Heft der NDL 1969 bezeichnet, kommt mehrere Jahre später noch zum Vorschein., als er von den "...Unschärfen in der philosophischen Konzeption des Buches, Ursachen seiner unterschiedlichen Aufnahme im Publikum...."229 berichtet. Als eine gekonnte Schriftstellerin, die ihr "Handwerkszeug beherrscht", lobte er Wolf 1969.

Doch tadelte er schon damals die Darstellung der Gesellschaft, in der Christa T. erkrankt und an der sie stirbt.

Die drohende Zerstörung der menschlichen Persönlichkeit! Die Vernichtung des menschlichen Selbstgefühls! Solche Kennzeichen einer antihumanistischen Gesellschaftsordnung in unsere sozialistische Welt zu projizieren, muß den Realismus der Darstellung in starkem Maße beeinträchtigen. ${ }^{230}$

Wie Behn vermerkt, war Haase seit 1969 Dozent am Institut für Gesellschaftswissenschaften beim ZK der SED. "Seine Rezension kam durch seine Funktion und durch

${ }^{227}$ Behn, 72.

228 ebda 102; Laut Behn war Mohr der erste Rczipient in der BRD(1971), der sich auf eine intensive Textarbeit einließ. "Die Ergcbnisse dicser Textarbcit setzte Mohr in überzeugender Weise in Beziehung zur Poetik Christa Wolfs und den sich daraus ergebenden Aspekten der Rezeption.

${ }^{229}$ Haase, 548.

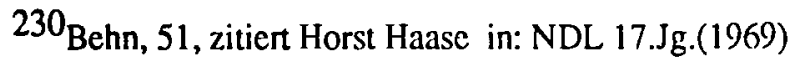


die Veröffentlichung in der "Neuen Deutschen Literatur...einer offiziösen Stellungnahme gleich". 231

Heinz Sachs, der Verleger der MDV, verlor seine Stelle, obwohl er offizielle Selbstkritik geübt hatte. "Verleger sein heißt ideologisch kämpfen"lautete der Titel des Artikels, in dem er von einer "problematischen Entscheidung der verantwortlichen Leitung" in bezug auf »Nachdenken über Christa T.« sprach. Zu dem Zeitpunkt, Anfang Mai, kurz vor dem VI. Schriftstellerkongreß, war der Roman jedoch noch nicht in der DDR zu erhalten gewesen, worauf Rolf Michaelis in seiner Reaktion zu Sachs' Selbstkritik einging. Laut Sachs sind zwei Aspekte des Romans problematisch: die Heldenwahl und die Darstellung der sozialistischen Gesellschaft, sodaß die Beantwortung Christa T.s Frage 'Wie soll man leben?' "...auf sozialistische Art schwerfällt". ${ }^{232}$ Christa T. kann kein Vorbild sein, nicht im Sinne des sozialistischen Helden, denn sie scheitert an der Gesellschaft, nicht an sich selbst. Wolf hat "...die Möglichkeiten, die die sozialistische Gesellschaft dem einzelnen bietet (selbst wenn sie in einer so ungünstigen persönlichen Situation lebt wie Christa T.) nicht zur Geltung..."233 gebracht. Meines Erachtens faßt Sachs folgende Aussage über die Funktion der DDR-Literatur als Beispiel sozialistischer Literatur die Hauptkriterien der Kritiker des Romans zusammen, die von nun an folgen sollten.

Wenn aber sozialistische Literatur ihre Funktion finden soll, kann sie das nur, wenn sie auf allgemein bewegende Fragen spezifisch sozialistische Antworten gibt. Gerade aber hier liegt das entscheidende Versäumnis des Verlages in der Zusammenarbeit mit der Autorin Christa Wolf. 234

$231_{\text {ebda, }} 40$.

232 ebda 55.

233 ebda 55

234 ebda 55 
Dies ist zu verstehen als Eingeständnis der Nichterfüllung der Aufgabe des Verlages zu garantieren, daß Werke mit fragwürdiger sozialistischer Tendenz unveröffentlicht bleiben. Beispielhaft dafür wird anhand Erich Loests Roman Es geht seinen Gang oder Mühen in unserer Ebene eine solche Aufgabenerfüllung im zweiten Teil dieses Kapitels dargestellt. Daß Stephan Hermlin schon 1969 zumindest Christa Wolfs Recht auf ihre Ausdrucksweise verteidigte, und zwar in einer französischen Zeitschrift, konnte erst 1973 in der DDR öffentlich zugegeben werden.

Ich bezeichne Christa Wolfs neuen Roman Nachdenken über Christa $T$. als avantgardistisch, weil er zeigt, daß der Aufbau des Sozialismus nicht nur eine ökonomische, sondern vor allem eine moralische Aufgabe ist. Zum Avantgardismus gehören in einem sozialistischen Land die Versuche, neue Erscheinungen beim Aufbau einer neuen Gesellschaft literaturfähig zu machen, auch wenn diese Versuche manchmal scheitern." 235

Es fragt sich, welche Aussagen Christa T.s oder der Erzühlerin,welche Charakterzüge einzelner Romanfiguren hätten geändert werden sollen, und woran der Lektor vom Inhalt her Anstoß hätte nehmen sollen. Da diese Frage zum Teil nur spekulativ beantwortet werden kann, und nicht, wie in Erich Loests Fall, anhand schriftlich festgehaltener Aufzeichnungen illustriert werden kann, bleibt ein Nachvollzug möglicher Kritik nur anhand einiger Textauszüge spekulativ.

Christa T.s Anspruch auf Phantasie etwa, der sie in dieser Gesellschaft scheinbar entsagen muß, wäre ein kritischer Punkt gewesen. Statt sich in eine menschlichere Gesellschaft gewandelt zu haben behauptet sie, ihre Gesellschaft würde unmenschlicher, kaltschnäuziger, gefühlsärmer.

Sie hat, jetzt spreche ich von Christa T., nichts inniger herbeigewünscht als unsere Welt, und sie hat genau die Art Phantasie gehabt, die man braucht, sie wirklich zu erfassen - denn was man auch sagen mag, mir graut vor der neuen Welt der Phantasielosen. Der Tatsachenmenschen. Der Hopp-Hopp-Menschen, so hat sie sie genannt. ${ }^{236}$

235 ebda 84.

${ }^{236}$ Christa Wolf, Nachdenken über Christa T. (Darmstadt: Luchterhand, 1987) 55. 
Und später, auf die Frage bei einer Sylvesterfeier, "...Was halten Sie für unerläßlich für den Fortbestand der Menschheit?..." schreibt Christa T.: " ..Gewissen...Phantasie."237 Wolf distanziert sich durch diese Aussagen von der Beschreibung des neuen sozialistischen Menschen, der hier sehr westliche, kapitalistische Züge aufweist. Dieser Art Mensch durfte man jedoch nicht im neuen Staat Ulbrichts begegnen, dem Staat, in dem schon entwickelte Sozialisten leben sollten.

Weitere Angriffspunkte hätte die Beschreibung des Aufbaus der DDR liefern können.

Die Wahrheit ist: Wir hatten anderes zu tun. Wir nämlich waren vollauf damit beschäftigt, uns unantastbar zu machen, wenn einer noch nachfühlen kann, was das heißt. Nicht nur nichts Fremdes in uns aufnehmen - und was alles erklärten wir für fremd! -, auch im eigenen Interesse nichts Fremdes aufkommen lassen, auch wenn es schon aufkam - ein Zweifel, ein Verdacht, Beobachtungen, Fragen -, dann doch nichts davon anmerken lassen. Weniger aus Angst, obwohl viele ängstlich waren, als aus Unsicherheit. Eine Unsicherheit, die schwerer vergeht als irgend etwas anderes, was ich kenne. ${ }^{238}$

Anspielungen auf die Angst der Bevölkerung, auch der den neuen Staat unterstützenden Bürger, vor der Zukunft, ob diese auch derart aussehen würde, wie man sie sich nach dem gescheiterten Versuch einer Demokratie erhofft hatte; Angst der Politiker vor westlichen Einflüssen, gegen die etwa durch Einführungsverbot bestimmter Literatur bis zur extremen Maßnahme des Mauerbaus und Ausreiseverboten gewappnet werden sollte. Das 'unantastbar machen' geschah auch durch wiederholte mündliche Angriffe gegen den westlichen Imperialismus, der angeblich den jungen deutschen Staat zu freiheitsentziehenden Maßnahmen zwang. Wolf bezeichnet das, was im Westen oft als Agressivität der DDR angesehen wird, treffend als 'Unsicherheit'. Ein sich in seiner Rolle sicher fühlender Staat, Menschen ähnlich, ist nicht leicht zu provozieren und handelt

237 ebda 171.

238 ebda 55. 
selbstsicher. Doch auch heute noch macht sich die Unsicherheit des Staates bemerkbar die, wie Wolfs Erzählerin erkennt, lange weilt.

Wolf beweist auch ihre Bibelfestigkeit und stellt damit indirekt dar, daß sie keine naive Sozialistin ist, die, weil es von der Partei nicht gewünscht wird, sich nicht mit der Heiligen Schrift befaßt. Sie spricht von ihrem Glauben an das Paradies DDR.

Die Idee der Vollkommenheit hatte uns erfaßt, aus unseren Büchern und Broschüren war sie in uns eingedrungen, und von den Podien der Versammlungen kam die Ungeduld dazu: Wahrlich, ich sage dir, heute noch wirst du mit mir im Paradies sein!"239

Wie von der Kanzel herunter war ihnen gepredigt worden an etwas zu glauben, also etwas Glauben zu schenken, was ihnen das Paradies im Diesseits bereiten würde.

Einen starken Gegensatz zu Loests Wülff, an dem mehre Jahre später Anstoß genommen werden sollte, scheint Christa T. darzustellen.

"Sie hat nicht versucht, sich davonzumachen, womit gerade in jenen Jahren so mancher begonnen hat. Wenn sie ihren Namen aufrufen hörte: »Christa T.! «, dann stand sie auf und ging hin und tat, was von ihr erwartet wurde." 240

Sie hat den Willen für das neue Paradies einzutreten, doch erkennt sie auch, daß diese Gesellschaft sie nicht als Individuum anerkennen will oder kann, ihr die Freiheit nimmt aus eigener Kraft und Initiative zu kämpfen:

"...aber wem soll sie sagen, daß sie lange dem Namensruf nachlauschen muß: Bin wirklich ich gemeint? Oder sollte es nur mein Name sein, der gebraucht wird? Zu anderen Namen gezählt, emsig addiert vor dem Gleichheitszeichen? Und ich könnte ebensogut abwesend sein, keiner würde es bemerken? Sie sah auch, wie man anfing, zu entschlüpfen, die bloße Hülle, den Namen zurückzulassen. Das hat sie nicht gekonnt." 241 Sie hatte, laut Wolf, den richtigen Zeitgeist, doch war dieser nicht typisch für diese bestimmte geschichtliche Zeit, wurde nicht von ihren Mitmenschen als der korrekte

${ }^{239}$ ebda 56.

240 ebda, 59.

$241_{\text {ebda, }} 59$. 
Zeitgeist empfunden. Christa T., wie Wolf selbst, war ihrer Zeit voraus. Beispielhaft dafür, aber auch für die verschwommenen Übergänge in der Erzählperspektive, zwischen der Erzählerin und der Autorin, ist diese Stellungnahme zum Recht auf freie Meinungsäußerung:

Christa T. hat, auch wenn sie lässig schien, anstrengend gelebt, das soll bezeugt sein, obwohl es hier nicht darum gehen kann, sie zu verteidigen: Kein Verfahren findet statt, kein Urteil wird gesprochen, nicht über sie noch über irgend jemanden sonst, am wenigsten über das, was wir »die Zeit« nennen, womit nicht viel gesagt ist. 242

Doch sehen Kritiker wie Erwin Pracht und Werner Neubert Christa T. nicht als Gegenteil zu Wülff. Nachdem sie Christa T. anerkennen, daß sie nicht die kapitalistische Welt vorzieht werfen sie ihr vor, sie sei ein Versager.

Sie ist aber andererseits ein Mensch, der sich festen Bindungen weitgehend entzieht, der keine 'Rolle' spielen will, der an der realen Welt mit ihren Widersprüchen häufiger verzagt, als daß er sich den Forderungen dieser Welt stellte, und der sich deshalb auf die Suche nach seiner 'eigenen' Welt begibt. ${ }^{243}$

Nicht vergessen werden darf, daß dieses Buch in den Jahren des NÖSPL herauskam, in einer Zeit, in der Technik und Fortschritt zu den wichtigsten Zielen gehörten, in denen der Wettbewerb mit dem westlichen Teil des Landes um ökonomische Unabhängigkeit, um das Erstreben einer Art Wirtschaftswunder in der DDR von großer Bedeutung war. Laut Frauke Meyer in der Zeitschrift 'alternative' entstand Nachdenken über Christa T.

"...in einer Entwicklungsphase der DDR..., in der die enorm forcierte 'wissenschaftlich-technische Revolution' neben dem ökonomischen Aufschwung eine beinahe bedingungslose technokratische Wissenschaftsgläubigkeit hervorbrachte, die gesellschaftliche Probleme nur noch unter dem Aspekt ihrer wissenschaftlichen bzw. technischen Lösbarkeit in den Blick treten ließ." 244

242 ebda, 59.

${ }^{243}$ Behn, 96.

${ }^{244}$ Behn, 139. 
Wolf weist eindeutig auf die Gefahren hin, die durch die Selbstverständlichkeit an der

Korrektheit dieser politischen Ziele dem Individuum drohen, der Verlust an Individualität.

So entstand um uns herum, oder auch in uns, was dasselbe war, ein hermetischer Raum, der seine Gesetze aus sich selber zog, dessen Sterne und Sonnen scheinbar mühelos um eine Mitte kreisten, die keinen Gesetzen und keiner Veränderung und am wenigsten dem Zweifel unterworfen war. Der Mechanismus, nach dem sich das alles bewegte aber bewegte es sich denn? -, die Zahnräder, Schnüre und Stangen waren ins Dunkel getaucht, man erfreute sich an der absoluten Perfektion und Zweckmäßigkeit des Apparats, den reibungslos in Gang zu halten kein Opfer zu groß schien - selbst nicht das: sich auslöschen. Schräubchen sein. 245

Wolf befaßt sich auch mit der Frage, ob denn dieser neue Staat, wie auch immer er ausfällt, so anders als der alte deutsche Staat sei, sei es der preußische oder der nationalsozialistische. Die Menschen darin, so scheint Wolf zu behaupten, haben sich nicht von Grund auf geändert. In ihrer Reaktion auf die Krötengeschichte, in der der Schüler Hammurabi einer Kröte den Kopf abbeißt, zeigte Wolf anhand Christa T.s Reaktion, wie klein der Unterschied zwischen brutalen Jugendlichen in der DDR, und Menschen des dritten Reiches sein kann. Das neue 'Paradies auf Erden' hatte die Entwicklung brutaler Verhaltensweisen seiner Jugendlichen, sadistischer Züge seiner frustrierten Bürger nicht verhindern können. Außerdem, so wurde Christa T. von einem ehemaligen Schüler belehrt, war "Anpassung" die einzige Chance zu überleben.

Überleben, ist ihm klar geworden, sei das Ziel der Menschheit immer gewesen und werde es bleiben. Das heißt, ihr Mittel zu jeder Zeit: Anpassung. Anpassung um jeden Preis... Die deutschen Erzieher haben schon immer an den Realitäten schütteln wollen, immer vergebens, ${ }^{246}$

behauptet dieser junge Arzt, demnach ein, sollte man meinen, recht intelligenter Mensch.

Die Idealisten haben schon immer versucht aus den Deutschen bessere Menschen zu

245 Wolf, Nachdenken über Christa T, 60.

246 ebda, 112. 
machen, doch ohne Erfolg. Es gibt demnach, so scheint Wolf zu behaupten, eine deutsche Natur, einen deutschen Charakter, der sich nicht ändern läßt. Sich anpassen, nicht gegen den Strom schwimmen, so überlebt man, auch noch in der neuen deutschen Form des Sozialismus.

Ein in den Rezensionen und Analysen wiederholt aufgegriffenes Thema ist Christa T.s Schwierigkeit "ich zu sagen". Christa T. hatte versucht als Schriftstellerin zu schreiben, doch hatte es nie so weit gebracht. Christa Wolf wirft mit Christa T.s unerfülltem Traum eine politische sowie eine künstlerische Frage auf. Ihre Heldin schreibt zwar, jedoch immer in der dritten Person. "SIE, die nur die Gegenwart kennt und sich nicht das Recht nehmen läßt, nach ihren eigenen Gesetzen zu leben" (168) nimmt sich jedoch nicht das Recht, sich in ihren schriftstellerischen Versuchen hinter ihre Helden zu stellen. Hinter der dritten Person versteckt sie sich, wie viele Schriftsteller der DDR. Loest sollte wenige Jahre später von seinem Lektor gebeten werden, seinen Roman in die dritte Person umzuschreiben, damit er auf diese Weise sich von dem Gesagten distanzieren könnte. Und auch Wolf selbst hat für ihren Roman eine ungewöhnliche, komplizierte Erzählperspektive aufgegriffen, hinter der sie sich zum Teil versteckt.

"Tatsachen! An Tatsachen halten".(170) So wollte Christ T. schreiben, falls sie es tun würde. Nicht mit verschlüsselten Worten, in einer Sprache, die sie täglich von offizieller. Seite hörte, die den Zeiten entsprechend ihre Interpretation des MarxismusLeninismus ändern, und infolgedessen neu erläutern würde. "Und darunter in einer Klammer: Aber was sind Tatsachen?"247 Die offizielle Antwort darauf, durch die parteitreue Gertrud Born ausgedrückt, lautete: "Die Spuren, die die Ereignisse in unserem Innern hinterlassen." 248 Keine klare Antwort, sondern ein Verantwortlichmachen Christa 
T.s für ihr eigenes Schicksal. Als gute Sozialistin wäre es nicht nötig gewesen, nach Tatsachen zu suchen, denn dadurch stellte sie den Wahrheits- und Wissensanspruch der Partei in Frage. Sie hätte sich anpassen sollen doch war sie "...süchtig nach Aufrichtigkeit." 249

Erstaunlich für die DDR-Kritiker, und erfreulich für die damals vierzigjährige Christa Wolf, muß die Reaktion von liberalen Kritikern in der Sowjetunion und in Polen gewesen sein. Als "Ereignis des Jahres 1969" bezeichnete Adam Krzeminski das Werk in 'Polityka'. Ein anonymer Rezensent hatte in einer Moskauer Literaturzeitschrift zum " 'moralischen Vorbild' ihrer Generation ausgerufen". ${ }^{250}$ Die Verurteilung des Werkes in der DDR wurde durch die positive Reaktion aus dem sozialistischen Ausland nicht beeinflußt. Die erste Auflage war schnell vergriffen, das Buch war durch die schnelle offizielle negative Stellungnahme sofort in Ungnade gefallen, und somit wurde eine Leserdiskussion, wie sie in den Literaturzeitschriften der DDR regelmäßig geführt werden, erst garnicht begonnen. Christa Wolfs Der geteilte Himmel war einer derartigen Diskussion ausgesetzt gewesen, doch dies sollte sich nicht in diesem Fall wiederholen.

Wie schon erwähnt hatte Max Walter Schulz auf dem VI. Schriftstellerkongreß im Mai 1969 Christa Wolf beschuldigt, sie würde Themen aufwälzen, die unproduktiv seien.

Wem nützt das? Wem nützt eine subjektiv ehrliche, parteilich gemeinte Absicht, wenn sie streckenweise im literarischen Text und im Gesamteindruck die Doppelbödigkeit der Aussage so eindeutig provoziert, daß sich die andere Seite nur zu wählen bracht, was sie gern herauslesen möchte. Wir sind nun einmal noch nicht allein auf der Welt, wir Sozialisten.... Besinn dich auf dein Herkommen, besinn dich auf unser Fortkommen, wenn du mit deiner klugen Feder der deutschen Arbeiterklasse, ihrer Partei und der Sache des Sozialismus dienen willst!"251

249 ebda, 171.

250 Stephan, 92.

251 Jagger, 134 
Die Einstellung der sozialistischen Genossen, die ihren Lob wenige Tage vor Schulzes Tadel ausgesprochen hatten, in Polen am 17.5., in der Sowjetunion am 14.5., war ungehört geblieben.

Erst nach dem VIII. Parteitag im Juni 1971, nach der Ablösung Ulbrichts durch Honecker und dem darauffolgenden politischen Klimaumschwung, sollte sich die Tabuisierung des Buches lockern. So hatte Kurt Hager auf dem 6. Plenum des ZK der SED verlauten lassen:

Wir können weder auf die Entdeckungen der Wissenschaften noch auf die Entdeckungen der Künste verzichten.... Es eröffnete sich mit dieser kulturpolitischen Orientierung der Weg für Autoren, Literaturwissenschaft und Literaturkritik, Gegenstand und Funktion sozialistischer Literatur neu zu bestimmen. 252

Bisher unterdrückte Werke Heyms und Kants erhielten endlich ihre Druckgenehmigung in der DDR, doch erst 1973 erschien die zweite Auflage der »Christa T.«. Viele DDR-Bürger, die vorher das Buch hatten lesen wollen, hatten es selbstverständlich weder in der Bibliothek noch im Buchhandel erhalten können. Aus diesem Grund war es ein Lieblingsgeschenk an DDR-Bürger geworden, welches westdeutsche Verwandte und Freunde ins Land geschmuggelt hatten. Als es 1973 in einer Höhe von 80 000 Exemplaren wieder in der DDR erscheinen durfte, war die Auflage schnell vergriffen. Bis 1980 hatte es drei Neuauflagen gegeben, doch ein Großteil der Kritiker in der DDR hielten an ihrer Einschätzung des Werkes fest, trotz der neuen Literaturphase und damit verbundenen Ideologie seit dem VIII. Schriftstellerkongreß. Nachdenken über Christa $T$, blieb demnach bei einigen Literaturkritikern in der DDR verpönt, war jedoch bei den Lesern in der DDR und vielen anderen Ländern beliebt. Das Buch war bis 1978 in viele Sprachen übersetzt worden, darunter Englisch, Französisch, Polnisch, Spanisch, Ungarisch, Tschechisch, Russisch und Japanisch. 
Sevin weist darauf hin, daß Christa Wolfs Einfluß auf die Rezeption ihres Buches durch ihre "essayistischen Selbstzeugnisse" bedeutend gewesen sein muß, denn er scheint eine "deutlich zunehmende Sympathie" erkennen zu können. 253 Sie hat "...wie kaum ein anderer zeitgenössischer Schriftsteller ihr Werk selbst kommentiert..."254. Diese Kommentare wurden auch zum größten Teil in der DDR veröffentlicht, wenn auch meist erst nach dem Druck der zweiten Auflage. Lesen und Schreiben erschien jedoch $1971 \mathrm{im}$ Aufbau Verlag in Berlin.

REZEPTION: SIND SIE IHRER ZEIT HINTERHER? LOESTS UND WÜLFFS 'REBELLION'

Erich Loests Erfahrungen mit dem DDR-Staat waren weitaus gravierender als Christa Wolfs. Sein Leben und das seiner Familie wurde drastisch von politischen Gegebenheiten der Zeiten, in denen er als Schriftsteller in der DDR tätig war, gezeichnet. Anhand seiner Erfahrung soll der Prozeß einer Buchproduktion, von Anfang, seit der Idee , bis zum Ende, zur Veröffentlichung, verfolgt werden. Dieses Buch Loests wurde einer anderen Form der Zensur als Wolfs ausgesetzt und steht beispielhaft für Werke der DDRLiteratur und deren Autoren, die ähnliches erfahren haben und noch erfahren.

Loest, Jahrgang 1926, lebt seit 1981 in der Bundesrepublik Deutschland. KarlHeinz Jakobs und er verließen die DDR im Frühjahr 1981, nachdem sie ein mehrjähriges Visum zur einmaligen Aus- und Einreise erhalten hatten.

Loest, wie viele Schriftsteller seines Alters, hatte nach Kriegsende große Hoffnungen für ein neues, sozialistisches Deutschland gehegt. Er wurde 1947 Mitglied der SED und ist seit 1950 freischaffender Schriftsteller. 1953 erhielt er seine erste 
Parteistrafe aufgrund von Veröffentlichungen nach dem 17. Juni, besuchte von 1955 bis 1956 das »Johannes R. Becher Institut«, und beteiligte sich an den Diskussionen, die auf den XX. Parteitag der KPdSU folgten. Chruschtschows Geheimrede über Stalins Verbrechen hatte in den sozialistischen Ländern großes Aufsehen erregt, und entfachte eine Diskussion in der DDR, die in Verhaftungen und Zuchthausstrafen gipfelte. Loests Beteiligung an den Debatten und sein Anschluß an den Philosophen Erich Bloch und den Literaturwissenschaftler Hans Mayer brachte ihm eine Strafe von sieben Jahren und sechs Monaten Zuchthaus ein, die er in Bautzen absaß3. Verurteilt wurde er wegen "angeblicher konterrevolutionärer Gruppenbildung". ${ }^{255}$ Seine Entlassung aus Bautzen erfolgte im September 1964. Danach schrieb er unter dem Pseudonym Hans Walldorf Kriminalromane, dann auch wieder Erzählungen und Romane unter seinem Namen.

Im Dezember 1971, auf der 4. ZK-Tagung der SED erklärte Erich Honecker, es gebe keine Tabus auf dem Gebiet von Kunst und Literatur, wenn man von der festen Position des Sozialismus ausgehe. Loest fühlte sich ermutigt, daß die Kulturdebatte, die unter Ulbricht geführt worden war, andere Dimensionen annehmen würde.

Eifrig wendeten [die Schriftsteller] Honeckers These, fanden sie verbindlich oder verschwommen,je nach dem Grade der Unverrückbarkeit ihres Glaubens in die heilige Sache des Sozialismus oder der Prügel, die sie schon von den eigenen Leuten bezogen hatten. (VZ 5)

Wie Loest in seinem Buch Der Vierte Zensor. Vom Entstehen und Sterben eines Romans in der DDR erläutert, wollte auch er prïfen, ob Honeckers Erklärung einer neuen, liberaleren Kulturpolitik tatsächlich glaubwürdig war und zu verwirklichen sei. Loests Buch ist eines der wenigen Dokumentationen, die sich mit dem Thema der Literaturproduktion in den siebziger Jahren, der Zensur in der DDR befassen, und dabei gleichzeitig ihre Behauptungen dokumentarisch belegen können. Dies gelang ihm durch

${ }^{255}$ Erich Loest, Der Vierte Zensor. Vom Entstehen und Stcrben eines Romans in der DDR (Köln: Edition Deutschland Archiv im Verlag Wissenschaft und Politik, 1984) 90, im folgenden unter dem Kürzel VZ mit den entsprechenden Scitenzahlen angegeben. 
regen Briefwechsel mit sämtlichen Instanzen, mit denen er zu verhandeln hatte, oder an die er sich mit Bitte um Hilfe wandte. Falls ihm schriftlich geantwortet wurde, was nicht immer der Fall war, verwahrte er die Korrespondenz als Beweismaterial auf. Anhand Loests eigener Erfahrung nachvollzieht er, mit welchen kultur- und parteipolitischen Ideologien und den damit verbundenen arbeitsbedingten Schwierigkeiten sich ein DDRAutor konfrontiert sieht. Die Verfasserin sieht sich gerechtfertigt, Loests Bestandsaufnahme Glauben zu schenken. Bei seinem Auszug aus der DDR nahm Loest sämtliche Aufzeichnungen mit, die er während der Debatte seines Manuskripts und später, nach Veröffentlichung des Buches, gesammelt hatte.

Günter Görlich beschrieb 1977 die kulturpolitische Lage in der DDR und die Rolle der Schriftsteller, zumindest derjenigen, die Mitglieder des Schriftstellerverbandes sind, wozu auch Loest zählte, folgendermaßen:

Meine Generation weiß aus eigenem Erleben, was es bedeutet, daß in unserem Land die politische, ökonomische, ideologische Herrschaft des Imperialismus überwunden wurde. Das ist die Grundlage aller unserer Erfolge. Darum anerkennen die Mitglieder des Schriftstellerverbandes die führende Rolle der Arbeiterklasse und ihrer Partei in der Kulturpolitik, darum verpflichten sie sich, dem Eindringen reaktionärer und revisionistischer Auffassungen im Bereich der Literatur entgegenzutreten und alle humanistischen Traditionen, besonders die der proletarischrevolutionären Literatur, zu pflegen und weiterzuführen. 256,257

Es gibt eine Vielzahl an Schriftstellern, Verbandsmitgliedern und Nichtmitglieder, die erfahren haben, auf welche weise die 'führende Rolle der Partei' handelt, als sei sie sich nicht sicher, daß der imperialistische Einfluß tatsächlich überwunden ist.

${ }^{256}$ Günter Görlich, "15\% Produktionssteigerung und immer noch zu wenig Bücher ," Kürbiskern 2 (1972): 157.

257 Imperialismus: Nach Marx.-Len. Auffassung höchstcs und letztes Stadium des Kapitalismus,. . . In der aktuellen SED-Propaganda spielen vor allem Begriffe wic US-I., Welti., westdeutscher I. eine Rolle. I. wie auch das Adjektiv »imperialistisch « sind nur auf kapitalistische (westliche) Staaten anwendbar. .. .Der Begriff stempelt die gesamte westliche Welt »historisch gesetzmäßig« zum aggressiven Gegner des sozialistischen Lagers, d.h. relativ unabhängig von der jeweiligen Politik des Westens. " Definition in: Martin Ahrends, Trabbi. Telespargel und Tränenpavillon. Das Wörterbuch der DDR-Sprache (München: Heyne, 1986) 92. 
Paranoide Reaktionen auf Schriftsteller und ihre Themen, Manuskripte oder schon verlegte Bücher sind wiederholt nachzuweisen.

Während der sogenannten zweiten 'Tauwetterperiode' Anfang der siebziger Jahre wurde bei Loest der Drang wach, "mal wieder etwas zu schreiben, das Hand und Fuß hat. (VZ 5) "Der Prüfstein ist immer noch die Praxis, wir sollen nicht herumklamüsern, sondern konfliktreiche, herzhafte Geschichten und Romane auf den Tisch legen, dann wollen wir mal sehen," (VZ 5) so Loests Reaktion auf Honeckers Aufruf an die Schriftsteller. Nicht außergewöhnlich für einen DDR-Autor dieser Jahre hospitierte Lost in einem Werk, da sein Held ein Ingenieur sein sollte. Er wollte das Milieu echt beschreiben, wollte wahrheitsgetreu einen Einblick in das Leben eines jungen Ingenieurs vermitteln, von seinen Sorgen und Nöten berichten. Selbstverständlich stellte er sich die Frage, die sich ein sozialistischer Schriftsteller stellen mußte:

Was war ein Held nun? Ein Aussteiger wohl nicht. Einer, der darüber nachgrübelte, was für einen Sinn es haben sollte, bis zur Erschöpfung zu rackern, zu lernen und nochmals zu lernen, wie Lenin es anempfohlen hatte, schon eher. War sein Held faul oder geniigsam, inwieweit sollte, durfte der Autor über ihn spotten und ihn an den Pranger stellen? Das war nicht ganz klar, quälte aber nicht und machte sogar einen Teil des Reizes beim Schreiben aus. (VZ 8)

Wenn Loest sich zu Beginn des Schreibprozesses noch nicht sicher war, welche Form sein Held annehmen würde, war er sich auf alle Fälle im klaren darüber, behauptet Loest, daß er ein Thema aufgreifen wollte, mit dem sich noch kein Schriftsteller befaßt hatte, oder, falls doch, der es nicht hatte veröffentlichen dürfen. Er wandte sich an den Leiter des Mitteldeutschen Verlages in Halle, Dr. Eberhard Günther, und unterbreitete diesem sein Vorhaben. Mit dem MDV hatte Loest schon früher zusammengearbeitet. Günther hatte Erfahrung mit der Zensur, so Loest, denn er hatte "...eine Zeitlang zur Zensurbehörde gehört, die sich Hauptabteilung für Literatur und Verlagswesen nennt, dort hatte er einmal einen Fehler gemacht und den Roman Das Kaninchen bin ich von Manfred Bieler zum Druck freigegeben. (VZ 8) Günther war dafür jedoch nicht mit 
Parteistrafen belegt worden und war Leiter des Verlages geblieben. Routinemäßig unterzeichneten Loest und sein Verlag im Dezember 1974 einen Förderungsvertrag, in dem das Interesse des Verlages an der beabsichtigten Arbeit an einem Roman mit dem vorläufigen Titel Es geht seinen Gang oder Mühen in unserer Zeit festgelegt wurde. Der Autor sollte für sechs Monate eine Arbeitshilfe von 500 Mark monatlich erhalten. Gebeten wurde Loest, dem Lektor und Parteisekretär des Verlages, Joachim Hottas, sobald wie möglich den ersten Teil des Manuskripts zu senden, damit dieser auch seinen Teil des Vertrags erfüllen konnte, nämlich das Manuskript zu redigieren. Es war Loests Angewohnheit wenn er schrieb, Durchschläge seiner Kapitel zu kursieren. Er bat seine Bekannten, als er z.B. das Kapitel über die Schlacht am Leuschnerplatz, das später am meisten umstrittene Kapitel, weiterreichte, ihm Kritik zukommen zu lassen. Dazu vermerkte er :

Ich bitte, mir zu sagen, was Du für langweilig hältst oder worüber Du eine andere Meinung hast, wo unsere Erfahrungen auseinandergehen. Aber eines verbiete ich mir: Niemand darf zu mir sagen: Was Du da geschrieben hast,druckt sowieso keiner! Ich kann jetzt keinen inneren Zensor gebrauchen. (VZ 9)

Ein 'saft- und kraftloses Romänchen' wollte er nicht schreiben, behauptet Loest, sondern feststellen, worin die 'feste sozialistische Position' bestand, von der Honecker sprach, und von der die Künstler ausgehen mußten. Selbstverständlich war er sich der Zensur bewußt, die von Seiten des Verlags auf ihn zukommen würde, eventuell auch des Ministeriums und des Schriftstellerverbandes. Mit dem 'vierten Zensor', wie ihn oft die von der Zensur betroffenen Schriftsteller bezeichneten, hatte er jedoch nicht gerechnet.

Neben seinem Lektor Hottas befaßte sich, was nicht ungewöhnlich war, ein zweiter Lektor, Gert Noglik, mit seinem Buch, indem er Manuskriptstellen las, jedoch kommentarlos blieb.

Ach, es schrieb sich leicht, nachdem erst einmal die wichtigsten Figuren ein- und ausgebaut waren. Nun ergaben sich Konstellationen wie von selbst, der Autor war gespannt darauf, was sich..." aus dem Verhalten seiner Personen "... ergeben mußte. (VZ 10) 
Im Juli 1975 schickte er 80 Seiten an den Verlag, im August weitere 80.

Im Herbst glaubt er, einen großen Teil des Romans beendet zu haben, und ließ ein Exemplar in die Bundesrepublik 'gelangen'. Loest verschweigt in seiner Dokumentation die Art, in der das Manuskript in den Westen gelang. Er läßt sich außerdem nicht auf eine Erläuterung seiner Motivation ein. Doch es erreichte Gerhard Zwerenz. Vier Wochen nach Abgabe beim Verlag der ersten 163 Manuskriptseiten, am 4.11.1975, mahnt er seinen Lektor mangels Antwort. "Nun fühle ich mich in der Luft hängend. Ich habe starke Nerven und kenne Euer Haus: das ist gut so, ein Neuling könnte leicht deprimiert werden." (VZ 11) In der Zwischenzeit beteiligte er sich, wie es besonders bei Schriftstellem in der DDR üblich ist, an Lesungen. Er las oft aus seinem neuen, unveröffentlichten Roman, so auch in Leipzig. Sein Lektor hatte sich ihm einmal auf seine Einladung hin angeschlossen und beantwortete Fragen der Zuhörer. "Es ist unsere Art, Bücher zu bringen!"(VZ 11) war Hottas Antwort auf die skeptische Frage aus dem Publikum, ob der Verlag wirklich dieses Buch verlegen würde.

Einige Tage später erhielt Loest jedoch Hottas schriftliche Ablehnung des Romans. Die Begründung: der Held sei "eine Durchschnittsfigur, ...die sich nicht beweisen müsse, weich und feige, wenig erregend, wenig interessierend. "(VZ 11) Und außerdem, kommentierte Hottas, habe das Publikum während der Lesung an den 'falschen' Stellen gelacht.

An Wülff, dem Helden des Buches, wie ihn Loest entwickelt hatte, sollte seit dieser Ablehnung immer wieder Anstoß genommen werden. Er paßte nicht in das Schema des sozialistischen Helden, der sich, wie schon andere DDR-Schriftsteller ihn dargestellt hatten, mit den Realitäten des sozialistischen Alltages herumschlagen durfte, der jedoch am Ende nicht an der Gesellschaft scheitern sollte.

Loest protestierte, und die Diskussion um das Buch wurde fortgesetzt, denn Hottas erklärte sich noch interessiert. Loest war gewillt ein paar Änderungen 
vorzunehmen, bat aber gleichzeitig um einen Vertragsabschluß. Der Autor und sein Verleger einigten sich, damit bis Anfang Januar 1976 zu warten. Mehr als ein Jahr war seit der Konzeption des Buches verstrichen. Am 15. Januar, nachdem Loest nichts vom Verlag vernommen hatte, bat er sowohl um sofortige Antwort auf seine Mahnung, als auch um die Rückgabe des Manuskripts. "Ich möchte es ergänzen und dem Verlag eine durchgehende Fassung (315 Seiten) zustellen."(VZ 13)

In diese Ereignisse fiel Loests Genehmigung, eine von ihm beantragte Reise in den Westen zu unternehmen, um die er sich schon seit Jahren bemiiht hatte. Bevor ihm eine Reiseerlaubnis genehmigt werden konnte, bestellte der Leiter der Auslandsabteilung ihn zu einem Gespräch. Dieser ermahnte, "es werde neuerdings in der BRD gern die Unteilbarkeit der deutschen Literatur herausgestellt, das sei verkapptes Vereinigungsgerede, L. solle auf der Hut sein und gegebenenfalls widersprechen."(VZ 13)

Klaus Höpcke, Stellvertreter des Ministers für Kultur der DDR, hatte im April 1975 im Neuen Deutschland noch einmal die offizielle Einstellung zum Thema Nationalliteratur dargelegt und die "Entwicklung der eigenen Literatur" im Einklang mit der "Literaturen der sozialistischen Brudervölker" gepriesen. ${ }^{258}$ Es war die Aufgabe eines jeden Repräsentanten der DDR, diesen Standpunkt zu unterstïtzen.

Loest erhielt die Genehmigung, durfte sich fünf Tage in der Bundesrepublik aufhalten, gab, der Ermahnung nicht folgend, dem Hessischen Rundfunk ein Interview und reiste nach München zu einem Gesprïch mit den Vertretern der Autoren-Edition des Bertelsman Verlages. Laut Loest beging er den Fehler, den Anwesenden zu unterbreiten, ihm würden in der DDR mit seinem Manuskript Schwierigkeiten gemacht, er wolle es nun der Autoren-Edition zur Ansicht geben. Darauf erwiderte Uwe Timm, einer der Editionsmitglieder, dies geschehe ohne die Genehmigung des DDR-Verlages. Bei seiner 
Rückkehr nach Frankfurt zu Zwerenz, bei dem Loest wohnte, stellte er fest, daß sein Freund wegen Timm Bedenken hatte. Von dessen Mitwirken bei der Autoren-Edition war. Zwerenz nicht unterrichtet gewesen. Tinım war DKP-Mitglied, darum befürchteten die beiden Schriftstellerkollegen, Timm würde die DDR über Loests Angebot unterrichten. Zwerenz erklärte Loest er habe gedacht, "...die DDR-Behörden würden vielleicht nicht allzu böse sein, wenn L.s Roman in der linksgenossenschaftlichen Edition erschiene und nicht in einem großbürgerlichen Verlag. (VZ 16) Doch Loest erkannte die Gefahr, die er gelaufen war. Er war im Begriff sich zu emanzipieren. Sein eigenmächtiges Handeln würde bei den Behörden weitaus größeres Mißtrauen erregen.

Wieder in die DDR zurïckgekehrt wandte er sich in einem, die bis zu diesem Zeitpunkt abgelaufenen Ereignisse seines Verhältnisses mit dem Verlag zusammenfassenden Beschwerdeschreiben an Verlagsleiter Günther. Darin unterrichtete Loest den MDV auch von seinem westdeutschen Kontaktverlag und dessen Interesse an seinem Roman. Entweder solle endlich eine Entscheidung über den Vertrag getroffen werden, oder er werde sich an einen anderen Verlag wenden. Fragt Loest seinen Verleger: "Die Frankfurter Allgemeine Zeitung erwägt einen Vorabdruck - mache ich das alles auf eigene Faust oder mit dem Verlag zusammen." (VZ 17) Es 'auf eigene Faust' zu unternehmen würde äußerst schwierig für ihn sein, doch ließ er keine Zweifel an seiner Absicht. Daß dies nicht ungehindert geschehen könnte, dafür hatten die Gesetzgeber der DDR gesorgt. Prompt erhielt Loest eine schriftliche Antwort, worin Günther vorschlug im Februar die Sachlage zu besprechen. Er driickte seine Empörung über Loests Ton aus und erwähnte seine ideologischen und ästhetischen Einwände gegen das Manuskript, das er nun endlich selbst zur Hand genommen hatte, um es zu lesen.

Loest mußte mit einer Konfrontation gerechnet haben, denn er begann zu diesem

\section{Zeitpunkt}


dreißigjährigen Friedenspfad durch den DDR-Bücherwald sollten nicht nur erfolgreiche Bücher von Interesse sein, sondern auch ungedruckte, er sollte die Namen von Förderern von Literatur ebenso kennen und nennen wie die von Verhinderern.(VZ 10)

Sämtliche Besprechungen hielt er von nun an schriftlich fest. Ein Ansatz wurde gemacht, den Konflikt durch ein gemeinsames Gespräch zu beheben. Teilnehmer waren Günther, Hottas, Cheflektorin Duty und Loest. Lektor Noglik war nicht anwesend, denn er hatte eine weitere Arbeit an dem Buch abgelehnt, ohne jemals Loest davon unterrichtet zu haben. Selbst über dessen Roman hatte er sich nie Loest gegenüber geäußert.

Die Verlagsvertreter erläuterten ihre Einwände zu dem Manuskript. Günthers hob Einspruch gegen die Wahl des Helden Wülff, der ein Versager sei im sozialistischen Sinn. Der erfahrene Cheflektor räumte ein, daß solche Leute wie Wülff in der DDR existierten, "...sie entsprächen keineswegs dem Geist der Epoche."(VZ 19) Auch beanstandete er die Rolle Grossers, Wülffs Vorgesetztem, der in seiner Arbeit überlastet ist und zu Herzanfällen neigt, woraus der Eindruck entstünde, "in unserer Wirtschaft würden die Leiter durch den Streß kaputtgemacht." (VZ19) Sein dritter Einwand galt der Darstellung des Schwimmlehrers und des Vaters, den Wülff als 'Nazi" beschimpft, und er fragte sich, ob da "...nicht unserer Leistungsgesellschaft ein antihumaner Zug angedichtet" würde. (VZ19) Cheflektorin Duty beanstandete, daß die Schuld an Wülffs Verhalten den Behörden zugeschoben würde. Aufgrund ihres Verhaltens den jungen Demonstranten auf dem Leuschnerplatz gegenüber, seien sie an Wülffs Versagen schuldig. Sie nahm an, dieses Bild entstiinde entgegen L.s Absicht beim Leser, worauf Loest ihr "...versichert, dies alles erfahre der Leser nicht entgegen, sondern mit seiner Absicht." (VZ19) Auch hatte sie gehofft, in Jutta, Frau Wïlff, das positive Gegenteil zu Wülff entwickelt zu sehen, was nicht der Fall war. Fazit der Unterredung war der Rat der Verlagsvertreter, Loest solle seinem Roman eine neutralere, weniger problematische Perspektive verleihen. Er solle es "...von einem erhöhten Standpunkt aus in der dritten Person noch einmal versuchen." (VZ 20) 
Die Aufgabe der Lektoren und Gutachter ist es in Zusammenarbeit mit dem Autor vor Erscheinen eines Buches zu garantieren, daß der Inhalt den ideologischen Thesen der Zeit entsprechen. Die Verlagsvertreter hatten versucht, ihre Aufgabe zu erfüllen.

Nachdem Loest das Ende des Buches erläutert hatte entstand eine politische Debatte, die in Günthers Verweigerung eines Vertragsangebots gipfelte. Vieles müsse geändert und das gesamte Buch überprüft werden.

Zwei Wochen später, bei einem erneuten Gespräch mit Günther, verweigerte Loest die Zensurmaßnahmen. Er erklärte, "er würde nicht grundlegend umarbeiten, sondern nur hier und da kosmetisch verbessern," (VZ 21) und drohte damit, sich an einen anderen Verlag wenden. "Es liegt eine grole Verantwortung darin, ein Buch herauszubringen" (VZ 21) erwiderte Günther. "Es liegt eine große Verantwortung darin, ein Buch nicht herauszubringen," (VZ 21) konterte Loest.

Loest war in die Enge getrieben worden, aufgrund seines Emanzipationsversuchs, und würde sich, zumindest in gewissem Maße, kompromißbereit zeigen müssen. Schreibt Loest:

Der Mitteldeutsche Verlag würde den Roman ablehnen, das stand für L. fest, aber vorher würde er das ganze Manuskript sehen wollen und Gutachten anfordern, das kostete Zeit und wieder Nervenkraft. Vorher kam L. aus dem Vorvertrag nicht heraus, es gab keinen anderen Weg. (VZ 21)

Im Mai 1976 lehnte die Autoren-Edition die Veröffentlichung seines Romans ab. Eines seiner Hörspiele wurde vom DDR-Hörspiel nicht angenommen. Dieses Hörspiel hatte er an den Hessischen Rundfunk verkauft, der es kurz darauf sendete. Erich Honeckers neue Kulturpolitik samt literaturpolitischer Freiheit, mit der viele Kulturschaffende in der DDR, darunter Loest, nach Ulbrichts Rücktritt und Honeckers Erklärung gerechnet hatte, schien sich nicht zu verwirklichen. "Grenzen überall - L. meinte, man könnte auch sagen: Tabus." (VZ 21) Seit Honeckers Rede waren schon vier Jahre verflossen, doch Loest konnte keine Lockerung der Zensur erkennen. Seine 
ursprüngliche Vermutung, die Funktionäre, die die kulturpolitischen Entscheidungen träfen bräuchten ihre Zeit, sich auf die neue Phase einzustellen, begann sich als ungerechtfertigt herauszustellen.

Im Laufe des Sommers erfuhr Loest von einer, deren Anonymität er bewahrt, "...hinter vorgehaltener Hand, Hottas verfasse eben ein zehnseitiges Ablehnungsbescheid, dazu habe man ein Außengutachten angefordert." (VZ 22) Um gewisse Kollegen und Freunde, die noch in der DDR leben oder noch nicht verstorben sind, vor Repressalien zu schützen, unterläßt es Loest an vielen Stellen in seiner Dokumentation Namen zu nennen. Dieses Außengutachten wurde benötigt, um sich an offiziell festgesetzte Regeln zu halten. Dem Lektor ist es nicht gestattet, die Entscheidung allein zu treffen, er benötigt ein Gutachten. Loest machte sich darauf gefaßt, und führte seine Arbeit an anderen schriftstellerischen Arbeiten fort.

Ein Antrag beim Schriftstellerverband ein zweitesmal in die Bundesrepublik reisen zu dürfen wurde mit der Begründung abgelehnt, falls man etwas von ihm wolle, sollte man 'gefälligst' nach Leipzig kommen. Loest hatte während seines ersten Besuches ohne Genehmigung eine Geschichte im Rundfunk gelesen, was ein weiterer Grund hätte sein können, ihn nicht reisen zu lassen. Im Oktober des darauffolgenden Jahres, 1977, durfte Loest seine zweite Reise antreten.

Ende des Jahres 1976, im September, erfuhr Loest, Joachim Nowotny, ein vom Verlag herangezogener neuer Außengutachter, habe es abgelehnt, ein negatives Gutachten zu schreiben.

Nowotny war ein "integrer Genosse, war Mitglied des Verbandsvorstandes (und sollte es noch zum Vizepräsidenten bringen), war Dozent am Literaturinstitut in Leipzig fürs Proseminar. Nowotny war nicht irgendeiner, und so horchte Günther auf. Kommando zurück! entschied er, erneut prüfen, erneut lesen!" (VZ 23)

Hier verdeutlicht sich, in welchem Ausmaß literarische Qualität oder schriftstellerisches Können mit dem Erfolg oder Mißerfolg eines Werkes zu tun haben. Der 
Anschein entstand, Nowotnys Gutachten, aus welchem Grund auch immer es positiv ausfiel, habe dem Verlag das Zeichen gegeben, Loest zu unterstützen. Berufliche Konsequenzen zogen Hottas und Duty. Sie verloren darüber ihre Arbeit an dem Projekt, und im selben Monat wurde Loest Klaus Walther, ein neuer Mitarbeiter, vorgestellt. Walther war Loest nicht unbekannt, ein Außenlektor, Kritiker und Genosse, Mitglied der Bezirksleitung der SED in Karl-Marx-Stadt. Wieder bat man Loest, seine Erzählperspektive zu ändern, mit der Begründung, auf diese Weise könnten Kommentare zu Wülffs Handlungen und Denkweise gegeben werden. Und von neuem sträubte sich der Autor gegen den Vorschlag, führte als Beispiel Erik Neutsch an. Dieser hatte 1973 einen Roman veröffentlicht, der als Gegenentwurf zu Christa Wolfs Nachdenken über Christa $\underline{\text { T gedacht war. Neutsch war auch 'angeraten' worden, in seinem Buch Auf der Suche }}$ nach Gatt einen, die Perspektive ändernden, Erzähler einzuführen. Er war dem Rat gefolgt. Loests Kommentar: "Mit dem hat Neutsch dann sein Buch gründlich verdorben." (VZ 24) Walther schlug weiter vor, Huppel als Gegenpol zu Wülff auszubauen, als der starke, erfahrene Arbeiter und das alte Parteimitglied, Absolvent der Arbeiter- und Bauernfakultät. "Der könnte doch Wïlff die Leviten lesen, ihm vorhalten, daß er sich drücke, heraushalte." (VZ 24) Loest besann sich und beschloß, von einer Arbeitsmethode gebrauch zu machen, die er sich als Schriftsteller angeeignet hatte. Auf "bewährte Methoden" zurückzugreifen, um "guten Willen zu zeigen.... Warum nicht hier und da zehn Zeilen anfügen, dachte er, und, wenn sie angeklebt wirken, bei späterem Arbeitsgang leise wieder rausstreichen."(VZ 24) Ein Vertrag stand immer noch aus, wofür Günther zuständig sei, laut Walther.

Ein weiterer Rückgriff auf berufliche Tricks sollte ihm ein wenig helfen. Er "ließ ein Kapitel neu tippen, das hinterließ immer einen guten Eindruck: Seht her, wie gründlich ich gearbeitet habe," (VZ 24) kommentiert Loest sarkastisch. 
Seit der Konzeption des Romanes hatte sich auf DDR internem und deutschdeutschem Gebiet einiges ereignet, was einerseits die Bürger in beiden Teilen Deutschlands hoffen lassen konnten, ihnen andererseits wieder vor Augen führte, daß sich weder die DDR einer Demokratisierung näherte, noch daß eine Wiedervereinigung der beiden Staaten in Aussicht stand. Am 7. Oktober 1974, zum 25. Jahrestag der Staatsgründung, war unangekündigt die Verfassung der DDR geändert worden.

An die Stelle des bisherigen Bekenntnisses zur 'deutschen Nation' und zur 'schrittweisen Annäherung der beiden deutschen Staaten bis zu ihrer Vereinigung auf Grundlage der Demokratie und des Sozialismus' tritt die Unterscheidung zwischen 'sozialistischer Nation (mit eigener Staatsangehörigkeit) und 'deutscher Nationalität' in der Absicht, die DDR von der Bundesrepublik Deutschland abzugrenzen. 259

Es gab nun keinen Bezug mehr auf ein einheitliches Deutschland. In Helsinki war am 1. August 1975 die Schlußakte der KSZE (Konferenz über Sicherheit und Zusammenarbeit in Europa) unter anderem von der DDR und der Bundesrepublik unterzeichnet worden. Diese Schlußakte "...erstrebt, einen multilateralen politischmoralischen Verhaltenskodex in Europa über die Ost-West-Grenzen hinweg aufzustellen." 260 Sie beinhaltet einen Punkt über "Zusammenarbeit in humanitären und anderen Bereichen", worin als Leitziel auch Reisen aus persönlichen und beruflichen Gründen und Informationsverbreitung, -zugang und -austausch angegeben werden. Im Juni 1976 tagten 29 kommunistische Parteien Europas in Ost-Berlin. Lebhaft diskutiert wurden die KSZE-Schlußakte und deren Zustimmung durch die DDR. Da alle Reden dieser Veranstaltung veröffentlicht werden mußten, konnte die Bevölkerung an der Debatte über die Gewährung der Menschenrechte in der DDR teilhaben. Infolgedessen stieg die Zahl der Ausreiseanträge stark an.

${ }^{259}$ Hans Georg Lehmann, Chronik der DDR. 1945/49 bis heute (München: dtv, 1987) 96. 260 ebda, 99. 
Ökonomische Schwierigkeiten in der DDR waren zum Teil durch die damalige weltweite Erhöhung der Erdölpreise bedingt. Die Schriftsteller erfuhren, daß das Papierkontingent nicht erweitert würde, was direkten Einfluß auf den Druck ihrer Werke und somit auf ihre finanzielle Lage hatte.

Alle merkten, daß begehrte Waren seltener waren als noch vor zwei oder drei Jahren, und teurer wurden sie sowieso. Preissprünge bei Schuhen, Lederwaren, Bettwäsche, knapper denn je waren Ersatzteile für Autos. Unsere beste Zeit, sagten die Leute, ist wohl vorbei.(VZ 23)

Man schrieb das Jahr 1976.

Auch auf kulturpolitischer Ebene hatte es Aufregung gegeben. Reiner Kunzes Ausschluß aus dem Schriftstellerverband im Oktober 1976 hatte Aufsehen erregt. Kunzes Die wunderbaren Jahre war im September in der Bundesrepublik erschienen. Jedoch die größten Konsequenzen brachte die oben behandelte Ausbürgerung Wolf Biermanns im November 1976 mit sich. Inwiefern das kulturpolitische Klima umgeschwungen war, zeigte sich durch diese Maßnahme. Biermanns Ausbürgerung, erlïutert Seyppel in seiner Behandlung dieser Jahre war nicht der Beginn des Umschwungs, sondern nur ein Zeichen der Zeit, die nicht lange nach Honeckers Amtsiibernahme begonnen hatte. Die schon beschriebenen Konsequenzen der Biermann Protestwelle waren enorm.

Inwiefern und auf welche Weise die veränderte politische Lage auf einen Schriftsteller Einfluß nahm, der den Protestbrief jedoch nicht unterzeichnet hatte, illustriert Loests persönliches Schicksal und das seines Buches. Zwei Jahre vor der Biermann-Affäre hatte er seinen Roman begonnen. Seinen Kampf gegen die von ihm verspürte Zensur führte er auch schon so lange. Nun hatte das Verhalten der Behörden einen weitverbreiteten Einfluß in Künstler- und Verlagskreisen. Erklärt Loest:

Nichts vorher und bis heute nichts wïhlte so auf, kehrte so um, polarisierte, stürzte so viele Menschen in unberechenbare Wirbel wie die Ausbürgerung Wolf Biermanns durch die Behörden der DDR und der darauf folgende Protest.(VZ 25) 
Loest erhielt seinen Vertrag drei Tage nach den Ereignissen des 17. November. Dies könne verwundern, doch sogar Bücher der Unterzeichner des Briefes erschienen wie geplant, darunter auch Christa Wolfs Kindheitsmuster in einer Erstauflage von 60000 Exemplaren. In seinem Vertrag wurde Loest eine Auflagehöhe von 12000 Exemplaren garantiert, $15 \%$ Honorar sollte er erhalten. Er erhob Einspruch gegen die seines Erachtens niedrige Auflagehöhe. "10 000 war die normale Startauflage, natürlich lag sie bei den Großen der Zukunft, Christa Wolf oder Strittmatter, wesentlich höher."(VZ 25) Loest gab sich jedoch zufrieden, besonders weil Günther erwähnte, eine zweite Auflage im selben Jahr sei möglich.

Bemerkenswert scheint, daß Loest sich den Unterzeichnern des Protestbriefes nicht anschloß. Sein Verleger wies in dem Gespräch darauf hin. Loests eigensinnige, jedoch verständliche Begründung:

Niemand habe ihn darum ersucht, und sollte es noch geschehen, werde er sich verweigern. Aber er werde sich auch nicht auf die Seite derer schlagen, die der Ausbürgerung zujubelten. Als er ins Zuchthaus gegangen sei, habe das keinen seiner Kollegen auf die Barrikaden gebracht, andererseits sehe er als alter Knastologe keine Veranlassung, eine Polizeimaßnahme zu lobpreisen.(VZ 26)

Die Strafmaßnahmen der Partei gegen die protestierenden Kulturschaffenden waren unterschiedlich ausgefallen. Loest wartete darauf bis Günther, der als Verleger direkt von der Affäre betroffen war, wieder mit ihm über seinen Roman reden könnte, denn dieser hatte nach der Vertragsunterzeichnung erneut von "gewissen Änderungen"(26) gesprochen. Im April, fünf Monate nach Vertragsabschluß, kam es zum, so hoffte Loest, letzten Streitgespräch über das Manuskript zwischen Günther und ihm. Stundenlang besprachen sie 26 Punkte, die beanstandet worden waren. Wieder einmal stand das Kapitel über die Schlacht am Leuschnerplatz zur Debatte, ein Satz sollte gestrichen werden, sonst, drohte Günther, würde er das Manuskript nicht einreichen. Der gesamte Schlußabsatz eines Kapitels wird gestrichen, Loests Kommentar, der an Goetz von Berlichingen erinnnert. Diese Passage verdeutlicht Wülffs Rückzug aus dem Leben 
eines engagierten DDR-Bürgers. Den engstirnigen Politiker scheint er aufzufordern:

"Genosse, du kannst mich mal...". Wülff stellt sich vor, er würde vor seinem Nachbarn, dem Mitglied des Zentralkomitees, sein Gesäß entblößen und fragen:

$\mathrm{Na}$, wie findest du das nach zehn Jahren? Ich müßte gewiß lange reden, ehe ich ihm begreiflich gemacht hätte, daß so was noch andere Narben hinterlie $B$, unsichtbare auf der Seele und auf diesem rotfunkelnden Organ, das politisches Bewußtsein heißt. Ich malte mir aus, wie der Genosse zuhörte und nicht lachte wie immerzu in der Zeitung. Ich hoffte, er sagte nicht: Davon weiß ich nichts, damals war ich in Berlin. Und ich hoffte noch viel weniger, daß er sagte: Vielleicht hast du dich an einem Haken auf dem Boden gerissen, hast du nicht damals deine Luftmatratze gesucht? Spinnerei. Aber eines halte ich für erwiesen: Daß, wo geschlagen wird, immer zwei sind."(VZ 27) 261

Verwunderlich und lächerlich zugleich erscheint die Begründung Günthers zur Streichung dieses Absatzes. "Auch hier gehe L. am Geist der Epoche vorbei, sozialistische Demokratie und Verantwortung seien ungleich kompliziert."(VZ 28) Es scheint, er habe selbst nichts gegen das Bild des 'politischen Organs' einzuwenden.

Bis Weihnachten 1977 sollte das Buch fertig sein, "wenn alles einigermaßen abliefe"(VZ 28), hatte Günther angedeutet. Es soll April 1978 werden, bis die erste Auflage des Romans endlich erscheint. Begründung für einen Verschub der Auflage vor Jahresende war die Kürzung des Papierkontingents, ein Argument das, laut Elke Stenzel und dem Kulturpolitischen Wörterbuch immer wieder Verwendung findet. Da jedem Verlag nur eine begrenzte Menge an Papier pro Jahr zugeteilt wird, muß der Verlag entscheiden, welche Werke zuerst auf den Markt kommen. Nicht nur von kulturpolitischen Kräften wird die Entscheidung, sondern auch marktwirtschaftliche Bedenken haben eine Auswirkung. Der Mangel an Papier ist unter betroffenen Schriftstellem als Zensurmaßnahme bekannt. Der MDV müsse wegen dieser Kürzung sein Programm neu gliedern, wurde Loest unterbreitet, doch Anfang 1978 würde es gewiss erscheinen.

${ }^{261}$ Dieser Teil ist auch nicht wieder in der endgültigen Fassung des Buches erschienen. Der Hinweis auf den Haken bezicht sich auf des jungen Wüllf Ausredc, wie er sein Gesäss verletzt habe. Der Vergleich des 'rotfunkelnden Organs', mit dem politischen Bewußtsein hat sich auch nicht im Text eingeschlichen. 
Auf der Leipziger Herbstmesse wurden unter Günthers Leitung die Rechte zu Loests Buch an die Deutsche Verlagsanstalt (DVA) Stuttgart weitergegeben. Bedenken hatte der Verlag dabei anscheinend keine. Um Devisen für die DDR zu erhalten, werden regelmäßig Lizenzausgaben von DDR-Werken in der Bundesrepublik veröffentlicht, auch von solchen, die in der DDR selbst nicht erscheinen dürfen. Die DVA stellte einen Auftrag, 3000 Exemplare sollten zusammen mit der DDR-Auflage in Leipzig gedruckt werden. Loest sollte 35\% seines Honorars in Valutaschecks erhalten.

Aufs neue beantragte Loest eine Reise in die Bundesrepublik, die ihm sofort genehmigt wurde. Er erklärt in seiner Dokumentation Der Vierte Zensor, "jetzt wollte er für ein Buch Reklame machen, das der DDR womöglich Ansehen, gewiß Devisen einbringen sollte."(VZ 29) Es stellt sich die Frage, inwiefern Loest diese Begründung ernst meint, oder zynisch ist. Nach all den Schwierigkeiten, die ihm in den Weg gelegt wurden, und, wie er selbst erläutert, sind dies nicht die ersten gewesen, sondern nur die ersten, die er so genau dokumentiert hat, bezweifelt die Verfasserin seine hier angegebene Motivation? Das Ansehen, das dieses Buch der DDR bringen sollte, wäre gewiss nicht solcher Natur, wie es sich die DDR-Behörden wünschen würden. Allein Günthers Einwände gegen den Helden des Buches und die daraus zu schließenden Probleme in der DDR-Gesellschaft wären erneut ein Beweis der Unzufriedenheit in der Bevölkerung und unter den Schriftstellern. Gerade durch die Biermann Ausbürgerung war der DDRLiteratur in der Bundesrepublik erhöhte Aufmerksamkeit geschenkt worden. Zu fragen wäre also, warum Loest nun gerade zu diesem Zeitpunkt so schnell seine Reisegenehmigung erhielt. Sein vorheriger Antrag, kurz nach den vielen Parteiausschlüssen, Verhaftungen, Ausreisen und Ausweisungen der Biermann-Sympathisanten, war nicht genehmigt worden.

Im Oktober 1977 war die Veröffentlichung der Romane zweier DDR-Schriftsteller untersagt worden: Jurek Beckers $\underline{\text { Schlaflose Tage und Rolf Schneiders November. Jurek }}$ 
Becker, einer der Unterzeichner des Biermann Protestbriefes, hatte als erster ein mehrjähriges Visum erhalten und war in die Bundesrepublik gegangen. Rolf Schneider lebte noch in der DDR. Im selben Monat erschien im MDV jedoch Werner Heiduczeks zweiter Roman Tod am Meer, der in der DDR großes Aufsehen erregte. Held des Romans ist ein "opportunistischer Schriftsteller, der sich angesichts des Todes mit seinen Fehlentscheidungen auseinandersetzt, die sich nicht nur als subjektive erweisen." 262 Der Roman, in Zügen autobiographisch, war sofort vergriffen.

L. meditierte darüber, ob solch ein Buch vor fünf Jahren begonnen, jetzt auf dem Mark, wirklich in diese Monate passe, ob sich der Wind nicht schon wieder gedreht habe.... War's kühl geworden in der Kulturpolitik? Eine Äußerung des Kulturministers dort, die Ablehnung eines Manuskripts hier, Klima setzt sich aus vielen Komponenten zusammen. Es war ja immer so gewesen, wenn die Kulturpolitik ins Schleudern gekommen war, nach dem 17. Juni 1953, nach dem XX. Parteitag der KPdSU drei Jahre später - nach einiger Zeit, langsam und leise hatten sich die beharrenden Kräfte konsolidiert, sie, die Hüter des Sozialistischen Realismus, des positiven Helden und der fiihrenden Rolle der Partei.(VZ 31)

Eine zweite Auflage des Buches wurde verboten, aber erst Wochen später.

Das 'Sterben eines Romans' kann zu unterschiedlichen Zeiten, während verschiedener Phasen seiner Herstellung, oder auch erst nach seinem Erscheinen geschehen. Von besonderer Bedeutung nach dem Erscheinen ist die Beurteilung der Literaturkritiker, die jahrelang die einzigen offiziellen Vertreter der Literaturpolitik waren, und somit auch der Literaturtheorie der Zeit, waren. Immer mehr Schriftsteller waren im Laufe der Jahre dazu übergegangen, sich selbst über Literaturtheorie auszulassen, doch stehen ihre Interpretationen und Vorschläge weitaus seltener im Einklang mit der offiziellen Linie. ${ }^{263}$ Die offizielle Literaturkritik, die jedoch in den meisten Fällen die Einstellung der Partei vertritt, befindet sich in den Organen der Partei und des Schriftstellerverbandes. Darin verlauten bekannte Kritiker wie Horst Haase,

${ }^{262}$ Manfred Braunek, Hrsg., Wcltlitcralur im 20. Jahrhundert, 560

${ }^{263}$ Beispiele sind Christa Wolf, Eva Strittmatter, Jurek Becker 
Alexander Abusch und Hans Kaufmann ihre Urteile. Zu finden sind diese Rezeptionen vor allem in den Zeitschrift "Neue Deutsche Literatur" und "Sinn und Form", sowie in "Neues Deutschland", dem Zentralorgan der SED und "Sonntag", eine Veröffentlichung des Kulturbundes.

Dr. Günther, der Verleger, hatte Heiduczeks Buch durchgehen lassen, ein Vergehen, für das er schon einmal in Ungnade gefallen war.

Die Konservativen, Abusch, Gotsche und wie sie hießen, mußten ja erst einmal dahinterkommen, daß hier ein in ihren Augen subversives Buch auf dem Markt war, dann mußten sie lesen, ihre Pfeile aus dem Köcher ziehen und auf die Bogensehne legen. Das brauchte Wochen.(VZ 32)

Sechs Monate später erschien Loests Roman unter dem Titel Es geht seinen Gang oder Mühen in unserer Ebene, "schwarz-gelb die Ostausgabe, schwarz-weiß die für die Bundesrepublik, vom gleichen Stock gedruckt die beiden, die Westware natürlich auf besserem Papier."(VZ 34) Im Juni, knappe zehn Wochen später, erfuhr der Autor, daß eine zweite Auflage verboten worden war. Es hieß, das Ministerium für Kultur hatte eine weitere Verbreitung des Buches auf diese Weise untersagt. In der Zwischenzeit, so erläutert Loest selbst, genoß der Autor seinen Triumpf über das System. Günter Kunert, der im darauffolgenden Jahr die DDR verlassen sollte, schrieb ihm:

Nun enthält auch Dein Buch keine Enthüllungen irgendwelcher Geheimnisse, das ist auch nicht der frappierende Zug daran, sondern die Intensität, mit der die Misere dargestellt ist, und - natürlich - daß sie überhaupt dargestellt ist. Ein erstaunliches Buch! Es ist wahrscheinlich das erste, das keinen faulen Kompromiß eingeht und seine kritischen Intentionen am Ende ins Harmonische abbiegt.(VZ 35)

Die "Leipziger Volkszeitung" druckte eine positive Kritik, sein Buch wurde als ein "freundliches Bekenntnis zum Realismus"(VZ 35) bezeichnet. Loest erhielt viel Post, von Schriftstellerkollegen, Studenten, Lehrern die sein Buch lobten oder sich wunderten, daß es erscheinen durfte. Da die Rolle der Literatur in der DDR eine sehr gesellschaftsbezogene ist, darf nicht unterschätzt werden, daß die Leserpost und Korrespondenz unter Kollegen kein außergewöhnliches Phänomen ist und sich nur besonders bei Loest und 
seinem Roman in Bewegung setzte. Bedeutend und bemerkenswert ist jedoch, so scheint es, die Anteilnahme seiner Kollegen und Bekannten an dem Schicksal seines Buches.

Ein Dorfschullehrer schrieb ihm:

Der Text enthält politische Sätze, die in der DDR bisher nicht gedruckt werden konnten. Ich weiß nicht, warum man dem Ex-Häftling gestattet, so zu schreiben. Gegen Schluß allerdings glaubt man zu verstehen, das Buch erfüllt eine wichtige neue Staatsfunktion. Es predigt das Glück der Genügsamkeit.... Wenn er [Wülff] aber in Ruhe gelassen wird, lebt und arbeitet er als loyaler Bürger der DDR.... Das rätselhafte Buch kann ebenso ein raffiniertes, opportunistisches Bekenntnis zum DDRUntertanen sein wie eine ungeheuerliche sarkastische Satire darauf.(VZ 37)

Stefan Heym nannte den Roman "ein liebenswertes Buch.... Und eigentlich ist es ein Propagandabuch für die DDR, denn immerhin sagt Autor Loest aus, daß dies ein Land ist, wo ein anständiger Kerl wie Ihr Wülff doch sein Glück finden kann."(VZ 37) Demnach läßt es sich bürgerlich in der DDR leben.

Für Loest, und auch seinen Verleger Günther, stellte sich im Juni die nie beantwortete und gewiß auch niemals zu beantwortende Frage über den Verursacher des Auflageverbots. Die erste Auflage, die 12000 Exemplare, war schnell vergriffen gewesen. Man mutmaßte, daß beim Auflageverbot von Heiduczeks Tod am Meer die sowjetische Botschaft verantwortlich gewesen sei. Sie hätte aber keinen spezifischen Grund gehabt, Einwände gegen Loests Buch zu erheben. In seinem Roman kritisiert er nicht den sowjetischen Einfluß auf die DDR und ihre Bürger. Dieser kommt nur indirekt in dem Bild der russischen Kirche zur Sprache, die als Denkmal erhalten wird. Mit größerer Sicherheit könnten sich regierende Funktionäre der DDR beleidigt und angegriffen gefühlt haben. Wiederholt läßr sich Wüllff über die Mächtigen aus. Manchmal spricht er direkt von ihrer Macht, dann wiederum verdeutlicht er, daß auch sie nur Menschen sind, wie er auch. Sie stellen sich zwar zur Schau, lächeln auf allen Fotos, erhalten Blumen, bewundern Betriebe, und wenn sie zuhause sind, dann verstecken sie 
sich in ihren Wohnsilos, bleiben der Bevölkerung entfernt in dem unpersönlichen "Oktoberbeton", sind ihren Mitmenschen nicht zugïngig.

Günther schlug vor, dem Ministerium gegenüber guten Willen zu zeigen und wieder einiges zu ändern, zu kürzen, Stellen umzuschreiben. "Aber welche denn bloß? Ich wußte nicht, wer was auszusetzen hatte, ich kannte meine Kritiker nicht. Aber mir war klar: Wenn du in dieser Weise nachgibst, schlägst du dir selber die Beine weg."(VZ 39)

\section{ZENSUR}

Loests Reaktion auf das Verbot, die zweite Auflage seines Romans Es geht seinen Gang oder Mühen in unserer Ebene zu drucken, hatte mit seiner Verweigerung begonnen, sich derartig zensieren zu lassen. Sie gipfelte 1981 in seiner Ausreise in die Bundesrepublik. Mit denen ihm zustehenden gesetzlichen Mitteln hatte er versucht, sich gegen die Macht der Funktionäre durchzusetzen. Zusammenfassend, in einem Brief an Günther, hielt er die ihm unterbreiteten Streichungsvorschläge fest und bestand auf dem Erscheinen der zweiten Auflage. Entweder würden die 22000 Exemplare seines Romans erscheinen, drohte er erneut, oder der Verlag würde ihn dafür bezahlen. Er erinnerte in seinem Brief an Christa Wolfs Christa T. und den Skandal, der um dieses Buch entstanden war.

Heute blicken die, die ihn verursacht haben, mit Scham auf ihn zurück. Wenn es einen Skandal um Es geht seinen Gang geben sollte: Ich werde mich nicht zu schämen haben. P.S.: Einen Durchschlag schicke ich sofort an Verbandspräsident Hermann Kant. (VZ 40)

Schon einmal waren 50000 Exemplare eines seiner schon gedruckten Romane eingestampft worden, und dies "auf einen Wink des Ministeriums für Staatssicherheit hin.... Was hast du für zermürbende Debatten führen, was für Kompromisse schließen, was für Demütigungen ertragen müssen!" (VZ 40) Nun hoffte Loest auf Hilfe seines Berufsverbandes. Hermann Kant hatte kurz zuvor Anna Seghers als Verbandspräsident 
abgelöst, unter den Vizepräsidenten befand sich Joachim Nowotny, der Außengutachter, dem er eventuell, so glaubte Loest, für die Veröffentlichung seines Buches zu Dank verpflichtet war.

Erläuterte Görlich:

Wir erwarten von unseren Mitgliedern den Nachweis eines kontinuierlichen Schaffens in angemessener Qualität, die Anerkennung des Statuts unseres Verbandes und die Bereitschaft, in Einklang mit unseren Zielen das Verbandsleben aktiv mitzugestalten. ${ }^{264}$

Loest nahm an er gehöre dazı, darum könne er mit Hilfe des Verbandes rechnen. Er suche die Konfrontation nicht, beteuerte er. Im Verlauf der kommenden Monate sollte er jedoch erfahren, daß er von einem alten Freund indirekt als 'Klassenfeind' bezeichnet wurde und von den Kulturbehörden als solcher behandelt werden sollte. Es entwickelte sich ein gespanntes Verhältnis nicht nur mehr zwischen Loest und seinem Verleger, sondern auch mit Mitgliedern des Schriftstellerverbandes, dem Präsidenten der Schriftstellerverbandes Kant, Klaus Höpcke und dem Büro für Urheberrechte. Ein offener Machtkampf schien sich nicht entfacht zu haben, jedoch ein versteckter. Loest erhielt meist Information über die Handhabung seines "Falls" durch dritte. Ihm wurde versichert, der Verband setze sich für ihn ein, doch kam bei einer Tagung des Verbandspräsidiums sein Fall nicht zur Sprache. An Klaus Höpcke habe er sich gewandt, wurde Loest schriftlich von Kant versichert. Loest werde bald vom Verlag hören. Dies geschah in Form eines Vorschlags "als Ersatz eine Krimi-Auflage" zu drucken. (VZ 40) Nach seiner Entlassung aus der Haft hatte sich Loest mit Krimis Geld verdient. Ob dieses Angebot eine Beleidigung sein sollte läßt sich nicht feststellen. Loest hatte sich seit Jahren aus der politischen Arena entfernt gehalten, sodaß sein festes Auftreten eventuell nicht mit dem ihm gebürtigen Ernst behandelt wurde.

${ }^{264}$ Günter Görlich," $15 \%$ Produktionsstcigerung und immer noch zu wenig Bücher" Kürbiskem 2 (1977): 157. 
Loest weigerte sich, wurde gebeten zu 'dulden', daß keine Nachauflage erscheinen würde, doch würde die MDV das Buch im Ausland vertreten. Und wieder schrieb und erhielt er Briefe, zustimmende und ablehnende. Loest wurde immer bewußter, daß er gegen eine ihm unbekannte Instanz anging, die sich nicht bevormunden lassen wollte.

Vielleicht dachten die, die den Schuß von der Kanzel auf den Roman abgeben hatten, [wer auch immer das war] ähnlich? Sie waren durch viele Jahre machtgewohnt, Unbehagen und Nichtverstehen setzte bei ihnen Denkmechanismen in Gang: Was mir nicht paßt, ist schädlich, was meinem Denken und Fühlen zuwiderläuft, feindlich dem Sozialismus.(VZ 42)

Er schrieb wieder seinem Verleger und deutete an, er werde die Auslandsrechte für sein Buch zurückfordern. Günthers Antwort: alle Rechte an dem Roman gibt der Verlag ihm 'mit sofortiger Wirkung' zuruick. Außerdem ging Günther auf Bemerkungen Loests ein, in denen er ein gewisses Verständnis für Günther auszudrücken versucht hatte. Günther müsse nur verantwortlich sein für Verbote, die "im Dunkel" verbleibende aussprachen, erklärte Loest. Der Verleger empörte sich über diese Analyse der Zensur.

[Er] wies die Bemerkungen über seine Stellung als Verleger in der DDR entschieden zurück: 'Sie zeugen nicht nur von einem völligen Unverständnis gegenüber dem Prinzip des demokratischen Zentralismus, sondern auch von einem tiefen Mißtrauen gegenüber den Leitungsorganen unseres Staates.' "(VZ 43)

Wie auch schon bei anderen Büchern, etwa Christa Wolfs Nachdenken über Christa T. Plenzdorfs Neuen Leiden des jungen W., begann sich die Literaturkritik mit Es geht seinen Gang zu befassen. Üblich ist diese offizielle Reaktion für die Meinungsbildung der Leser in der DDR bestimmt und dient als Signal an Literaturschaffende, welcher Stil und Inhalt akzeptabel oder unakzeptabel ist. Einige Kritiken waren vernichtend. Werner Neubert beanstandete im "Sonntag", Loest habe die Beziehung von Individuum und Gesellschaft im Sozialismus völlig falsch dargestellt. Gegenkritiken, von denen Loest Kopien erhielt, wurden weder beantwortet noch gedruckt. Günter Kunert verfaßte eine zwölf Seiten starke Denkschrift, nicht nur in bezug auf Loest, sondern Heiduczek und sich selbst, die er an den "Sonntag" schickte. Auch diese erschien nie. "Zu den vielen 
öffentlichen Geheimnissen hierzulande gehört auch dies: Daß es eigentlich keine Literaturkritik gibt, nur ideologische Zensuren für künstlerische Produkte aller Gattungen, " (VZ 45) erklärte er darin. Christa Wolf schrieb ihm. Sie lobte sein Buch, übte auch etwas stilistische Kritik.

In diesem Land versteht man ganz gut, einander fertigzumachen, besonders unter Autoren, da sollten wir doch auch ein bißchen darauf achten, uns, wenn es möglich ist, gegenseitig zu bestärken.... Ich hoffe es geht Dir gut und du kannst normal arbeiten.(VZ 48)

Aus Frustration besprachen Heiduczek und Loest eines Abends während eines Essens, zu der die SED-Berzirksleitung bekannte Autoren eingeladen hatte, die Möglichkeit einer Bittschrift an den Staatsratsvorsitzenden, Erich Honecker. Ihre Wut war an diesem Abend besonders hervorgetreten, als sie sich wieder einmal all der Privilegien bewußt wurden, die die Funktionäre im sozialistischen Arbeiter- und Bauernstaat genossen. Der Unterschied zur Gesellschaftsform des verhaßten imperialistischen Westen schien ihnen nicht sehr groß. Dieselben Leute, die in Loests Roman in dem Bildband als freundliche Parteimitglieder auf den Fotos strahlen, saßen nun bei Kaviar und Sekt.

Die Entscheidung wurde getroffen, auf alle Fälle der Westpresse diese Bittschrift nicht zu unterbreiten, wie das bei Biermann der Fall gewesen war. Doch Heiduczek mahnte diesmal noch zu warten. Zu einem späteren Zeitpunkt sollte Loest derjenige sein, der davon abriet. Heiduczek erhoffte sich Hilfe, denn auch er hatte versucht, für seinen Fall zu plädieren und sich schriftlich an zensierende Instanzen gewandt, an die sowjetischen Botschaft und an Kurt Hager.

Einige Kollegen Loests blieben auch nicht stumm, denn er selbst hatte viel in Freundes- und Bekanntenkreisen von seiner Situtation gesprochen. Wolfgang Schreyer teilte Franz Fühmann mit, er habe eine Denkschrift an den MDV geschickt. Fühmann fand sie "viel zu kompromißbereit."(VZ 49) In seiner Denkschrift hatte Schreyer die kulturpolitischen Tendenzen und Gegebenheiten dargelegt, die in den Jahren offen- 
sichtlich geworden waren. Dieser Brief ist, meines Erachtens, ein wichtiges Dokument zur kulturpolitischen Lage dieser Zeit, und faßte die Beobachtungen vieler DDR-Schriftsteller zusammen.

Ein vorübergehender Wettersturz für engagierte DDR-Literatur? Möglich, aber über diesen wiederkehrenden Klimaverschlechterungen werden wir allmählich alt und grau, ohne mit dem zu Worte zu kommen, was wir zur Entwicklung unserer Gesellschaft zu sagen habe. Mich erschreckt die Tatsache, daß diesmal bereits erteilte Druckgenehmigungen faktisch annulliert und damit der Verlag wie die HV des MfK [Hauptverwaltung des Ministeriums für Kultur] für letztlich unbefugt erklärt worden sind. Das kann man schwerlich hinnehmen, sollte es überhaupt nicht für möglich halten. So nämlich wird das Vertrauen in eine sinnvolle Zusammenarbeit dieser Häuser mit den Autoren, die sich nun betroffen fühlen und eigene Texte bedroht sehen müssen, nachhaltig erschüttert. Nach drei Jahrzehnten müßte unser Staat doch Kulturinstitutionen haben, die fähig sind, ihre Arbeit selbst zu tun.... Nun greift aus dem Dunkel höherer Sphären, außerhalb der Normalität, drastisch ein vierter Zensor ein, um bemerkenswerte, publikumswirksame Bücher im vollen Lauf zu stoppen.(VZ 48)

Schreyer sprach weiterhin von seiner Befürchtung, daß diese etwa drei Jahre früher begonnene 'Tendenzwende' wieder zu Literatur führen würde, die die Autoren aus Gründen der Entmutigung für die Schublade schreiben würden. Sie würden entmutigt, Kritisches vorzulegen. "Die Motive des Eingriffs liegen bei Loest auf der Hand: Sorgen um Komplex Jugend, Staat, Disziplin und innere Sicherheit." (VZ 49) Doch seien dies Themen, mit denen sich die Bevölkerung und der Staatsapparat endlich auseinandersetzen müßten, und dies täte Loest. Keine Tabus will er also mehr, wie Honecker versprochen hatte. Loest, wie auch Schreyer, ein erfolgreicher und bisher anerkannter Autor, sahen sich als sozialistische Schriftsteller. Sie schlossen sich den Schriftstellern an, die im Laufe der vergangenen Jahre immer offener ihr Verlangen nach grösserer Freiheit bei der Themenwahl und der Darstellung der Problemstellungen verlangt hatten. Franz Fühmann reagierte auf Schreyer mit der Erklärung, er wïrde niemals wieder zur Selbstzensur zurückkehren.

Wenn ihr [der Verlag] so weitermacht, wird er [der Schriftsteller] nicht bitterer und schärfer - ich wünsche keine Feindschaft, aber ihr provoziert 
sie, und wenn ihr sie partout wollt, ja, dann eben so! Das wäre doch die Konsequenz! (VZ 49)

Auch Armin Müller befürchtete eine Konsequenz für alle Schriftsteller, falls der Staat sich in dieser Sache durchsetzen könnte: "...was Dir und Heiduczek geschieht, kann morgen mir oder einem anderen geschehen." (VZ 50)

Doch der Verband schien sich für Loest eingesetzt zu haben, denn Loest erfuhr, die Verbandsspitze habe eine zweite Auflage des Romans erreicht. Zum Vorstand, also zur Verbandsspitze, gehören die auf den Schriftstellerkongressen gewählten Mitglieder, die Vorsitzenden der Betriebsräte und die Verbandssekretäre. Laut Köhler-Hausmann sind $80 \%$ des Vorstands SED-Mitglieder. ${ }^{265}$ Es sei schwer zu durchschauen, inwiefern die Schriftsteller in ihrem Verband frei ihre Interessen vertreten können. "Die wichtigste Position hat nicht, wie man vermuten könnte, der Präsident inne, er vertritt den Verband eher repräsentativ nach außen, sondern das Sekretariat." ${ }^{266}$ Die Stelle des 1. Sekretärs wird nicht von Autoren eingenommen, "...sondern von Gesellschaftswissenschaftlern bzw. Agitationsexperten der SED." 267 Gerhard Henniger, der Sekretär des Verbandes, soll nun gerade "einer von denen" gewesen sein, "die Öl auf die Wogen gegossen" hatten. (VZ 52) Als Reaktion auf Kants Rede, die als "Verdammungsrede" bekannt wurde, und in der er sowohl auf die Kritiker der Bundesrepublik eingeht, die sich mit DDR-Literatur befassen, als auch auf Loests Bitten, der Verband solle sich für ihn bei seinem Verlag einsetzen, meinte Loest:

L. hatte sich nicht von seinem Verlag unrichtig behandelt gefühlt, sondern von Kräften weit darüber. Nun entscheidet ja nicht der Schriftstellerverband über die Herausgabe von Literatur, er übt keine Zensur aus, hat kein Einspruchsrecht bei Streitigkeiten zwischen Autor

265 Reinhild Köhler-Hausmann, Literaturbetricb in der DDR: Schriftsteller und Literaturinstanzen (Stuttgart: Metzler, 1984) 137. Köhler-Hausmann erläutert, wie stark die parteiliche Kontrolle im Schriftstellerverband ist, was sich auf sciner Zusammensctzung,besonders des Vorstands, erkennen lässt.

$266_{\text {ebda, }} 139$.

${ }^{267}$ ebda, 139. 
und Verlag, bestimmt keine Auflagenhöhe. Er berät hier und da, und das ist schon alles. (VZ 55)

Loest hatte gerade eine Denkschrift an den Vorstand des Verbandes abgeschickt, als er die Nachricht über die 2. Auflage erhielt. Er hatte darin auf Gefahren hingewiesen, die der Literatur drohten, wenn jemand, der eine Druckgenehmigung erhalten hatte, derartigen Zensurmaßnahmen ausgesetzt würde. Auch ging er auf die bundesrepublikanische Reaktion zu seinem Buch ein, die positiv aufgefallen war. Inwiefern die Veröffentlichung eines Buches in der Bundesrepublik von Bedeutung für die Literaturpolitik in der DDR ist, wurde bereits erläutert. Bemerkenswert ist die bundesrepublikanische Reaktion auf ein Werk aus der DDR, das als systemkritisch eingestuft werden könnte. Das Aufbegehren der Jugendlichen etwa, die Beatmusik hören wollen, kann als ein systemkritischer Aspekt des Buches interpretiert werden. Westliche Leser, die etwa dem anderen deutschen Staat nicht zugeneigt sind, und derer gibt es genügend, genießen diese Art Rebellion des Volkes. Spielt sich jedoch derartiges auf bundesdeutschem Boden ab, sind sie seltener dazu geneigt, solches Verhalten gut zu heißen. Loest argumentierte, die Kritiker "wußten nichts vom Auslagenstop und wïrdigten das Buch ohne diesen Aspekt."(VZ 52) Ein Anruf Kants und die Bitte um ein persönliches Gespräch mit Klaus Höpcke, dem Stellvertreter des Kultuministers Hoffmann, war die Reaktion seines Verbandes. Höpcke war besorgt zu erfahren, "ob L. vorhabe, ein sozialistischer Schriftsteller zu bleiben, oder ob er auf den schwankenden Wellen des Ost-WestKonflikts zu schaukeln gedächte." (VZ 53) Loest verneinte diese Frage. Im Gespräch kam man auf Loests Antrag beim Büro für Urheberrechte, vier Geschichten in einer Anthologie veröffentlichen zu dürfen, die in der Bundesrepublik erscheinen sollte. Höpcke deutete auf unmißverständliche Weise auf die Erwartung des Staates hin, wie Loest sich als gesetzlich korrekt verhaltender Bürger zu benehmen habe. Höpcke hoffte, Loest wolle nicht "gegen Gesetze und Bestimmungen verstoßen", (VZ 53), und wiederum verneinte Loest. "Auf keinen Fall, dazu habe er viel zu viel Angst."(VZ 53) "Angst, 
meinte Höpcke nachsichtig, sei nicht der beste Ratgeber, er hoffe viel mehr auf Verständnis und Einsicht."(VZ 53)

In seinem autobiographischen Buch Durch die Erde ein Riß sollte Loest später eines der Resultate seiner Haft in Bautzen erläutern.

Macht besitzen wollte er auf keinen Fall.... Nie wieder, wenn er erst draußen war, wollte er sich einen Teil der Gewalt zu Lehen geben lassen, auf daß er aufgehoben wäre und fallen gelassen werden könnte, gehorchte er denen über sich nicht mehr. ${ }^{268}$

Dieses unbequeme Verhältnis zur Macht ist auch in Wülff verkörpert und in Loests Verhalten in seiner prekären Situation zu erkennen. Ihm war nicht daran gelegen, sich mit den Mächtigen dieses Staates absichtlich anzulegen. Er hatte schon einmal für seine politische Überzeugung büßen müssen, und war nach seiner Entlassung nie offiziell rehabilitiert worden. Angst mag er nun gehabt haben, doch nicht genug, um sich aus der Kontroverse zurückzuziehen. Er hatte nach den 'Spielregeln' gespielt, die ihm gesetzlich garantiert zu sein schienen. Und auf eine gerechte Behandlung wollte er nun bestehen.

Bislang hatte sich L. an die Forderung gehalten, die von Staat, Partei und Verband immer wieder aufgestellt worden war: Strittige Dinge im eigenen Haus klären, nicht zum Fenster hinausreden, sich nicht westlichen Presseorganen anvertrauen! (VZ 57)

Zu diesem Zeitpunkt gab er jedoch dem Deutschland Archiv ein Interview, in dem er sich über seine Frustration ausließ.

Wenn da ein einflußreicher Politiker wäre, der sagte: Das Buch ist nicht nützlich für uns, es enthält Fehler, er stellt die Dinge auf den Kopf, es paßt nicht in unsere Landschaft aus diesem und jenem Grund - dann könnte ich mich wehren, könnte debattieren und Verbündete suchen. Aber so überfällt mich das Stopzeichen aus dem absoluten Dunkel.(VZ 58)

Der Antrag, zur Buchmesse nach Frankfurt zu fahren, wurde ihm genehmigt, und er warb am Stand der DVA für sein Buch. Westdeutsche Kritiker lobten es weiterhin, die Aussicht auf Devisen für die DDR schien gut. Eventuell lag darin die Motivation seitens 
der DDR, Loest eine Reiseerlaubnis zu genehmigen. Während seines Aufenthalts in der Bundesrepublik unterzeichnete Loest einen Vertrag für eine zweite Auflage mit der DVA. Und dies, so nimmt Loest an, war der entscheidende Schritt:

Von dem aus es kein Zurïck mehr gab, von dem aus es weiterlief bis zur Ausreise im März 1981. Andere Schriftsteller waren ja auch keine Lieblingskinder ihrer Staatsmacht, hatten sich eigene Schritte gestattet, hatten Haltung bewahrt und waren nicht auf Geheiß von oben Kollegen in den Rücken gefallen, hatten sich Achtung und Selbstachtung und vielleicht sogar den Respekt der Funktionäre errungen, die nicht leicht mit ihnen umspringen konnten. Sie hatten sich ihre Heimat erhalten, Leser in Ost und West, waren dennoch durch Westeuropa gereist, nach den USA und nach Indien gefahren: Helga Schütz, Christa Wolf, Heym, Fühmann, Fries, de Bruyn, Plenzdorf - wo lag nun der Punkt, von dem aus L. nicht wieder ans heimische Ufer fand? Er sieht ihn an jenem Morgen, als er...die Rechte an diesem Roman für die westliche Hemisphäre ïbertrug. Er fragte nicht das Büro für Urheberrechte der DDR und machte sich damit strafbar. (VZ 63)

Loest muß sich die Frage gestellt haben, wie er als DDR-Schriftsteller eingestuft wurde. Der Behandlung nach zu urteilen war er keines der 'Lieblingskinder', doch hatte er sich nach seiner Haftentlassung nichts weiter zuschulden kommen lassen, was ihm als staatsfeindlich angerechnet werden konnte. Sein Lebensstil entsprach weniger dem eines gutsituierten Bürgers als eines Arbeiters. Sohn eines Einsenwarenhändlers, 1947 Eintritt in die SED, 1955 Besuch des Literaturinstituts »Johannes R. Becher«, so ließen sich die Etappen seines Lebens auflisten. Er lebte in Leipzig , in einem Altbau, hatte kein Auto, lebte eher proletarisch als bürgerlich. Er hatte sich nicht, wie viele DDR-Schriftsteller, das Ehepaar Wolf und Joachim Seyppel etwa, aufs Land zurückgezogen, sondern wollte und war, Wülff ähnlich, dem Milieu treu geblieben, in dem er aufgewachsen war.

Loest war sich bewußt, daß er zuerst das Büro für Urheberrechte um Erlaubnis hätte fragen sollen, bevor er auf diese Art selbständig handeln konnte. In seinem Vierten Zensor weist er zwar auf Schriftstellerkollegen wie Stefan Heym hin, die für derartiges unabhängiges Verhalten bestraft worden waren, doch gibt er keine eindeutige Erläuterung, was ihn zu diesem Zeitpunkt zu seinem Handeln motiviert hatte. Dem Ton nach zu urteilen, fühlte er sich eventuell zu diesem Zeitpunkt durch die moralische Unter- 
stützung seiner Kollegen in seinem 'Kampf' gegen die Zensur unterstützt. Möglicherweise wollte er auch sich und seiner Familie beweisen, wie unabhängig er zu handeln gedachte. Was auch immer ihn bewegte, er hinterließ seinen Vertrag in der Bundesrepublik und bat seinen neuen Vertragspartner zu schweigen. "Meine Oberen werden, wenn das Buch hier weiterhin erscheint, rechtzeitig Lunte riechen. Mal sehen, wie ich mich dann rausreden kann."(VZ 63) 269 Zweifel an dem wahren Grund des westdeutschen Interesses kamen in ihm auf, doch schien dies seinen Genuß3 über seinen endlich errungenen kleinen Erfolg nicht zu trüben. Wie immer wieder von den Funktionären und Literaturkritikern angeführt wird ist es gut möglich, daß sich ein Buch nicht wegen seines Inhaltes, sondern seiner politischen Entstehungsgeschichte in der Bundesrepublik verkauft. Es ist schwierig, weder diese Vermutung noch das Gegenteil zu beweisen. Laut Loest gingen jedoch die Kritiken in der westlichen Presse meist auf die "politischen Querelen" ein, "vom literarischen Gehalt war wenig die Rede." (VZ 70)

Die Idee der Unterschriftensammlung, welche die Solidarität der Schriftstellerkollegen mit Loest beweisen sollte, wurde nach Loests Riickkehr aus der Bundesrepublik von einem Freund wieder aufgegriffen. Doch diesmal riet Loest ab. Er gab sich meines Erachtens mit seinem ersten Erfolg zufrieden, obwohl er seine Ablehnung nicht mit diesen Worten begründete. Seine Begrïndung bezog sich auf seine Ohnmächtigkeit dem Apparat gegenüber, dem nicht beizukommen sei.

Im November 1978 bat Höpcke Loest persönlich einen Verlag an, dem er sein Buch vorlegen solle. Loest ging auf den Vorschlag ein, der damit endete, daß sein Buch in einer einmaligen zweiten Auflage von zehntausend Stück erschien. Nach dem Verkauf sollte Loest seine Rechte alle wiedererhalten. Keine weitere Auflage sollte danach je

${ }^{269}$ Im Verlaufe der zweiten Hälfte seiner Dokumentation geht Loest auf eine andere Form der Zensur ein. Er bemüht sich nachzuweisen, daß auch auf Veranstalter von Lesungen Einfluß geübt wurde, wie etwa Bibliotheken und Jugendgruppen, sodaß $\mathrm{cr}$ in crhötcm Maße, gleichlaufend mit seinen Bemühungen um die zweite Auflage, aus Lesungen ausgeladen, oder überhaupt erst gamicht mehr eingeladen wird. 
wieder erscheinen. Mit dieser Regelung, so hoffte man gewiß, würde der Streit beendet. Loest würde zufriedengestellt, da er auf eine zweite Auflage bestanden hatte. Er errang einen Pyrrhussieg, wie Loest es selbst nennt. "Er hatte die Staatsmacht zu einem Zugeständnis genötigt, das würde sie ihm heinzzahlen."(VZ 74) ${ }^{270}$

Seine Aussichten, das ihm vom MDV versprochene Honorar au erhalten, waren sehr gut, so hatte man ihn informiert. Ein Protestschreiben war vermieden worden. Günther, Hotta und Duty hatten sich vor ihrer Kontrollkommission verantworten müssen und waren vom Parteigericht beschuldigt worden, "in den Fällen Heiduczek und L. politisch blind und für die Partei schädlich gehandelt zu haben. Das Ergebnis waren Parteistrafen."(VZ 90)

Das Loest dem Deutschland Archiv ein Interview gegeben hatte, verärgerte nun wieder Kant, so vernahm Loest. Dieser sei erbost, denn er habe sich für Loest eingesetzt. Der habe nun jedoch, als einziger außer Günter Kunert, die auf dem letzten Schriftstellerkongreß "geforderten Spielregeln verletzt," 271 und seine ostdeutschen Probleme in der westdeutschen Presse diskutiert. Loest reagierte darauf wiederum mit einem Brief an Kant, in dem er seinem Ärger Luft machte. Zusammenfassend beschreibt er darin den Mangel an Unterstützung seines Verbandes.

So sollte man in einer demokratischen Organisation mit einem Mitglied nicht umgehen. Ich fühle mich auch in anderer Beziehung im Stich gelassen: Prof. Dr. Neubert durfte im SONNTAG auf mein Buch einschlagen, aber dieses kulturbundliche Organ ließ bis zur Stunde kein Widerwort zu, nicht von Kunert, nicht von Mattheur, nicht von v. Tümpling.... Diese Behandlung durch die Presse ist nicht das, was ich als Klärung von Problemen im eigenen Land bezeichnen kann; Kunert nannte sie unzivilisiert. (VZ 71)

Loest hatte sich, nach monatelangem Warten auf eine vertragliche Regelung mit dem Greifenverlag, wieder besonnen und drohte Kant, in seiner verärgerten Stimmung,

270 Pyrrhussieg: nach den verlustreichen Sicgen des König Pyrrhus von Epirus über die Römer. = Scheinsieg, zu teuer erkaufter Sicg.

${ }^{271}$ Loest, Der Vierte Zensor, 70. 
mit der schon erwähnten Idee der Bittschrift. Diese würde er, von zwei bis drei Dutzend Schriftstellern unterzeichnet, direkt an den Staatsratsvorsitzenden Honecker richten.

Vielleicht könnte dann von der Machtspitze her aufgetaut werden, was unten eingefroren ist. Hin und wieder dachte ich, mein Fall sei nicht wichtig genug, aber es geht ja einigen anderen Kollegen nicht besser; vielleicht kann man so auch für sie das Eis brechen. (VZ 72)

Es waren zwei Jahre seit dem Biermann-Protestbrief verflossen, als Loest seine Drohung im Januar 1979 aussprach. Kant hatte neun Monate vorher das Amt als Verbandspräsident übernommen. Er hatte sich heftig gegen die Biermann Unterstützer gewandt und es war zu erwarten, daß er, als neuer Prïsident, eine neue Protestwelle mit den unvermeidlichen und unangenehmen Nachwirkungen vermeiden wollte.

Von seinen Motivationen für sein handeln schien sich Loest selbst nicht immer sicher zu sein, oder so stellt er es zumindest in seiner Dokumentation fest. Als mutiger Kämpfer für die Schriftsteller gegen die Zensur, der sie unterworfen wurden, erscheint Loest nicht. Diesen Eindruck versucht er auch in keiner Weise zu vermitteln. Loest vermittelt sogar wiederholt von sich das Bild, wenn nicht eines Feiglings, so doch eines Wolfgang Wülff, der lieber sein Leben genießen will, frei von Kontroversen. Doch auch finden sich Züge Huppels in ihm, dem auf der Arbeiter- und Bauernfakultät ausgebildeten Arbeiter und erfolglosen Schriftsteller. Huppel ist Parteimitglied, wie Loest es war. Er glaubte an den Erfolg des Sozialismus nach den Enträuschungen des Nationalsozialismus und sah sich mit verantwortlich, als guter Sozialist, dem Kampf um das neue System nicht nur ideologisch beizustehen, sondern ihn auch in Tat und Kraft zu unterstützen. Wo war Huppel fehlgegangen, oder lautet die Frage: Wo hatte ihn der Staat enttäuscht?

Loest befaßte sich nun, wie Huppel, mit seiner Rolle im System:

"Stefan Heym besaß den Ruf des Prellbocks - wie weit war...er selber in diese Rolle hineingeglitten, wie kam er heraus? Wollt er heraus? Wie war es mit der Eitelkeit des Märtyrers, mit der eigenen Eitelkeit bestellt?" (VZ 73) 
Welche persönlichen Gründe Loest auch immer motiviert haben mögen, Mut hatte er gezeigt. Und für diesen wurde er in der Bundesrepublik gelobt und aus der DDR verbannt. Das Ende der tabufreien Periode hatte schon sein Ende vor 1976 gefunden. Zu viele Schriftsteller waren den politischen Repressalien zum Opfer gefallen. $\mathrm{Zu}$ viel Aufmerksamkeit hatten die Ereignisse in der DDR auf sich gezogen, und viel zu unsicher war sich die DDR noch in ihrer eigenen Politik. Die Emanzipationswelle der Kulturschaffenden mit ihrem Verlangen nach größerem Vertrauen der Funktionäre in sie und eine damit verbundene erhöhte Meinungsfreiheit hatte die Regierenden verärgert. "Nie wird nachzuweisen sein, wer »Es geht seinen Gang « zu Fall gebracht hat und eine zweite Auflage einem Schriftstellerprotest als kleineres Übel vorzog,"(VZ 76) schreibt Loest. Die Vermutung, daß Honecker es selbst gewesen war, wird von einem Schriftstellerfreund Loests geäußert. "Glaub mir, Honecker liest selber nicht, da hat ihm einer seiner Referenten gesteckt, daß du ihn erwïhnst." (VZ 76)

Der Anlaß zu Loests Ausreise kann nicht nur in Verbindung mit seinem Roman betrachtet werden. Das Denken und Handeln seiner Kollegen in den Jahren seit Honeckers Übernahme als Staatsoberhaupt, die allgemeine Frustration, die sich zwischen Kulturschaffenden und Kulturpolitikern bemerkbar gemacht hatte, entlud sich unter anderem auch auf Loest. Stefan Heym hatte seinen Roman »Collin« in der Bundesrepublik veröffentlichen lassen, hatte den Verkauf der Rechte in eigene Hände genommen, ohne DDR-Genehmigung, und wurde darum, wie schon erwähnt, schließlich wegen Verstoßes gegen Zoll- und Devisenbestimmungen zu M 9000 Geldstrafe verurteilt. In einem Brief an Honecker protestierten acht Schriftsteller gegen einen Artikel im Parteiorgan »Neues Deutschland «, in dem Heym als "ehemaliger US-Bürger" bezeichnet wurde. Unter den Unterzeichnern waren Becker, Jakobs, Seyppel und Loest. Resultat dieses Protests war der Ausschluß fünf Unterzeichner aus dem Schriftstellerverband im Juni 1979 und Loests freiwilliger Austritt, um seinem dritten Ausschluß 
zuvorzukommen. Im selben Monat wurde das 3. Straftrechtsänderungsgesetz erlassen.

Das politische Strafrecht wurde verschärft:

Neu aufgenommen oder mit höheren Strafen belegt sind z.B. das Sammeln und Weitergeben von nicht der Geheimhaltung unterliegenden

Nachrichten," wozu Loests Notizen zählen könnten, "»staatsfeindliche

Hetze « einschließlich Diskriminierung der Freundschafts- und

Bündnisbeziehungen, Aufzeichnung und Weitergabe von Informationen,

Manuskripten, Material ins Ausland, die den Interessen der DDR schaden

könnten. (VZ 93)

1981 übersiedelte Loest also in die Bundesrepublik, wo er weitgehend unbekannt war, sich aber sehr rasch auf dem Buchmarkt und im Bewußtsein der literarischen Öffentlichkeit durchsetzte. (Er ist der einzige, dem dies so gelungen ist.) Er erhielt den Hans Fallada und den Jakob Kaiser Preis. 1984 wurde er stellvertretender Vorsitzender des Schriftstellerverbandes. In einem Interview des Deutschlandfunks im August 1983 machte Loest seine Absicht klar, in der Bundesrepublik zu bleiben wo er auch heute noch lebt. 1988 wurde ihm zum erstenmal ein Besuch in der DDR genehmigt. ${ }^{272}$ Loest ist einer der wenigen DDR-Autoren die ihr Land verließen, dem ein Besuch genehmigt wurde. Reiner Kunze etwa, der Anfang 1989 an der Beerdigung seiner Mutter teilnehmen wollte, wurde der Antrag auf eine Einreise verweigert. Er läßt vermuten, daß Loest die DDR-Regierung durch seine Ausreise und sein Verhalten in der Bundesrepublik nicht derartig verärgert hat, daß ihm sämtlicher Kontakt zu seiner Heimat untersagt wird. Nach den Veröffentlichungen seiner Bïcher im Westen, und besonders nach seinem Buch Der Vierte Zensor verwundert die Haltung der DDR-Regierung. Dieses ungeregelte, nicht offiziell manifestierte Verhalten beweist meines Erachtens, inwiefern sich die machthabenden Politiker weiterhin entweder im Unklaren über eine allgemeingültige Strategie sind, oder, daß sie eher Macht ausüben können durch unberechenbares Verhalten.

${ }^{272}$ Erich Loest, "Nach zwci Tagen hat man sich wieder ans Gröbste gewöhnt" Stern 1 (1988): 113. 


\section{KAPITEL V \\ "WARUM SCHREIBEN SIE?" UND WIE?}

Abschließend möchte ich auf die Schlußfolgerungen eingehen, zu denen ich gekommen bin. Ich habe mich mit der Literaturproduktion in der DDR, also der Literaturproduktion in einem sozialistischen Staat, auseinandergesetzt. Zwei Romane wurden vorgestellt, um eine Basis für die spezifischen Zensurmaßnahmen zu liefern, die an diesen Werken vernommen wurden oder, oft zu vieler Erstaunen, nicht vollzogen wurden. Anhand dieser beiden Romane aus den sechziger bzw. siebziger Jahren wurden zuerst Schritte nachvollzogen, die ein DDR-Autor möglicherweise zur Vollendung eines seiner Werke gehen muß.

Christa Wolfs Nachdenken über Christa T. und Erich Loests Es geht seinen Gang oder Mühen in unserer Ebene wurden aus verschiedenen Grïnden für diese Analyse ausgewählt. Die Auswahl beruhte auf ihrem repräsentativen Charakter für DDRBelletristik eines gewissen Zeitabschnittes. Beide Autoren und ihre Werke weisen Gemeinsamkeiten auf, die in dieser These behandelt werden: sie befassen sich mit der Rolle des Individuums in einer Gesellschaft, sie wurden Zensurmaßnahmen ausgesetzt und wurden dadurch, in Wolfs Fall direkt nach Veröffentlichung, bei Loest erst später, in der Bundesrepublik bekannt, und die Autoren bemïhen sich um die Ausführung ihres Berufes im Sinn eines überzeugten, jedoch nicht unkritischen sozialistischen Schriftstellers. Wolf und Loest hatten ihre persönliche Auffassung der Aufgabe eines sozialistischen Schriftstellers realisiert.

Die besprochenen Romane waren mir als wichtige Werke der DDR-Literatur erschienen, weniger, weil sie Aufsehen erregt hatten, sondern eher, weil sie mir einen 
Einblick sowohl in die Psyche der DDR-Bürger als auch das tägliche Leben in der DDR zu gestatten schienen. Wie in der These erläutert wird, gewinnt der Leser zum Beispiel durch Nachdenken über Christa T. ein größeres Verständnis der Probleme, mit denen sich die Generation Christa Wolfs auseinandersetzte. Wolf, die durch ihren sehr eigenwilligen Stil und ihre verschlüsselte Sprache auffällt, befaßte sich mit der Rolle des Individuums und dessen Scheitern in und an der modernen sozialistischen Gesellschaft. Daß der Roman in der DDR geschrieben wurde, schränkt ihn nicht auf einen sozialistischen Leserkreis ein, der sich allein mit dem Problem Christa T.s identifizieren könnte. Christa T.s Schwierigkeiten, sich als einfühlsame, sensible Person in einer zielstrebigen, vieler zwischenmenschlicher Beziehungen beraubten Gesellschaft zurechtzufinden, ist keinesfalls ein rein sozialistisches Problem. Der Markterfolg des Buches allein beweißt, daß es Allgemeingültigkeit besitzt. Die größtenteils negative offizielle Reaktion in der DDR war jedoch weitgehend ausschlaggebend für die Politisierung des Werkes und seiner Autorin in der DDR und der Bundesrepublik.

Auch Erich Loests Es geht seinen Gang erlaubt einen Einblick in das Leben eines DDR-Bürgers, in das Sich-einfinden-wollen Wülffs, der jedoch zwischen zwei Klassenschichten gefangen zu sein scheint. Wülff verkörpert die Lage vieler junger Männer, die einer Generation angehören, die in der DDR aufgewachsen ist und sich nicht im Sinne der Partei im neuen Sozialismus entwickelt haben oder entwickeln konnten.

Um einer genauen Betrachtung dieser beiden Werke gerecht zu werden, um überhaupt der Behandlung des Themas DDR-Literatur gerecht zu werden, muß als Voraussetzung ein Verständnis über, wenn auch nicht unbedingt für, die besondere Lage des Schriftstellers in diesem Teil Deutschlands vermittelt werden. Dies ist eines der Ziele dieser These. Da der Literatur in der DDR seitens ihrer Regierung, begründet durch ihre marxistisch-leninistische Basis, eine besondere Rolle zugeschrieben wird, kann man, meines Erachtens, nur mit einer genaueren Kenntnis dieser Rolle ein gerechtes Urteil über 
DDR-Literatur fällen. Es ist nicht notwendig, daß Leser, egal ob in Ost oder West, mit der politischen Ideologie des Staates übereinstimmen, um Gefallen an DDR-Literatur zu finden.

Als DDR-Autor kann man sich derartige ideologische Freiheit, besonders in bezug auf Themenwahl und -ausfuihrung, nicht erlauben. In dieser Arbeit ging ich auf die besonderen Aufgaben ein, die an einen Autor allgemein, und auch einen DDR-Autor speziell gestellt werden. Diese Erwartungen basieren in der DDR auf politisch-ideologischen Thesen, welche in regelmäßigen Abstïnden auf Parteitagen und Schriftstellerkongressen proklamiert werden. Anhand einer chronologischen Aufzeichnung der ideologischen und politischen Entwicklung der DDR habe ich die Bedingungen illustriert, die meist nicht künstlerisch-ästhetischer Natur sind, sondern Ratschläge zur Darstellung gemeinschaftlicher Ziele geben, darum das Denken und Handeln der Kunstschaffenden beeinflussen, und in den meisten Fällen bestimmen. Dazu gehört beispielsweise die Darstellung des Helden, der die sozialistischen Ideale verkörpert und für den Staat tragbar sein muß. Weiterhin wird das Aufgreifen gesellschaftlich aktueller Themen verlangt, sei es beispielsweise die Abrechnung mit dem Nationalsozialismus in den ersten Nachkriegsjahren, oder die Darstellung des neuen ökonomischen Plans der sechziger Jahre.

Wie ich erläuterte, werden nicht nur Forderungen an die Kunstschaffenden gestellt, sondern teilweise genießen sie auch Privilegien, die nur geringen Teilen der Bevölkerung zustehen. Durch ihren Status als Berufsschriftsteller und die Mitgliedschaft einiger in ihrem Berufsverband, dem Schriftstellerverband der DDR, werden ihnen Privilegien gewährt, wie beispielsweise wochen- oder monatelange Forschungsreisen in den Westen, schnelleren Zugang zu einem Auto und einer größeren Wohnungen. Selbstverständlich liegt es jedoch an den Schriftstellern selbst, ob sie von ihren Sonderrechten Gebrauch machen wollen. 
Ich habe weiterhin versucht, auf die Schwierigkeiten einer Definition des DDRSchriftstellers, sowie auf unterschiedliche Interpretationen und Ausführung dieses Berufs einzugehen. Trotz der, im Vergleich zur Bundesrepublik Deutschland, staatlich, ideologisch und rechtlich fest verankerten Definition eines Schriftstellers seitens der DDR, ist es nicht angebracht, die DDR-Schriftsteller undifferenziert voneinander zu betrachten. Ihre eigene Einstellung zu ihrer Rolle, ihre persönliche Motivation zur literarischen Ausführung einer Idee, eines Themas, gerade unter Gefahr der Zensur, darf nicht unbeachtet bleiben. Und diese unterschiedliche Ausführung und Auffassung führt zu verschiedenartiger Behandlung seitens der Behörden. Äußert sich Seyppel zu diesem Thema:

Irgendwie, und ich halte mich bewußt vage, ist Schreiben das Bedürfnis nach einer Form authentischer Daseins- und Buchführung, dort nämlich, wo einmal erfahren worden ist, daß Unverbindlichkeit der Tod auch unserer Freiheit ist. ${ }^{273}$

Befaßt man sich mit dem Thema Zensur, so entsteht meist sofort ein negatives Bild, worauf ich in meinen Ausführungen hingewiesen habe. Viele DDR-Schriftsteller haben unter dieser Zensur gelitten, wie sie selbst ausführlich erläuterten, und es gibt weiterhin Schriftsteller in der DDR, die noch darunter leiden. Andere Schriftsteller hingegen, wie etwa Christa Wolf, haben sich nicht offensichtlich gegen ihren Staat gewandt, und der Staat hat sie nicht verstoßen. Doch hat auch sie ein ambivalentes Verhältnis zu ihm, auf den ihr Schriftstellerkollege Fries eingeht:

Christa Wolf hat beides getan, handeln und erzählen, und das Unvereinbare beider Tätigkeiten erfahren.... Die Kandidatin des ZK und Cheflektorin eines Verlages optierte kïnftig für die eigenen Seelenlage, also für die Literatur. "Die Wirklichkeit dieses Jahrhunderts selbst", sagt Christa Wolf in einem ihrer vielen Aufsätze, "wendet sich gegen die Prosaschreiber."...Mißtrauen gegen die gesamtdeutschen Fehlleistungen der kritischen Sachverwalter auf selbstgemauertem Sockel? Schreiben in beiden deutschen Ländern gerinnt zu politischen Kapital bei ungleicher 
Rendite. Die Wolf hat da zu unser aller Nutzen ihre Erfahrungen gesammelt und aufgeschrieben. ${ }^{274}$

Fries' Kommentar zu Wolfs Verzicht auf aktive Teilnahme an der Leitung, ich sage Überwachung, der korrekten Ausfïhrung vorgegebener Richtlinien in literarischen Kreisen, ist aufschlußreich. Ihren Verzicht darauf, als Cheflektorin zu arbeiten und die zensierenden Eingriffe unternehmen zu miissen, zu denen Lektoren verpflichtet sind, ihre Abwesenheit auf Schriftstellerkongressen, ihr auftreten als selbstsichere, dadurch nicht offensichtlich manipulierbare Persönlichkeit hat ihr erlaubt, anders auf Zensur zu reagieren, als dies viele ihrer Schriftstellerkollegen konnten. Sie hat etwa, wie Fries es ausdrückt, die Polemik um ihre Christa T. "...nicht wie andere mit einem Ortswechsel quittiert." 275 , ein oft wiederholter Vorwurf seitens junger oder verbliebener DDRAutoren gegen die 'Dissidenten'.

In der Analyse der Werke Wolfs und Loests, und den Auswirkungen darauf, habe ich demnach nicht nur auf die Gemeinsamkeiten hinweisen wollen, sondern auch auf die Gegensätze. Wolf und Loest wurden aus verschiedenen Gründen zu der Auswahl ihrer Themen und ihrem Schreiben motiviert. Beide sind Zensurmaßnahmen unterworfen worden, doch haben sie grundverschiedene Konsequenzen daraus gezogen. Christa Wolf hat Anfang 1989 ihren sechzigsten Geburtstag in der DDR gefeiert, Erich Loest hatte seine Heimat aufgegeben und war in die Bundesrepublik gezogen. Beide haben, motiviert durch persönliche Gründe, ihre Pflicht als Schriftsteller ausgeführt, wie sie sie verstanden, und tun dies auch weiterhin.

In einem Gespräch mit Walter Kempowski im Sommer 1988 verdeutlichte sich für mich die Individualität, sogar die teilweise vorhandene Rivalität der emigrierten Autoren untereinander. Ich erwartete, daß die Schriftsteller, die von ihrem Staat in einer

${ }^{274}$ Der DDR-Autor Fritz Rudolf Frics, ciner der wichtigsten Schriftsteller der DDR heute, in einem Artikel zu Wolfs sechzigstem Geburtstag. (Frankfurter Allgemeine Zeitung 66 (18. März 1989) 27. 
Weise dirigiert und zensiert wurden, daß sie als Konsequenz ihres Bestehens auf das Recht der freien Meinungsäußerung ihre Heimat verließen, aufgrund der Repressalien, denen sie aufgesetzt waren, ein enges Verhältnis zueinander haben würden. Doch scheinen sich, laut Kempowski, die 'Dissidenten' in ihrer neuen Heimat nicht vereinigt zu haben. Dieser Mangel an Solidarität verwundert vielleicht zuerst, und ich biete meine eigene Interpretation dazu an. In Fragen, die ich schriftlich an Karl-Heinz Jakobs gerichtet hatte, hatte ich ihn gebeten, sich über seine Einstellung zu Christa Wolf auszulassen, denn in seinem Buch Das endlose Jahr schien er antagonistische Anspielungen auf sie zu machen, über deren Ursprung er den Leser im Unklaren lies. Nachdem er sich humorvoll über die Anzahl meiner Fragen ausgelassen hatte, enthielt er sich einer eindeutigen Antwort.

Bei den Antworten auf ihre [meine] Fragen bin ich zur Zeit auf Seite 312 des zweiten Bandes. Ich fürchte es wird ein dreibändiges Werk. Sobald es druckreif ist, werde ich es Ihnen zuschicken. Aber Spaß beiseite, tatsächlich bin ich an den Fragen zerschellt. Immer, wenn ich mich hinsetzte, um sie zu beantworten, brach ich unter der Wucht der Fragen zusammen. ${ }^{276}$

Ich war weder verwundert über diese Reaktion, noch war ich erbost. Jakobs schien mir durch den Entzug einer klaren Antwort mitzuteilen, daß er, der, wie viele Schriftsteller aufgrund der staatlichen Repressalien gegen ihn die DDR verließ, immer noch nicht fähig ist, frei seine Meinung zu äußern. Immer wieder stößt man in der DDRLiteratur auf Verschlüsselungen und Unklarheiten. Die Zensur scheint den Stil zu beeinflussen, und der Stil beeinflußt wiederum die Zensur. Ob mein Urteil gerechtfertigt ist, und dies demnach der wahre Grund für seine Verweigerung auf Antwort ist, oder ob ich indirekt der Zensur der DDR zum Opfer gefallen bin, kann ich nicht mit Sicherheit behaupten. Dieser Mangel an Klarheit erläutert jedoch eine Beobachtung, die ich anhand

276 Karl-Heinz Jakobs in cinem Bricf vom 18.5.1988 an Prof. Laureen Nussbaum, durch die ich meine Fragen an ihn richtete. 
meiner Arbeit an dieser These gemacht habe. Es gibt nicht eine offizielle Form der Zensur, sondern differenzierte, aufeinander nicht abgestimmte Zensurmaßnahmen. Wie Erich Loest in seinem Buch Der Vierte Zensor darstellt, bleibt wage, wer wen zu welchem Zeitpunkt zensiert, unter welchen Umständen, und aus welchen Gründen. Ergreift ein Autor in der DDR die Feder, um sich iiber ein Thema auszulassen, dann kann er sich niemals sicher sein, ob, und falls ja, wann er zensiert werden wird. Mit dieser ständigen Ungewißheit muß er arbeiten. Er muß demnach vor dem Schreibprozeß oder, falls er es sich finanziell leisten kann, auch nach der Fertigstellung des Manuskripts, für sich selbst klären, inwiefern er gewillt ist, sich der eventuellen unberechenbaren Zensurmaßnahmen auszusetzen.

Auch darf bei einer Betrachtung der Zensur nicht unbeachtet bleiben, daß die Zensierten in vielen Fällen nicht Opfer der Maßnahmen sind, sondern zum Teil willige Partner. Bedingt durch die politische Situation in der DDR, bedingt auch durch die persönliche Einstellung zu ihrem Staat und ihrer Rolle und Aufgabe in diesem, gewiß auch sehr bedingt durch ihre persönliche Interpretation der Rolle des Schriftsteller, gibt es eine Anzahl Autoren, die ein Einschreiten kulturpolitischer, und demnach parteiverbundener Instanzen akzeptieren. Auch diese Schriftsteller, seien es parteitreue wie etwa Hermann Kant und Stephan Hermlin, seien es zurückgezogene und undurchschaubare wie Christa Wolf, sind zensiert worden, unterstützen jedoch ihren Staat teilweise öffentlich, in Ost und West. Hermlin sprach Anfang 1989 in einem SpiegelInterview über "die Reformfähigkeit des SED-Staats." 277 Darin erläuterte er ein Verschärfen der Zensur, jedoch weniger auf literarischem Gebiet als bei Film und Fernsehen. Es stellt sich die Frage, ob der Umschwung des Interesses der Bevölkerung auf die modernen Medien sich befreiend auf Schriftsteller auswirken könnte, die ihre 
Leser zum Denken anregen wollen. Es wäre demnach aufschlussreich zu verfolgen, ob eine Interessenverlagerung der Bevölkerung von Literatur auf die Medien Film und Fernsehen eine erhöhte Produktion an kritischer Gegenwartsliteratur bewirken wird, die jedoch einen kleineren Leserkreis ansprechen wird.

Der Schriftsteller, der, laut Seyppel, "an einer Definition dieser Welt mitzuarbeiten" 278 versucht, muß auch in der DDR weiterhin für sich selbst entscheiden, ob er schreiben oder schweigen will. Er kann sich der Zensur aussetzten oder entziehen, verhindern vermag er sie noch nicht. 


\section{LITERATURVERZEICHNIS \\ PRIMÄRLITERATUR}

Loest, Erich. Es geht seinen Gang oder Mühen in unserer Ebene. München, dtv, 1978

Loest, Erich. Der Vierte Zensor. Vom Entstehen und Sterben eines Romans in der DDR.

Köln: Edition Deutschland Archiv, 1984.

Wolf, Christ. Nachdenken über Christa T. Darmstadt: Luchterhand, 1987.

\section{SEKUNDÄRLITERATUR}

Abusch, Alexander. Literatur im Zeitalter des Sozialismus. Berlin: Aufbau, 1967.

Ahrends, Martin, Hrsg. Trabbi, Telespargel und Tränenpavillon. Das Wörterbuch der DDR-Sprache. München: Heyne, 1986.

Behn, Manfred. DDR-Literatur in der Bundesrepublik Deutschland: Die Rezeption der epischen DDR Literatur in der BRD 1961-1975. Meisenheim am Glan: Hain, 1977.

Behn, Manfred, Hrsg. Wirkungsgeschichte von Christa Wolfs "Nachdenken über Christa T.". Königstein: Athenäum, 1978.

Berger, Manfred. Kulturpolitisches Wörterbuch. 2. erw. und überarb. Auflage. Berlin: Dietz, 1978.

Blumensath, Christel und Heinz Blumensath. Einfuihrung in die DDR-Literatur. Stuttgart: Metzler, 1978.

Brettschneider, Werner. Zwischen literarischer Autonomie und Staatsdienst: Literatur der DDR. Berlin: Erich Schmidt Verlag, 1974.

Childs, David. The GDR: Moscow's German Ally. University of Nottingham, 1983

Cosentino, Christine. "Eine Untersuchung des sozialistischen Realismus im Werk Christa Wolfs." German Quarterly, March 2, 1974.

Dahlke, Günther. "Geteilter Himmel und geteilte Kritik." Sinn und Form 2 1965: 110117.

Demetz, Peter. Postwar German Literatur. A Critical Introduction. New York: Westem Publishing, 1970. 
Diersch, Manfred und Walfried Hartinger, Hrsg. Literatur und Geschichtsbewußtsein: Entwicklungstendenzen in der DDR-Literatur in den sechziger und siebziger Jahren. Berlin: Aufbau, 1976.

"Diskussion mit Christa Wolf." Sinn und Form. 4, 1976: 861-89.

Durzak, Manfred, Hrsg. Die deutsche Literatur der Gegenwart: Aspekte und Tendenzen. Stuttgart: Reclam, 1971.

Eckart, Gabriele. So sehe ick die Sache. Köln: Kiepenheuer und Witsch, 1984.

Emmerich, Wolfgang. Kleine Literaturgeschichte der DDR. Darmstadt: Luchterhand, 1985.

Fischbeck, Helmut, Hrsg. Literaturpolitik und Literaturkritik in der DDR. Eine

Dokumentation. Frankfurt am Main: Diesterweg, 1976.

Franke, Konrad, Hrsg. Erzähler aus der DDR. Tuibingen: Erdmann, 1973.

---, Hrsg. Kindlers Literaturgeschichte der Gegenwart: Literatur der DDR. Zürich und München: Kindler, 1974.

Gerber, Mary, ed. Studies in GDR Culture and Society 2. Proceedings of the Seventh Intemational Symposium on the German Democratic Republic. Washington: University Press of America, 1982.

---, ed. Studies in GDR Culture and Society 3. Selected Papers from the Eighth International Symposium on the German Democratic Republic. Lanham: University Press of America, 1983.

---, ed. Studies in GDR Culture and Society 5. Selected Papers from the Tenth New Hampshire Symposium on the German Democratic Republic. Lanham: University Press of America, 1985.

Getler, Michael. "Writing around the Edges in East Germany." International Herald Tribune. Paris: 13. März 1978.

Görlich, Günter. "15\% Produktionssteigerung und immer noch zu wenig Bücher." Kürbiskern 2, 1977: 157.

Greiner, Bernhard. Literatur der DDR in neuer Sicht: Studien und Interpretationen. Frankfurt am Main: Peter Lang, 1986.

Grimminger, Rolf, Hrsg. Hansers Sozialgeschichte der deutschen Literatur vom Jahrhundert bis zur Gegenwart. München: Hanser, 1983.

Haase, Horst. "Aspekte eines Kongresses. Betrachtungen zum IX. SchriftstellerkongreB der DDR." DDR-Literatur ' 83 im Gespräch. 1983, 70.

---, . "Nachdenken über ein Buch. Christa Wolf: Nachdenken über Christa T. NDL 4, 1969. 
---, Geschichte der Literatur der Deutschen Demokratischen Republik. Von den Anfängen bis zur Gegenwart. Band 11. Berlin: Volk und Wissen, 1976.

Deutsches Institut für Wirtschaftsforschung Berlin, Hrsg. Handbuch DDR-Wirtschaft. Reinbek bei Hamburg: Rohwolt Taschenbuch, 1984.

Hannig, Waltraud. "The GDR - a country of books and readers." Contemporary Review January 1984: 243-4.

Helwig, Gisela, Hrsg. Die DDR Gesellschaft im Spiegel ihrer Literatur. Köln: Verlag Wissenschaft und Politik, 1986.

Hermlin, Stephan. "In den Kämpfen dieser Zeit. Rede auf dem VIII. Schriftstellerkongreß der DDR 1978." In: Stephan Hermlin. Äußerungen. 1983 (Zuerst 1978)

Hilzinger, Sonja. "Als ganzer Mensch zu leben... "Emanzipatorische Tendenzen der neueren Frauen-Literatur der DDR. Frankfurt am Main: Peter Lang, 1985.

---, Christa Wolf. Stuttgart: Metzler, 1986.

Hohendahl. Peter Uwe und Patricia Herminghouse, Hrsgg. Literatur in der DDR in den siebziger Jahren. Frankfurt am Main: Suhrkamp, 1983.

---. Hrsgg. Literatur und Literaturtheorie in der DDR. Frankfurt am Main: Suhrkamp, 1976.

Hueber, Theodore. The Literature of East Germany. New York: Ungar, 1970.

Jäger, Manfred. Kultur und Politik in der DDR. Ein historischer Abriß. Hrsg. Ilse Spittmann-Rühle und Gisela Helwing. Edition Deutschland Archiv. Köln: Verlag Wissenschaft und Politik, 1982.

---, Sozialliteraten. Funktion und Selbstverständnis der Schriftsteller in der DDR.

Düsseldorf: Bertelsmann, 1973.

---, "Generationswechsel in der Literatur der DDR." Deutschland Archiv 17 1984: 87375.

Kaufmann, Hans. Über DDR-Literatur: Beiträge aus 25 Jahren. Berlin, Weimar: Aufbau, 1986.

---, "Zur DDR-Literatur der siebziger Jahre." Sinn und Form 1 1978: 171-76.

Kleinschmid, Harald. " 'Es ist nicht immer günstig, Künstler zu sein.' Zur Kulturpolitik auf dem XI. Parteitag." Deutschland Archiv 18 (1986): 640-41.

Köhler-Hausmann, Reinhild. Literaturbetrieb in der DDR: Schriftsteller und Literaturinstanzen. Stuttgart: Metzler, 1984.

Jacobs, Karl-Heinz. Das endlose Jahr. Düsseldorf: Claassen, 1983.

Lehmann, Hans Georg. Chronik der DDR. $1945 / 49$ bis heute. München: dtv, 1987. 
Löffler, Anneliese, Hrsg. Auskïnfte: Werkstattgespräche mit DDR-Autoren. Berlin und Weimar: Aufbau Verlag, 1976.

Maner, Wolfram, Hrsg. Erinnerte Zukunft. Würzburg: Königshausen und Neumann: 1985.

Mayer-Burger, Bernhard. Entwicklung und Funktion der Literaturpolitik der DDR 19451978. München: Tuduv Verlagsgesellschaft, 1984.

Noll, Hans. Der Abschied: Journal meiner Ausreise aus der DDR. Hamburg: Hoffmann und Campe, 1985.

Richter, Hans. Werke und Wege: Kritiken, Aufsätze, Reden. Halle: Mitteldeutscher Verlag, 1984.

Raddatz, Fritz J. Traditionen und Tendenzen - Materialien zur Literatur der DDR. Frankfurt: Suhrkamp Verlag, 1972.

Reich-Ranicki, Marcel. Zur Literatur der DDR. München: R. Piper Verlag, 1974.

Ronge, Volker. Von driiben nach hïben. Wuppertal: Verlag 84 Hartmann \& Petit, 1984.

Schlenstedt, Dieter. Die Neuere DDR-Literatur und ihr Leser. Berlin: Akademie Verlag, 1979.

Schriftstellerverband der Deutschen Demokratischen Republik, Hrsg. IX. Schriftstellerkongreß der Deutschen Demokratischen Republik. Rede und Diskussion. 1984.

Schubbe, Elimar. Dokumente zur Kunst- Literatur- und Kulturpolitik der SED. Stuttgart: Seewald, 1972.

Sevin, Dieter. Christa Wolf, Der geteilte Himmel, Nachdenken über Christa T.: Interpretationen. München: Oldenbourg, 1982.

Silberman, Marc, Hrsg. Zum Roman in der DDR. Stuttgart: Klett, 1980.

Sommer, Dietrich, Hrsg. Funktion und Wirkung. Berlin und Weimar: Aufbau, 1978.

Stahl, Sigrid. Der Ausbruch des Subjekts auf gesellschaftlicher Konformität. Ansätze literarischer Verweigerung am Beispiel der DDR-Prosa der zweiten Hälfte der siebziger Jahre. Frankfurt am Main: Peter Lang, 1984.

Steinbach, Dieter, Hrsg. Wolf Biermann und die Tradition: Von der Bibel bis Ernst Bloch. Stuttgart: Klett, 1981.

Stephan, Alexander. Christa Wolf. München: Beck, 1987.

Streisand, Marianne. "Meine Meinung über die Literaturkritik in 'Sinn und Form'." Sinn und Form 2 (1978): 469-74.

Tate, Dennis. The East German Novel. Identity. Community. Continuity. Bath: Bath University Press, 1984. 
Tempel, Karl G. Die Parteien in der Bundesrepublik und die Rolle der Parteien in der DDR. Berlin: Landeszentrale für politische Bildungsarbeit, 1987.

Timmermann, Heiner. Bundesrepublik - DDR Grundziige im Vergleich. Opladen: Leske \& Budrich, 1984.

Voigtländer, Annie, Hrsg. Liebes- und andere Erklärung: Schriftsteller über Schriftsteller. Berlin und Weimar: Aufbau, 1974.

Walther, Klaus, Hrsg. Ansichten. Aufsätze zur Literatur der DDR. Halle (Saale): Mitteldeutscher Verlag, 1976.

Weber, Heinz-Dietrich. Über Christa Wolfs Schreibart. Konstanz: Universitätsverlag Konstanz, 1984.

Wittstock, Uwe. Über die Fähigkeit zı trallern: Das Bild der Wandlıng im Prosawerk von Christa Wolf und Franz Fühmann. Frankfurt am Main: Athenäum, 1987.

Was zählt ist die Wahrheit: Briefe von Schriftstellern der DDR. Halle (Saale): Mitteldeutscher Verlag, 1975.

Wolf, Christa. "Selbstversuch: Traktat zu einem Protokoll." Sinn und Form 2 (1977):

---, Die Dimension des Autors. Essays und Aufsätze. Reden und Gespräche, 1959 - 1985. Darmstadt: Luchterhand, 1987. Lizenzausgabe.

Wolff, Lutz C., Hrsg. Frauen in der DDR: 20 Erzählungen. München: dtv, 1976.

Zipser, Richard A. und Karl-Heinz Schoeps. DDR-Literatur im Tauwetter. Bern: Lang, 1983. 3 Bände. 